Accepted for publication, Journal of Experimental Psychology: General

\title{
Remembering Election Night 2016: Subjective but not objective metrics of autobiographical memory vary with political affiliation, affective valence, and surprise
}

\author{
Kimberly S. Chiew ${ }^{1}$, Bailey B. Harris ${ }^{1}$, R. Alison Adcock ${ }^{2}$ \\ ${ }^{1}$ Department of Psychology, University of Denver \\ ${ }^{2}$ Center for Cognitive Neuroscience, Duke University
}

Author Note: Data for this publication has been uploaded to the Open Science Framework and is available here: https://osf.io/hkdjw/

CAmerican Psychological Association, 2021. This paper is not the copy of record and may not exactly replicate the authoritative document published in the APA journal. Please do not copy or cite without author's permission. The final article is available, upon publication, at: https://www.apa.org/pubs/journals/xge

Word count: 13,613

Corresponding author:

Kimberly S. Chiew, Ph.D.

Department of Psychology

University of Denver

2155 S. Race Street

Denver, CO USA 80208

kimberly.chiew@du.edu 


\section{$\underline{\text { Abstract }}$}

Flashbulb memories represent a unique phenomenon linking research on cognition with research on emotion, yet most studies on this phenomenon have characterized collective events that are negative and unexpected in nature. In contrast, the 2016 American election of Donald Trump was a public, culturally-shared event, eliciting extreme emotional responses that were positive for some individuals but negative for others, as well as varying levels of surprise. We longitudinally evaluated autobiographical memories for Election Night 2016 in a large online sample of Clinton supporters, Trump supporters, and third-party/non-voters over a 12-month period, in terms of both objective memory metrics (information quantity and memory consistency) and subjective memory metrics (including memory confidence, metacognition, and sensory experience). Emotional responses to the election outcome varied widely, with Clinton supporters reporting highly negative responses, Trump supporters reporting highly positive responses, and third-party/non-voters reporting mildly negative responses. Emotional intensity was enhanced in surprised versus non-surprised individuals. Relative to third-party/non-voters, Clinton and Trump supporters reported greater memory vividness, event importance, and sensory experience. Additionally, limited valence effects on subjective memory were observed (including higher memory confidence in Trump supporters and higher memory rehearsal in Clinton supporters). These differences in subjective experience were observed despite similar levels of information quantity and consistency as a function of valence. This characterization of memories for surprising positive events suggests they share many of the paradoxical qualities of memories for negative events often discussed as "flashbulb memories", but 
also points to potential differences in memory phenomenology for personal versus collectively-experienced events. 


\section{Introduction}

The 2016 election of Republican Donald Trump as the United States' $45^{\text {th }}$ president is considered a towering event in recent American politics: media sources described it as a "cataclysmic, history-making upset" (Cillizza, 2016), stunning many critics and members of the public anticipating a victory by opponent Democrat Hillary Clinton (Francia, 2018). The 2016 American presidential election was also characterized by particularly strong emotional responses by supporters of both the Republican and Democratic political parties, in terms of positive opinions towards their preferred candidate as well as negative opinions towards the opposing candidate (Faris et al., 2017; Schill \& Kirk, 2017). Emotional responses to sociopolitical events, often elicited as a function of group affiliation and anticipated policy changes, have been welldocumented in the social sciences literature (Craig, Martinez, Gainous, \& Kane, 2006; Kawachi \& Berkman, 2000; Rahn, Kroeger, \& Kite, 1996) but the outcome of the 2016 American election is notable in terms of both the intensity of emotion and surprise elicited (Ceaser, Busch, \& Pitney Jr, 2019; Hoyt, Zeiders, Chaku, Toomey, \& Nair, 2018).

Election Night 2016 (which took place November 8, 2016) is also a memorable event for many Americans. Indeed, accounts of memories for the event abound on Internet forums such as Reddit.com (https://www.reddit.com/r/AskAnAmerican/comments/7bi2oa/what was your experienc e on election night last/); Esquire.com developed an oral history project, The Untold Stories of Election Day 2016 (Hendrickson et al., 2017), and Tufts University students developed a similar video project, Where Were You on Election Night? 
(https://vimeo.com/192629189), dedicated to documenting personal experiences of the event. Thus, Election Night 2016 is a potential flashbulb memory event: an unexpected, emotionally-laden, consequential event associated with vivid, long-lasting memories (Talarico \& Rubin, 2003). Flashbulb memories have been studied in conjunction with a number of significant public events, including the assassination of John F. Kennedy (Brown \& Kulik, 1977), the explosion of the Challenger shuttle (Neisser \& Harsch, 1992), and the $9 / 11$ terrorist attacks (Talarico \& Rubin, 2003). Intriguingly, these investigations have revealed that while flashbulb memories are characterized by strong confidence and subjective vividness, they have not necessarily been characterized by accuracy or consistency over time.

Given these inconsistencies and the potential significance of flashbulb memories in influencing people's personal narratives and identities (Berntsen, 2017), characterizing their phenomenology and mechanisms are important goals for memory research. However, most investigations of flashbulb memories for public events have been conducted for unexpected, negative events; thus, current understanding of flashbulb memories may be largely limited to negative valence. Given that the outcome of the 2016 presidential election was positive for some but negative for others, and a Trump victory was anticipated by some but was highly surprising for others (Valentino, King, \& Hill, 2017), Election Night 2016 offers a unique opportunity to characterize both negative and positive autobiographical flashbulb memories for a highly consequential public event that was highly-localized in time (November 8, 2016).

Although many investigations of autobiographical memories elicited by public events have characterized negatively-valenced memories, a limited number of studies 
have been able to characterize autobiographical memory for a single public event perceived as positive or negative by different individuals while controlling for other event properties. These studies include investigations of memories for major sporting event outcomes as a function of team affiliation (Botzung, Rubin, Miles, Cabeza, \& LaBar, 2010; Breslin \& Safer, 2011; Kensinger \& Schacter, 2006) as well as other studies of highly significant political events, such as the 2008 American presidential election (Holland \& Kensinger, 2012) and the UK's 2016 EU referendum ('Brexit'; Raw, Rorke, ELLIS, Murayama, \& Sakaki, 2020). These investigations have yielded mixed evidence regarding the effect of valence on autobiographical memory: while some studies report higher memory consistency for negative events and higher memory confidence for positive events (Holland \& Kensinger, 2012; Kensinger \& Schacter, 2006; Raw et al., 2020), other studies have reported greater memory consistency and confidence for positive versus negative events (Botzung et al., 2010; Breslin \& Safer, 2011). Notably, two of these studies investigated valence effects in memories for a common event (the 2004 baseball playoff final between Boston Red Sox and New York Yankees (Breslin \& Safer, 2011; Kensinger \& Schacter, 2006)) and revealed differing results as a function of retrieval interval, with higher memory consistency for the game as a negative event when retrieved at $\sim 6$ months (Kensinger \& Schacter, 2006), and higher memory consistency for the game as a positive event when retrieved at $\sim 4$ years, potentially because of increased memory rehearsal, in a separate participant group (Breslin \& Safer, 2011). Other work has suggested that emotional intensity may be a more important predictor of memory properties than valence altogether (Talarico, LaBar, \& Rubin, 2004). 
Additionally, because the 2016 election outcome was surprising to some but not to others, it offers the opportunity to examine the influence of surprise and its interactions with valence on autobiographical memory. While flashbulb memories typically result from surprising and consequential events, surprise has rarely been systematically examined as a potential modulator of autobiographical memory formation. One study (Coluccia et al., 2010) examining autobiographical memories for surprising and unsurprising negative events suggested stronger emotional responses to a surprising event, but no significant differences in memory consistency or confidence as a function of surprise. In contrast to this observation, growing evidence from the cognitive neuroscience literature suggests that surprise may play an important role in memory encoding: surprising events are typically remembered better than nonsurprising events, an observation that has been linked to interactions between regions in the mesolimbic dopamine system responsive to novelty (e.g., the nucleus accumbens) and memory-related regions in the medial temporal lobe (MTL) such as the hippocampus (Axmacher et al., 2010; Bunzeck \& Düzel, 2006; Wittmann, Bunzeck, Dolan, \& Düzel, 2007). Such interactions have been characterized using a reinforcement learning perspective, in which surprising events are argued to generate reward prediction errors (RPEs) indexed by activity in mesolimbic dopaminergic neurons (Schultz, Dayan, \& Montague, 1997). Recent work has suggested that larger RPEs (both positive and negative) are associated with improved episodic memory for associated surprising events (Clewett, Schoeke, \& Mather, 2014; Rouhani, Norman, \& Niv, 2018). However, this effect may vary with valence: Murty and colleagues (Murty, LaBar, \& Adcock, 2016) reported enhanced memory for surprising incidental information 
under rewarding, but not punishing, contexts, in association with engagement of the hippocampus by surprising events under reward but not punishment anticipation. Differing effects of surprise by valence may have accounted for the null effects of surprise on autobiographical memory observed by Coluccia and colleagues (2010), given that they only examined memories for negative events.

While extant evidence for the influence of surprise on cognitive processing in general and memory in particular, has largely relied on the use of traditional laboratory paradigms, one recent study (Otto \& Eichstaedt, 2018) identified and characterized the influence of surprise on naturalistic behavior using city-level Twitter and sales data. This study linked surprising events with population-level changes in behavior; specifically, real-world unexpected outcomes (e.g., weather events) were associated with mood states (indexed by language use on Twitter) and risk-taking behavior (e.g., sales of lottery tickets), but did not specifically characterize effects of surprise on memory encoding. Taken together, prior literature indicates that how potential effects of emotional valence, surprise, and their interaction may impact memory for a real-life, naturalistic event remains an open question.

To address this, we examined autobiographical memories for Election Night 2016 (November 8, 2016) in a U.S.-based sample to determine the extent to which autobiographical memory differed as a function of political affiliation (inferred by individuals' presidential candidate vote) and surprise (inferred by their expected election outcome). Data was collected online using Amazon Mechanical Turk at three timepoints, separated by 6 -month intervals, over a 12-month period (beginning two weeks after the election - November 2016, May 2017, November 2017) to assess 
autobiographical memory for, and emotional responses to, the event over time. We hypothesized that, in general, both objective memory and subjective memory metrics such as vividness would decline over time. Further, given prior findings that unexpected events are remembered better than expected events (Axmacher et al., 2010; Clewett et al., 2014) and that memory benefit for surprise may be greater in positive contexts (Murty et al., 2016), we hypothesized that individuals for whom the election outcome was a positive event (i.e., Trump supporters) and/or a surprising event would have superior memory to those who construed the election outcome as negative (i.e., Clinton supporters) and/or unsurprising. Given increasing evidence that emotional arousal might be critical to memory vividness and recollection (Clewett \& Murty, 2019; Clewett, Huang, Velasco, Lee, \& Mather, 2018), we hypothesized that third-party/non-voters' responses to the election outcome would be lower in arousal and more neutral in valence than emotional responses in either Clinton or Trump supporters, and associated with decreased levels of reported memory vividness and recollection. Taken together, this approach enabled us to longitudinally characterize autobiographical memory for a significant public event over a wide range of potential emotional arousal, valence, and surprise levels.

\section{Methods}

\section{Participants}

At Timepoint 1 (T1) of the study (November 23-24, 2016), 500 U.S.-based adult participants (18 years and older) were recruited from Amazon Mechanical Turk to take part in the study and were compensated $\$ 3$ for their time. One participant was excluded for poor data quality. Thus, the final usable sample at T1 was $N=499$ (279 male, 217 
female, 3 gender-unspecified; mean age $=35.75$ years, $S D=10.56)$. The study was approved by Duke University Campus Institutional Review Board and informed consent was obtained from all participants before commencing the study.

Of the participants that took part at T1, N=354 (200 male, 152 female, 2 genderunspecified; mean age $=36.77$ years, $S D=10.97)$ returned to take part at Timepoint 2 (T2), approximately six months after T1 (May 23-29, 2017). Of the participants that returned to take part at $\mathrm{T} 2, N=276$ ( 161 male, 115 female; mean age $=37.18$ years, $S D$ $=11.14)$ returned again to participate at Timepoint $3(\mathrm{~T} 3)$, approximately twelve months following T1 (November 23-29, 2017). Using participant self-report of the candidate they voted for (Clinton, Trump, or third-party/non-voting) as a metric of political affiliation, and their anticipated election outcome (Clinton or Trump victory) as a metric of surprise, participants were assigned to one of six groups according to a $3 \times 2$ (Political Affiliation $x$ Surprise) factorial design. Demographic information for our participant sample at all three timepoints of the study is presented in Table 1.

An important note is that sample recruitment on Amazon Mechanical Turk was open to U.S. based individuals ages 18 years and older, but recruitment was not targeted to obtain a nationally representative sample or equal numbers of participants in each cell of our $3 \times 2$ factorial design. As a result, the numbers of participants recruited for each design cell varied. In particular, we recruited small numbers of Clinton supporters ( $\mathrm{N}=5$ at $\mathrm{T} 1)$ and third-party/non-voters ( $\mathrm{N}=16$ at $\mathrm{T} 1)$ who reported anticipating a Trump victory, limiting our ability to compare surprised and non-surprised individuals within these groups. We note this limitation where relevant in our Results section and discuss its implications in our Discussion section. 
Study Procedure

U.S.-based participants were recruited from Amazon Mechanical Turk for T1 (November 2016) and subsequently invited to return for T2 six months later (May 2017). T2 participants were then invited to return for T3, six months following T2 (November 2017). At each timepoint, participants completed a series of online questionnaires accessed through Amazon Mechanical Turk and programmed in Qualtrics.

Several measures were collected from our participants at these three timepoints; we describe only the measures examined in the present study below. At T1, participants completed the Event-Related Questionnaire (ERQ), the Autobiographical Memory Questionnaire (AMQ), and additional survey measures not included in the present study. At T2 and T3, participants again completed the ERQ and the AMQ. Study design (including sample sizes in each of our participant groups of interest at each timepoint, varying by Political Affiliation $x$ Surprise) is presented in Figure 1.

\section{Measures}

Event-Related Questionnaire (ERQ). Participants completed a survey adapted from the questionnaire used in Kensinger and Schacter's study of autobiographical memories of the 2004 American League playoffs final baseball game in rival fans (Kensinger \& Schacter, 2006; our adapted questionnaire is presented in Appendix 1). The ERQ prompts participants to report their political affiliation (i.e., vote choice), anticipated outcome of the election, a series of open-ended personal detail questions regarding their memories of Election Night, as well as self-reported emotions before and 
after election outcome, subjective memory vividness, emotion intensity, perceived event importance, and perceived memory rehearsal (in terms of thinking, speaking, and consuming media about the event) following election outcome. Participants' vote choice and anticipated outcome was used to classify them into six groups in terms of Political Affiliation (Clinton supporters, Trump supporters, or third-party/non-voters) and Surprise (unsurprised or surprised).

Responses to the ERQ's open-ended personal detail questions were scored to assess quantity and consistency of memory information following Kensinger and Schacter (2006). At T1, personal detail responses were scored for the quantity of information recalled. At T2 and T3, personal detail responses were scored for both the quantity of information provided as well as the consistency of information relative to T1 information. Confidence in the answers for each personal detail question was also selfrated on a 7-point Likert scale at T2 and T3. Average quantity, consistency, and confidence metrics were obtained at each timepoint by averaging scores for responses to the five open-ended personal detail questions.

Quantity and consistency of personal detail responses was calculated as follows (Kensinger \& Schacter, 2006): Each response to a personal detail question was scored on quantity of information (either $0,0.5$, or 1 point) by two independent raters. A score of 0 was awarded to an answer when no information was recalled in response to a given question; a score of 0.5 was awarded to an answer when some information was recalled but was somewhat vague; a score of 1 was awarded to an answer when specific detail(s) was provided in the response. Interrater reliability was moderately high 
(Cronbach's $\alpha>.75$ ) and the average of the two raters' scores was used in analyses examining quantity of personal detail.

Consistency of information was also rated at $\mathrm{T} 2$ and $\mathrm{T} 3$, relative to $\mathrm{T} 1$, following prior protocol (Kensinger \& Schacter, 2006). The consistency of each response was scored as $0,0.5$, or 1 point. When the information reported at T2 or T3 completely differed from T1 information, or if participants could not recall any information at T2 or T3, consistency was scored as 0 . When a piece of information was recalled in a slightly different manner, or if some aspects of the information were missing at T2 or T3 compared to $\mathrm{T} 1$, consistency was scored as 0.5 . If the same information, with the same amount of detail, was recalled at T2 or T3 compared to T1, consistency was scored as 1. If the participant provided additional information at $\mathrm{T} 2$ or $\mathrm{T} 3$ compared to $\mathrm{T} 1$, this did not impact their consistency scores.

In addition to open-ended personal detail questions, our ERQ also asked participants to self-report emotional responses to and memory properties for this event by endorsing measures of emotion (happiness, sadness, excitement, fear, and anger) experienced before and after election outcome, memory vividness, emotion intensity, perceived event importance, and memory rehearsal on 7-point Likert scales. These variables are also listed in Appendix 1. We created measures of positive and negative affective responses to the event by averaging self-reported emotion ratings after the event ("happy" and "excited" for positive, and "sad", "afraid", and "angry" for negative).

Autobiographical Memory Questionnaire. Participants completed an adapted version of the Autobiographical Memory Questionnaire (AMQ; Rubin, Schrauf, \& Greenberg, 2003; Rubin \& Siegler, 2004; presented in Appendix 2), which has been 
used to characterize cognitive processes and phenomenological judgments involved in autobiographical memory (AM) for a specific event. Based on the theoretical premise that autobiographical memories are the products of component processes, each item variable on the AMQ is intended to index self-reports of these component processes, as well as properties and metacognitive judgments based on the activity of these processes. Participants were asked, upon remembering the event (Election Night 2016 and the outcome of the election), to endorse each of the following variables, grouped by proposed category, on a 7-point Likert scale (all variables previously reviewed in Rubin et al., 2003; Talarico, LaBar, \& Rubin, 2004):

Metacognitive judgments: Reliving ("I feel as though I am reliving the event"), which has been argued as central to autobiographical memory as distinct from other forms of memory (in the subject's ability to represent a given, previous experience in memory as separate from other events); Belief ("Things really occurred the way I remember"), argued as a basic feature of autobiographical memory that may depend on subject knowledge of the memory event, separate from relived experience.

Component processes: Visual imagery ("I can see it in my mind"), the tendency to remember the event in terms of visual information; Setting ("I know the setting where it occurred"), the tendency to remember the setting or context of the event; Hearing imagery ("I can hear it in my mind"), the tendency to remember the event in terms of auditory information; In-words recall ("The memory is in words"), the tendency to remember the event in terms of language content; Story recall ("The memory is a coherent story"), intended to assess narrative coherence of the memory independent of language. 
Reported properties of events or memories: Importance ("This event is a central part of my life story"), the subject's judgment of the importance of the remembered event to their life; Rehearsal-thought ("I purposely thought about this event"), the subject's judgment of memory rehearsal of the event through thought; Rehearsal-talk ("I have talked about this event"), the subject's judgment of memory rehearsal of the event through talking.

\section{Data Analytic Strategy}

We first characterized potential demographic differences associated with political affiliation and surprise by dividing our sample at T1 into six groups according to these factors (Political Affiliation: Clinton supporters, Trump supporters, and third-party/nonvoters; Surprise: surprised or unsurprised by election outcome) and examined whether these groups differed on reported gender, age, race, and years of education. Chisquare tests tested for differences in frequencies of categorical variables (gender and race) and one-way analyses of variance (ANOVAs) tested for differences in continuous variables (age and years of education).

Second, we examined the extent to which Political Affiliation and Surprise were associated with differences in emotional response to the election event, using the selfreported measures of average positive and negative affect experienced after the event at T1 (positive affect: "happy" and "excited"; negative affect: "sad", "afraid", and "angry"). Finally, with the emotion metrics reported for both before and after election outcome, we calculated "change scores" for positive and negative affect (Affect After minus Affect Before). It has been previously argued that fluctuations in mood might scale with the 
difference between expected and actual reward outcomes (real-world "prediction errors") and that these fluctuations are associated with changes in behavior (Eldar, Rutledge, Dolan, \& Niv, 2016; Otto \& Eichstaedt, 2018). We thus investigated the extent to which reported changes in emotion in response to election outcome differed as a function of Political Affiliation and Surprise.

For our primary analyses, we tested the hypothesis that autobiographical memories of Election Night 2016 would vary as a function of political affiliation (relating to emotional valence), surprise, and time. We specifically predicted that individuals that reported the election outcome as a positive, surprising event (i.e., Trump supporters anticipating a Clinton victory) would report enhanced autobiographical memory. We examined the influence of these three predictors (political affiliation, surprise, and time) on autobiographical memory variables from the ERQ and the AMQ (outlined in detail in the next paragraph) using mixed linear models (MLMs) implemented using the nlme package in $\mathrm{R}$ (version 3.4.3; www.r-project.org). MLMs permit control of the variance associated with random factors without data aggregation, are relatively robust to heterogeneity of variance due to unequal samples (Singer \& Willet, 2003), and enabled use of all of our participants' data, including those who did not return after T1. MLMs included fixed effects of Political Affiliation (Clinton supporters, Trump supporters, or third-party/non-voters), Surprise (surprised or unsurprised, corresponding to those expecting a Clinton or a Trump presidential victory) and Time (T1, T2, T3; modeled as a continuous variable) and subjects modeled as a random effect, with maximum likelihood estimation. Where two or more fixed effects significantly predicted model outcome, follow-up analyses including the interaction term(s) between the fixed effects were 
conducted. Model selection was conducted by comparing each model against a baseline: for each of the three fixed effects alone, the baseline model included only the intercept. Models including two-way interactions were tested against a baseline including main effects of the two fixed predictors in question, and the three-way interaction model (Political Affiliation $x$ Surprise $x$ Time) was tested against a baseline including main effects and two-way interactions.

Following this model structure, we first examined memory detail quantity, consistency, and confidence, calculated from ERQ responses as described above. Memory detail quantity (scored at all three timepoints), and memory consistency (at T2 and T3, relative to T1) were scored using responses to the ERQ's open-ended personal detail questions (as described above), and memory confidence was examined as selfreported at T2 and T3 (memory confidence was not rated at T1). Potential differences in memory detail quantity, consistency, and confidence were examined via planned comparisons to test the hypothesis that these three metrics of memory would be greatest in surprised Trump supporters, and decline over time.

Using parallel MLM analyses, additional outcomes from the ERQ were also examined: reported memory vividness, memory vividness for activities and location, emotion intensity, perceived personal importance of the event, perceived broader importance of the event, frequency of thought regarding the event, frequency of media consumption regarding the event, and frequency of speaking about the event. We used the same model structure to characterize variables from the $A M Q$, including metacognitive judgments (reliving and belief), reported component processes (visual imagery, setting recall, hearing imagery, in-words recall, and story recall variables), and 
reported properties of event memories (importance, rehearsal-thought, and rehearsaltalk). Given the large number of outcome variables examined (eighteen) in these analyses, and the fact that we were somewhat agnostic on which specific metrics of autobiographical memory might differ as a function of our predictors, we used an adjusted alpha criterion $(.05 / 18=.003)$ to correct for family-wise error rate.

Next, we conducted follow-up analyses with individual differences in emotion response to the election outcome (positive and negative affect measures reported at $\mathrm{T} 1$, as described above) to examine whether these emotion responses predicted memory outcomes over and above using Political Affiliation (associated with robust group-level differences in emotion) alone. We created a composite Negative Affect score (using each participant's reported measures of "sad", "afraid", and "angry", and reverse-scored reported measures of "happy" and "excited" experienced after the event at T1; Cronbach's $\alpha=.93$ ) and, given our interest in the effects of both valence and intensity of emotion on memory outcomes, examined the model with the addition of the meancentered linear term for Negative Affect alone, as well as adding the linear and quadratic terms for Negative Affect together, and tested for improvement with each model relative to Political Affiliation alone. Model building and comparison process for each outcome variable is presented in the supplement and effects of examining individual-level emotion measures as predictors in addition to Political Affiliation as a group-level variable are described in Results below.

Finally, given observed demographic differences in gender and years of education between our six participant groups (see Demographic Differences as a Function of Political Affiliation and Surprise below), we re-ran our original MLMs 
(Affiliation, Surprise, and Time) described above, significant relative to their baseline models, with gender and years of education added as fixed effects and testing for model improvement with the addition of these predictors. The model building and comparison process for each outcome variable is presented in the supplement. Significant effects of gender and years of education on these outcome variables are also presented in the supplement.

\section{$\underline{\text { Results }}$}

Demographic Differences as a Function of Political Affiliation and Surprise

We first examined whether individuals differing by political affiliation (Clinton supporters, Trump supporters, and third-party/non-voters) and surprise (surprised or not-surprised by election outcome) - six groups in total - differed demographically on reported gender, age, race, and years of education. We found that the six groups significantly differed on gender $[\chi 2(10, N=499)=20.644, p=.024, V=.144]$ and years of education $\left[F(5,490)=5.749, p<.001, \eta_{p}^{2}=.056, N=491\right]$, but not on age $[F(5,496)$ $\left.=1.807, p=.110, \eta_{p}^{2}=.018, N=497\right]$ or race $[\chi 2(35, N=499)=45.041, p=.119, V$ $=.134]$.

Following Beasley \& Schumacker (Beasley \& Schumacker, 1995), we conducted post-hoc tests following up on the Chi-square analysis for gender, correcting for multiple comparisons (Gender(3) x Group(6)) by using an adjusted alpha criterion (.05/18 $=.003)$. Results revealed significantly more female than male participants identified as surprised Clinton supporters (female proportion deviation from the null hypothesis: $p$ $=.0004 ;$ male proportion deviation from the null hypothesis: $p=.0009$ ). No other groups 
significantly differed in their gender proportions. Post-hoc Tukey tests following the significant one-way ANOVA for years of education revealed that surprised Clinton supporters had significantly more education than unsurprised Trump supporters ( $p$ $=.002)$.

Given demographic differences between the support base of the American Republican and Democratic parties (Newport, 2013), it was unsurprising that our groups differed demographically as a function of Political Affiliation (with surprised Clinton supporters being more likely to be female and more highly educated). As a precaution, we reran our primary analyses of both emotion and memory outcomes to examine whether gender and years of education could account for our observations. While gender was observed as a significant predictor in some analyses (specifically, higher emotion intensity, event importance, and rehearsal were observed in females versus males), our predictors of interest (Political Affiliation, Surprise, and Time) overwhelmingly remained significant with these additions (with the exception of the main effect of Surprise on changes in negative affect, which dropped from significant to trendlevel with the addition of gender to the model). These analyses are outlined in the Supplement section, and while they indicate that our primary results hold while accounting for differences in gender and years of education between our participant groups, potential differences in emotion and memory between our participant groups should be interpreted with these demographic differences in mind.

\section{Emotion Differences as a Function of Political Affiliation and Surprise}

We anticipated that Election Night 2016 would be reported as highly positive by Trump supporters, as highly negative by Clinton supporters, and as less emotionally- 
intense (potentially positive or negative) by third-party/non-voters, with potential modulation of emotion by surprise. To examine this, we analyzed self-report measures of positive and negative affect after the event reported at T1 (visualized in Figure 2a and 2b) using a 3x2 (Political Affiliation $\times$ Surprise) univariate ANOVA. As anticipated, there was a significant main effect of Political Affiliation on reported positive affect $[F(2,493)=$ 154.131, $\left.p<.001, \eta_{\mathrm{p}}^{2}=.385\right]$, with the highest positive affect reported in Trump supporters $(M=5.89, S D=1.35)$, followed by third-party/non-voters $(M=2.81, S D=$ 1.65) and the lowest positive affect reported in Clinton supporters $(M=1.71, S D=$ 1.10); all post-hoc contrasts between these groups were significant (all $p s<.001)$. The main effect of Surprise and the interaction of Political Affiliation $\times$ Surprise did not reach significance.

With negative affect as a dependent variable, we observed significant main effects of Political Affiliation $\left[F(2,493)=34.726, p<.001, \eta_{p}^{2}=.123\right]$ and Surprise $\left[F(1,493)=17.059, p<.001, \eta_{p}^{2}=.033\right]$ and a significant interaction of Political Affiliation $x$ Surprise $\left[F(2,493)=4.149, p=.016, \eta_{p}^{2}=.017\right]$. As anticipated, the significant effect of Political Affiliation was driven by higher negative affect reported by Clinton supporters $(M=5.54, S D=1.60)$, compared to third-party/non-voters $(M=3.73$, $S D=1.85)$ or Trump supporters $(M=1.89, S D=1.26)$; all post-hoc contrasts were significant (all $p s<.001)$. The significant main effect of Surprise was driven by higher negative affect reported by surprised individuals (surprised: $M=4.63, S D=2.10$; unsurprised: $M=2.06, S D=1.44$ ), and the significant Political Affiliation $\times$ Surprise interaction was driven by significantly greater negative affect in surprised vs. nonsurprised Clinton supporters $(p=.004)$ and third-party/non-voters $(p=.013)$ but no 
difference between surprised and unsurprised Trump voters $(p=.278)$; but note that due to low numbers of unsurprised Clinton supporters and third-party/non-voters, effects of surprise on negative affect in these groups should be taken as tentative. Thus, as predicted, Political Affiliation was associated with positive and negative affective responses to the election event.

We also used self-reported measures of positive and negative affect experienced before and after election outcome to calculate change scores (after minus before; positive scores indicate increased affect, negative scores indicate decreased affect; visualized in Figure 2c and 2d) examined using a 3x2 (Political Affiliation $x$ Surprise) ANOVA. For positive affect, we observed a significant main effect of Political Affiliation $\left[F(2,493)=60.704, p<.001, \eta_{p}^{2}=.198\right]$ and Political Affiliation $\times$ Surprise $[F(2,493)=$ $\left.6.543, p=.002, \eta_{p}^{2}=.026\right]$. As anticipated, Clinton supporters reported their positive affect decreasing $(M=-2.84, S D=1.84)$ and Trump supporters reported their positive affect increasing with election outcome $(M=1.90, S D=1.85)$; third-party/non-voters also reported their positive affect decreasing with election outcome, but to a lesser extent than Clinton supporters' $(M=-1.14, S D=2.73)$. These change scores all significantly differed from each other (all $p s<.001$ ). The significant Political Affiliation $\mathrm{x}$ Surprise interaction was driven by greater increases in positive affect for surprised vs. unsurprised Trump voters $(p<.001)$, but no significant difference for Clinton voters $(p$ $=.304)$ or third-party/non-voters $(p=.322)$. Note that due to low numbers of unsurprised Clinton supporters and third-party/non-voters, the null effect of surprise on change in positive affect in these groups should be taken as tentative. 
For reported changes in negative affect, we observed significant main effects of Political Affiliation $\left[F(2,493)=38.794, p<.001, \eta_{p}^{2}=.136\right]$, Surprise $[F(1,493)=4.010$, $\left.p=.046, \eta_{p}^{2}=.008\right]$, and Political Affiliation $x$ Surprise $\left[F(2,493)=8.252, p<.001, \eta_{p}^{2}\right.$ $=.032]$. As anticipated, Clinton supporters reported increased negative affect $[M=3.14$, $S D=1.97]$, and Trump supporters reported decreased negative affect with election outcome $[M=-1.30, S D=1.63]$; third-party/non-voters also reported increased negative affect with the election, but to a lesser extent than Clinton supporters' $[M=0.82, S D=$ 1.83]. The significant main effect of Surprise was driven by greater increases in negative affect reported by surprised vs. unsurprised individuals overall (surprised: $M=$ $1.89, S D=2.67$; non-surprised: $M=-0.47, S D=1.40)$, which was qualified by the presence of a significant Political Affiliation x Surprise interaction. This significant interaction was driven by greater reported increases in negative affect in surprised Clinton supporters $(p=.014)$ and greater reported decreases in negative affect in surprised Trump supporters $(p=.002)$ but no significant modulation of negative affect change in third-party/non-voters by surprise $(p=.131)$. Note that due to low numbers of unsurprised Clinton supporters and third-party/non-voters, observed effects of surprise on change in negative affect in these groups should be taken as tentative.

Thus, consistent with predictions, Clinton supporters (and third-party/non-voters, to a lesser extent) reported decreased positive affect and increased negative affect in response to the election outcome, while Trump supporters reported the opposite. Further, reported changes in negative affect were generally larger in surprised vs. nonsurprised Trump supporters (with suggestions of a similar finding in Clinton supporters, which was limited due to low numbers of non-surprised individuals in this group). While 
our participants' reports of affect experienced before and after the election outcome are limited by both being retrospective (instead of being prospective and retrospective), our findings remain consistent with findings from the reinforcement learning literature, where greater prediction errors or expectancy violations (e.g., surprises) have been associated with greater fluctuations in mood (Eldar, Rutledge, Dolan, \& Niv, 2016). In the next section, we examine whether these factors were also associated with differences in autobiographical memory.

Differences in Autobiographical Memory as a Function of Political Affiliation, Emotion, Surprise, and Time

Memory Quantity, Consistency, and Confidence. We first examined memory quantity, consistency, and confidence (in terms of information provided in response to open-ended personal detail questions, as described in Methods) as a function of fixed effects Political Affiliation, Surprise, and Time (with consistency characterized at T2 and T3, relative to T1; confidence reported at T2 and T3 only), with subjects modeled as a random effect, to test the hypothesis that memory fidelity would be best in those for whom the election outcome was a surprising, positive event (i.e., surprised Trump supporters). These data are visualized in Figure 4. Additionally, a composite measure of Negative Affect (both linear and quadratic terms) was added to the Political Affiliation model to examine for effects of individual-level emotion responses over and above Affiliation group effects on outcomes. Significant effects for each of these analyses are described below and full model results are available in the supplement.

Memory quantity increased over time and with both high and low negative affect. Adding Time as a fixed effect significantly improved model fit over baseline (i.e., random 
effects only; Likelihood Ratio $(L R)=122.486, p<.001)$, due to increasing memory quantity over time (estimate $=.049,95 \% \mathrm{Cl}=.041-.058, p<.001$ ). Additionally, while Affiliation alone was not significant over baseline (where the baseline model contained random effects only; $L R=2.875, p=.238$ ), adding Negative Affect significantly improved model fit over Affiliation alone (linear and quadratic terms: $L R=6.317, p$ $=.043$ ), due to increasing memory quantity in individuals both low and high in negative affect (Negative Affect linear term: estimate $=.006,95 \% \mathrm{Cl}=-.003-0.016, p=.212$; quadratic term: estimate $=.004,95 \% \mathrm{Cl}=.001-.008, p=.021)$.

Memory consistency increased over time. Adding Time as a fixed effect significantly improved model fit over baseline $(\operatorname{LR}=4.775, p=.030)$, due to increasing memory consistency over time (estimate $=.031,95 \% \mathrm{Cl}=.003-.059, p=.030)$. No other significant effects were observed across analyses.

\section{Reported memory confidence was highest in Trump supporters and increased} over time and with both high and low negative affect. Adding Affiliation and Time as fixed effects significantly improved model fit over baseline (Affiliation: $L R=7.411, p$ $=.025$; Time: $\operatorname{LR}=5.907, p=.015)$. The significant effect of Affiliation was due to higher reported memory confidence in Trump supporters than Clinton supporters (estimate $=.311,95 \% \mathrm{Cl}=.065-.557, p=.014)$. The significant effect of Time was due to higher reported memory confidence over time (estimate $=.177,95 \% \mathrm{Cl}=.034-.320, p$ $=.016)$. Additionally, adding Negative Affect significantly improved model fit over Affiliation alone (linear and quadratic terms: $L R=10.422, p=.006$ ) due to increasing memory confidence reported by individuals both low and high in negative affect 
$($ Negative Affect linear term: estimate $=.057,95 \% \mathrm{Cl}=-.022-0.136, p=.158$;

quadratic term: estimate $=.050,95 \% \mathrm{Cl}=.018-.082 p=.003)$.

Additional ERQ Variables. In addition to metrics of memory quantity, consistency, and confidence, we evaluated the following reported measures: subjective memory vividness, subjective memory vividness for activities and location, emotion intensity, perceived personal event importance, perceived broader event importance, and perceived memory rehearsal (in terms of thinking, speaking, and consuming media about the event) following election outcome, as outcome variables using the model structure previously outlined (testing for fixed effects Affiliation, Surprise, and Time, interactions between fixed effects where two or more of them were significant, and subjects as a random effect). Additionally, following previous analyses of memory quantity, consistency, and confidence, a composite measure of Negative Affect (as a linear and quadratic term) was added as a predictor to the Political Affiliation model to examine for effects of individual-level emotion responses over and above Affiliation group effects on outcomes. Significant effects for each of these measures (surviving adjusted alpha criterion of .003 , correcting for family-wise error) are described below and full model results are available in the supplement.

\section{Subjective memory vividness did not differ between Clinton and Trump}

supporters, increased with both high and low negative affect, and declined over time. Adding Affiliation and Time as fixed effects significantly improved model fit over baseline (Affiliation: $\mathrm{LR}=23.584, p<.001$; Time: $\mathrm{LR}=15.578, p<.001$ ). The significant effect of Affiliation was due to lower reported memory vividness in third-party/non-voters versus 
both Clinton supporters (estimate $=-.540,95 \% \mathrm{Cl}=-.804-.275, p<.001$ ) and Trump supporters (estimate $=-.733,95 \% \mathrm{Cl}=-1.035--.431, p<.001$ ); the significant effect of Time was due to decreasing reported memory vividness over time (estimate $=-.186$, $95 \% \mathrm{Cl}=-.278--.094, p<.001)$. Additionally, adding Negative Affect significantly improved model fit over Affiliation alone (linear and quadratic terms: $L R=19.638, p$ $<.001)$ due to increasing memory vividness reported by individuals both low and high in negative affect (Negative Affect linear term: estimate $=.072,95 \% \mathrm{Cl}=-.007-0.150, p$ $=.075$; quadratic term: estimate $=.069,95 \% \mathrm{Cl}=.037-.101, p<.001)$.

Subjective memory vividness for activities and location was enhanced in Trump supporters, increased with both high and low negative affect, and declined over time. Adding Affiliation and Time as fixed effects significantly improved model fit over baseline (Affiliation: $L R=28.693, p<.001$; Time: $L R=19.249, p<.001$ ). The significant effect of Affiliation was due to higher subjective memory vividness for location reported by Trump supporters versus Clinton supporters (estimate $=.256,95 \% \mathrm{Cl}=.014-.498, p=.038$ ), and lower subjective memory vividness for location reported by third-party/non-voters compared to both Clinton voters (estimate $=-.567,95 \% \mathrm{Cl}=-.831--.303, p<.001$ ) and Trump voters (estimate $=-.823, \mathrm{Cl}=-1.126--.521, p<.001$ ). The significant effect of Time was due to decreasing reported vividness over time (estimate $=-.215,95 \% \mathrm{Cl}=$ $-.311--.120, p<.001)$. Additionally, adding Negative Affect significantly improved model fit over Affiliation alone (linear and quadratic terms: $L R=13.903, p=.001$ ) due to increasing memory vividness reported by individuals both low and high in negative affect (Negative Affect linear term: estimate $=.067,95 \% \mathrm{Cl}=-.012-0.146, p=.098$; quadratic term: estimate $=.057,95 \% \mathrm{Cl}=.025-.089, p=.001)$. 
$\underline{\text { Reported emotion intensity did not differ between groups of Clinton and Trump }}$ supporters, but increased with both high and low negative affect, particularly high

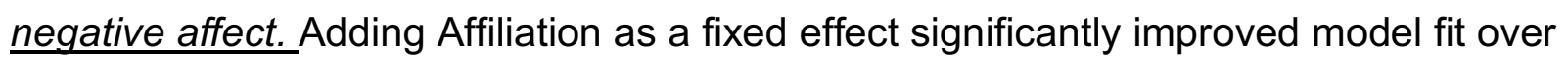
baseline $(L R=42.388 p<.001)$, due to decreased emotion intensity reported by thirdparty/non-voters versus Clinton supporters (estimate $=-.906,95 \% \mathrm{Cl}=-1.185--.627, p$ $<.001$ ) and Trump supporters (estimate $=-.891,95 \% \mathrm{Cl}=-1.209--.572, p<.001$ ) Additionally, adding Negative Affect significantly improved model fit over Affiliation alone (linear term alone: $\mathrm{LR}=25.026, p<.001$; linear and quadratic terms: $\mathrm{LR}=110.771, p$ $<.001)$ due to increasing emotion intensity reported by individuals both low and high in negative affect, but particularly those high in negative affect (Negative Affect linear term: estimate $=.250,95 \% \mathrm{Cl}=.176-.325, p<.001 ;$ quadratic term: estimate $=.151,95 \%$ $\mathrm{Cl}=.121-.181, p<.001)$. Note that using individual-level negative affect as a predictor revealed valence differences in reported emotion intensity that were not observed at the group level with Political Affiliation.

\section{Perceived personal event importance did not differ between Clinton and Trump} supporters, but increased with both high and low negative affect, particularly high

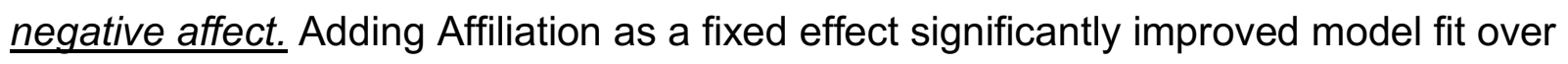
baseline $(L R=41.386, p<.001)$, due to decreased perceived personal event importance reported by third-party/non-voters versus Clinton supporters (estimate $=$ $-.869,95 \% \mathrm{Cl}=-1.154--.585, p<.001)$ and Trump supporters (estimate $=-.979,95 \%$ $\mathrm{Cl}=-1.304--.653, p<.001)$. Additionally, adding Negative Affect significantly improved model fit over Affiliation alone (linear term alone: $L R=13.070, p<.001$; linear and quadratic terms: $\mathrm{LR}=67.251, p<.001$ ) due to increasing perceived personal event 
importance reported by individuals both low and high in negative affect, but particularly those high in negative affect (Negative Affect linear term: estimate $=.186,95 \% \mathrm{Cl}$ $=.106-.266, p<.001 ;$ quadratic term: estimate $=.127,95 \% \mathrm{Cl}=.094-.159, p$ $<.001)$. Note that using individual-level negative affect as a predictor revealed valence differences in perceived personal event importance that were not observed at the group level with Political Affiliation.

\section{Perceived broader event importance did not differ between Clinton and Trump} supporters, but increased with both high and low negative affect, particularly high negative affect, and decreased over time. Adding Affiliation and Time as fixed effects significantly improved model fit over baseline (Affiliation: LR $=23.120, p<.001$; Time: $L R=17.178, p<.001)$. The significant effect of Affiliation was due to lower perceived broader event importance reported by third-party/non-voters versus Clinton supporters (estimate $=-.624,95 \% \mathrm{Cl}=-.875--.372, p<.001)$ and Trump supporters (estimate $=$ $-.491,95 \% \mathrm{Cl}=-.778--.204, p=.001)$. The significant effect of Time was due to decreasing reported perceived broader event importance over time (estimate $=-.180$, $95 \% \mathrm{Cl}=-.265--.095, p<.001)$. Additionally, adding Negative Affect significantly improved model fit over Affiliation alone (linear term alone: $L R=15.149, p<.001$; linear and quadratic terms: $L R=47.416, p<.001$ ) due to increasing perceived broader event importance reported by individuals both low and high in negative affect, but particularly those high in negative affect (Negative Affect linear term: estimate $=.178,95 \% \mathrm{Cl}$ $=.106-.251, p<.001 ;$ quadratic term: estimate $=.085,95 \% \mathrm{Cl}=.055-.114, p$ $<.001)$. Note that using individual-level negative affect as a predictor revealed valence 
differences in perceived broader event importance that were not observed at the group level with Political Affiliation.

\section{Reported rehearsal (Frequency of thought) was elevated in Clinton supporters}

and surprised individuals, increased with both high and low negative affect, particularly high negative affect, and declined over time. Adding Affiliation, Surprise, and Time as fixed effects significantly improved model fit over baseline (Affiliation: $L R=26.637, p$ $<.001$; Surprise: $L R=15.498, p<.001$; Time: $L R=24.942, p<.001)$. The significant effect of Affiliation was due to lower reported frequency of thought in Trump versus Clinton supporters (estimate $=-.466,95 \% \mathrm{Cl}=-.734--.199, p=.001$ ) and thirdparty/non-voters versus Clinton supporters (estimate $=-.714,95 \% \mathrm{Cl}=-1.006--.421, p$ $<.001)$. The significant effect of Surprise was due to higher reported frequency of thought in surprised versus unsurprised individuals (estimate $=.634,95 \% \mathrm{Cl}=.320$ $-.948, p<.001)$. The significant effect of Time was due to decreasing reported frequency of thought over time (estimate $=-.253,95 \% \mathrm{Cl}=-.352--.154, p<.001)$. Additionally, adding Negative Affect significantly improved model fit over Affiliation alone (linear term alone: LR $=23.945, p<.001$; linear and quadratic terms: $L R=40.093, p$ $<.001)$ due to increasing frequency of thought reported by individuals both low and high in negative affect, but particularly those high in negative affect (Negative Affect linear term: estimate $=.234,95 \% \mathrm{Cl}=.149-.319, p<.001 ;$ quadratic term: estimate $=.072$, $95 \% \mathrm{Cl}=.038-.107, p<.001)$. Note that using individual-level negative affect as a amplified valence results observed at the group level with Political Affiliation.

\section{Reported rehearsal (Frequency of media consumption) was elevated in Clinton} supporters and surprised individuals, increased with both high and low negative affect, 
particularly high negative affect, and declined over time. Adding Affiliation, Surprise, and Time as fixed effects significantly improved model fit over baseline (Affiliation: LR = 21.184, $p<.001$; Surprise: $\operatorname{LR}=10.418, p=.001 ;$ Time: $\operatorname{LR}=17.237, p<.001)$. The significant effect of Affiliation was due to lower reported frequency of media consumption about the event in Trump supporters versus Clinton supporters (estimate $=$ $-.384,95 \% \mathrm{Cl}=-.665--.103, p=.008)$ and third-party/non-voters versus Clinton supporters (estimate $=-.690,95 \% \mathrm{Cl}=-.997--.383, p<.001$ ). The significant effect of Surprise was due to higher frequency of media consumption reported by surprised versus unsurprised individuals (estimate $=.542,95 \% \mathrm{Cl}=.214-.870, p<.001$ ). The significant effect of Time was due to decreasing reported frequency of media consumption over time (estimate $=-.235,95 \% \mathrm{Cl}=-.346--.125, p<.001)$. Additionally, adding Negative Affect significantly improved model fit over Affiliation alone (linear term alone: $\mathrm{LR}=18.041, p<.001$; linear and quadratic terms: $\mathrm{LR}=34.814, p<.001$ ) due to increasing frequency of media consumption reported by individuals both low and high in negative affect, but particularly those high in negative affect (Negative Affect linear term: estimate $=.219,95 \% \mathrm{Cl}=.129-.309, p<.001 ;$ quadratic term: estimate $=.076,95 \%$ $\mathrm{Cl}=.040-.112, p<.001)$. Note that using individual-level negative affect as a predictor amplified valence results observed at the group level with Political Affiliation.

Reported rehearsal (Frequency of speaking) was elevated in Clinton supporters, increased with both high and low negative affect, particularly high negative affect, and declined over time. Adding Affiliation and Time as fixed effects significantly improved model fit over baseline (Affiliation: $\mathrm{LR}=17.034, p<.001$; Time: $\mathrm{LR}=9.129, p=.003$ ). The significant effect of Affiliation was due to lower reported frequency of speaking 
about the event in Trump supporters versus Clinton supporters (estimate $=-.312,95 \%$ $\mathrm{Cl}=-.582--.042, p=.024)$ and third-party/non-voters versus Clinton supporters (estimate $=-.603,95 \% \mathrm{Cl}=-.898--.308, p<.001$ ). The significant effect of Time was due to decreasing reported frequency of speaking about the event over time (estimate $=$ $-.153,95 \% \mathrm{Cl}=-.253--.054, p=.003)$. Additionally, adding Negative Affect significantly improved model fit over Affiliation alone (linear term alone: $L R=21.234, p$ $<.001$; linear and quadratic terms: $L R=45.645, p<.001$ ) due to increasing frequency of speaking about the event reported by individuals both low and high in negative affect, but particularly those high in negative affect (Negative Affect linear term: estimate $=.228,95 \% \mathrm{Cl}=.143-.313, p<.001 ;$ quadratic term: estimate $=.089,95 \% \mathrm{Cl}=.054$ $-.123, p<.001)$. Note that using individual-level negative affect as a predictor amplified valence results observed at the group level with Political Affiliation.

$\underline{A M Q}$ Variables. Parallel to the analyses conducted on ERQ variables, we examined the extent to which AMQ measures varied as a function of fixed effects Political Affiliation, Surprise, and Time, with subjects modeled as a random effect. Follow-up analyses using the Negative Affect composite measure (linear and quadratic terms) as a predictor in addition to Political Affiliation were also conducted. From the $A M Q$, we examined reported measures of reliving, belief, component processes (visual imagery, setting recall, hearing imagery, in-words recall, and story recall variables), and properties of event memories (importance, rehearsal-thought, and rehearsal-talk). Significant effects (surviving adjusted alpha criterion correcting for family-wise error 
rate, $p=.003$ ) for each AMQ metric are described below and full model results are available in the supplement.

$\underline{\text { Reported event reliving did not differ between Clinton and Trump supporters, but }}$ increased with both high and low negative affect. Adding Affiliation as a fixed effect significantly improved model fit over baseline $(\operatorname{LR}=33.499, p<.001)$, due to decreased reported reliving of the event in third-party/non-voters than Clinton supporters (estimate $=-.956,95 \% \mathrm{Cl}=-1.319--.592, p<.001)$ and Trump supporters (estimate $=-1.156$, $95 \% \mathrm{Cl}=-1.572--.744, p<.001)$. Additionally, adding Negative Affect significantly improved model fit over Affiliation alone (linear and quadratic terms: LR $=31.014, p$ $<.001)$ due to increased reported reliving of the event reported by individuals both low and high in negative affect (Negative Affect linear term: estimate $=.188,95 \% \mathrm{Cl}=.081$ $-.295, p=.001 ;$ quadratic term: estimate $=.106,95 \% \mathrm{Cl}=.063-.149, p<.001)$.

\section{$\underline{\text { Reported memory belief was greater in Trump supporters, but also increased }}$} with both high and low negative affect and declined over time. Adding Affiliation and Time as fixed effects significantly improved model fit over baseline (Affiliation: LR = 20.868, $p<.001$; Time: $\mathrm{LR}=33.278, p<.001)$. The significant effect of Affiliation was due to greater reported memory belief in Trump supporters versus Clinton supporters (estimate $=.327,95 \% \mathrm{Cl}=.077-.577, p=.011)$ and lower reported memory belief in third-party/non-voters versus both Clinton supporters (estimate $=-.408,95 \% \mathrm{Cl}=-.682$ $--.133, p=.004$ ) and Trump supporters (estimate $=-.734,95 \% \mathrm{Cl}=-1.047--.421, p$ $<$.001). The significant effect of Time was due to decreasing reported memory belief over time (estimate $=-.226,95 \% \mathrm{Cl}=-.302--.150, p<.001$ ). Additionally, adding Negative Affect significantly improved model fit over Affiliation alone $(L R=48.178, p$ 
$<.001)$ due to increasing memory belief reported by individuals both low and high in negative affect (Negative Affect linear term: estimate $=.135,95 \% \mathrm{Cl}=-.076-0.139, p$ $=.001 ;$ quadratic term: estimate $=.107,95 \% \mathrm{Cl}=.076-.139, p<.001)$.

Reported visual imagery of the memory did not differ between Clinton and Trump supporters, increased with both high and low negative affect, and declined over time. Adding Affiliation and Time as fixed effects significantly improved model fit over baseline (Affiliation: $L R=31.499, p<.001$; Time: $L R=15.808, p<.001$ ). The significant effect of Affiliation was due to lower tendency to "see" the memory reported by third-party-nonvoters versus Clinton supporters (estimate $=-.690,95 \% \mathrm{Cl}=-.980--.400, p<.001$ ) and Trump supporters (estimate $=-.925,95 \% \mathrm{Cl}=-1.256--.595, p<.001)$. The significant effect of Time was due to decreasing reported tendency to "see" the memory over time (estimate $=-.157,95 \% \mathrm{Cl}=-.233--.080, p<.001$ ). Additionally, adding Negative Affect significantly improved model fit over Affiliation alone (linear and quadratic terms: $L R=47.943, p<.001$ ) due to increasing tendency to "see" the memory reported by individuals both low and high in negative affect (Negative Affect linear term: estimate $=.136,95 \% \mathrm{Cl}=.052-0.219, p=.002 ;$ quadratic term: estimate $=.114,95 \%$ $\mathrm{Cl}=.080-.148, p<.001)$.

Reported setting recall did not differ between Clinton and Trump supporters, but increased with both high and low negative affect, particularly high negative affect. Adding Affiliation as a fixed effect significantly improved model fit over baseline (LR = $14.328, p=.001)$, due to decreased setting recall reported by third-party/non-voters than Clinton supporters (estimate $=-.453,95 \% \mathrm{Cl}=-.718--.187, p=.001$ ) and Trump supporters (estimate $=-.546,95 \% \mathrm{Cl}=-.850--.243, p<.001$ ). Additionally, adding 
Negative Affect significantly improved model fit over Affiliation alone (linear term alone: $\mathrm{LR}=9.833, p=.002$; linear and quadratic terms: $\mathrm{LR}=39.948, p<.001)$ due to increasing setting recall reported by individuals both low and high in negative affect, but particularly those high in negative affect (Negative Affect linear term: estimate $=.155$, $95 \% \mathrm{Cl}=.077-.232, p<.001 ;$ quadratic term: estimate $=.088,95 \% \mathrm{Cl}=.057-.119$, $p<.001)$. Note that using individual-level negative affect as a predictor revealed valence differences in reported setting recall that were not observed at the group level with Political Affiliation.

Reported hearing (auditory) imagery of the memory did not differ between Clinton and Trump supporters, increased with both high and low negative affect, and declined over time. Adding Affiliation and Time as fixed effects significantly improved model fit over baseline (Affiliation: $\mathrm{LR}=31.835, p<.001$; Time: $\mathrm{LR}=30.546, p<.001$ ). The significant effect of Affiliation was due to lower tendency to "hear" the memory reported by third-party/non-voters versus Clinton supporters (estimate $=-.823,95 \% \mathrm{Cl}=-1.177$ $-.469, p<.001$ ) and Trump supporters (estimate $=-1.145,95 \% \mathrm{Cl}=-1.548--.741, p$ $<.001)$. The significant effect of Time was due to decreasing reported tendency to "hear" the memory over time (estimate $=-.269,95 \% \mathrm{Cl}=-.364--.174, p<.001)$. Additionally, adding Negative Affect significantly improved model fit over Affiliation alone (linear and quadratic terms: $L R=27.500, p<.001$ ) due to increasing tendency to "hear" the memory reported by individuals both low and high in negative affect (Negative Affect linear term: estimate $=.144,95 \% \mathrm{Cl}=.040-0.249, p=.007$; quadratic term: estimate $=.104,95 \% \mathrm{Cl}=.062-.146, p<.001)$. 
Reported In-Words recall did not differ between Clinton and Trump supporters. Adding Affiliation as a fixed effect significantly improved model fit over baseline ( $L R=$ $16.973, p<.001)$, due to decreased tendency to think about the memory "in words" reported by third-party/non-voters than Clinton supporters (estimate $=-.671,95 \% \mathrm{Cl}=-$ $1.012--.330, p<.001)$ and Trump supporters (estimate $=-.720,95 \% \mathrm{Cl}=-1.109-$ $-.331, p<.001)$. Adding Negative Affect did not significantly improve model fit over Affiliation alone (when considering familywise error rate; $L R=4.007, p=.045$ ).

$\underline{\text { Reported story recall was greater in Trump than Clinton supporters, but }}$ increased with both high and low negative affect, and declined over time. Adding Affiliation and Time as fixed effects significantly improved model fit over baseline (Affiliation: $\mathrm{LR}=34.345, p<.001$; Time: $\mathrm{LR}=28.219, p<.001$ ). The significant effect of Affiliation was due to greater reported tendency for event memory to be experienced as a coherent story in Trump supporters versus Clinton supporters (estimate $=.385,95 \%$ $\mathrm{Cl}=.121-.649, p=.004)$, and lower reported tendency in third-party/non-voters versus both Clinton supporters (estimate $=-.612,95 \% \mathrm{Cl}=-.902--.323, p=<.001$ ) and Trump supporters (estimate $=-.998,95 \% \mathrm{Cl}=-1.328--.668, p<.001)$. The significant effect of Time was due to decreasing reported tendency for event memory to be experienced as a coherent story over time (estimate $=-.226,95 \% \mathrm{Cl}=-.308--.143, p$ $<$.001). Additionally, adding Negative Affect significantly improved model fit over Affiliation alone (linear and quadratic terms: $L R=30.809, p<.001$ ) due to increasing reported tendency for event memory to be experienced as a coherent story by individuals both low and high in negative affect (Negative Affect linear term: estimate 
$=.097,95 \% \mathrm{Cl}=.012-0.182, p=.026 ;$ quadratic term: estimate $=.094,95 \% \mathrm{Cl}=.060$ $-.128, p<.001)$.

\section{$\underline{\text { Reported importance of the memory event did not differ between Clinton and }}$}

Trump supporters, but increased with both high and low negative affect, particularly high negative affect, and declined over time. Adding Affiliation and Time as fixed effects significantly improved model fit over baseline (Affiliation: LR $=31.902, p<.001$; Time: $\mathrm{LR}=11.009, p=.001)$. The significant effect of Affiliation was due to lower memory importance reported by third-party/non-voters versus Clinton supporters (estimate $=$ $1.025,95 \% \mathrm{Cl}=-1.377--.673, p<.001$ ) and Trump supporters (estimate $=-.827,95 \%$ $\mathrm{Cl}=-1.228--.426, p<.001)$. The significant effect of Time was due to decreasing reported memory importance over time (estimate $=-.133,95 \% \mathrm{Cl}=-.211--.054, p$ $=.001)$. Additionally, adding Negative Affect significantly improved model fit over Affiliation alone (linear term alone: $L R=11.050, p=.001$; linear and quadratic terms: $\mathrm{LR}=17.551, p<.001)$ due to increasing memory importance reported by individuals both low and high in negative affect, but particularly those high in negative affect (Negative Affect linear term: estimate $=.188,95 \% \mathrm{Cl}=.083-0.294, p=.001$; quadratic term: estimate $=.058,95 \% \mathrm{Cl}=.016-.100, p=.007)$.

\section{Reported rehearsal (Thought) did not differ between Clinton and Trump} supporters, increased with both high and low negative affect, and declined over time. Adding Affiliation and Time as fixed effects significantly improved model fit over baseline (Affiliation: $L R=18.626, p<.001$; Time: $L R=54.464, p=.001$ ). The significant effect of Affiliation was due to reduced reported thoughts about the event in third-party/nonvoters versus Clinton supporters (estimate $=-.642,95 \% \mathrm{Cl}=-.951--.332, p<.001$ ) 
and Trump supporters (estimate $=-.681,95 \% \mathrm{Cl}=-1.033--.328, p<.001$ ). The significant effect of Time was due to decreasing reported thoughts about the event over time (estimate $=-.346,95 \% \mathrm{Cl}=-.437--.256, p<.001$ ). Additionally, adding Negative Affect significantly improved model fit over Affiliation alone (linear and quadratic terms:

$L R=21.793, p<.001)$ due to increasing thoughts about the event reported by individuals both low and high in negative affect (Negative Affect linear term: estimate $=.131,95 \% \mathrm{Cl}=.039-0.223, p=.005 ;$ quadratic term: estimate $=.077,95 \% \mathrm{Cl}=.040$ $-.114, p<.001)$

$\underline{\text { Reported rehearsal (Talk) did not differ between Clinton and Trump supporters, }}$ but increased with both high and low negative affect, particularly high negative affect, and declined over time. Adding Affiliation and Time as fixed effects significantly improved model fit over baseline (Affiliation: $L R=13.318, p=.001$; Time: $L R=39.522$, $p<.001)$. The significant effect of Affiliation was due to decreased reported talking about the event in third-party/non-voters versus Clinton supporters (estimate $=-.592$, $95 \% \mathrm{Cl}=-.909--.274, p<.001)$. The significant effect of Time was due to decreasing reported talking about the event over time (estimate $=-.285,95 \% \mathrm{Cl}=-.372--.197, p$ $<.001)$. Additionally, adding Negative Affect significantly improved model fit over Affiliation alone (linear term alone: $\mathrm{LR}=8.825, p=.003$; linear and quadratic terms: $\mathrm{LR}$ $=46.507, p<.001$ ) due to increasing talking about the event reported by individuals both low and high in negative affect, but particularly those high in negative affect $($ Negative Affect linear term: estimate $=.172,95 \% \mathrm{Cl}=.080-0.263, p<.001 ;$ quadratic term: estimate $=.119,95 \% \mathrm{Cl}=.082-.156, p<.001)$. 
Taken together, these analyses indicate robust and expected differences in emotional response to election outcome as a function of Affiliation (with Clinton supporters reporting a strong negative response, Trump supporters reporting a strong positive response, and third-party/non-voters reporting a mildly negative response). Surprised individuals reported a greater emotional response than unsurprised individuals. Contradictory to predictions, objective measures of memory, such as memory quantity and memory consistency, significantly increased over time, while subjective measures of memory generally declined over time. Additionally, subjective memory differed with Political Affiliation: both Clinton and Trump supporters reported more vivid memories, with stronger sensory component processes and higher perceived event importance, than third-party/non-voters. Limited differences in subjective memory, including memory confidence, perceived rehearsal, and the presence of a coherent story, were observed as a function of valence between Clinton and Trump supporters. Further, adding individual-level emotion responses as a predictor revealed valence effects on perceptions of event importance and reported setting recall. Implications of these results are discussed below.

\section{Discussion}

The outcome of the 2016 U.S. presidential election was a highly consequential, emotional, and surprising sociopolitical event likely to elicit a flashbulb memory; however, perceptions of this event as emotionally positive or negative, and surprising or non-surprising, varied widely between individuals as a function of political affiliation and expectation. The extent to which valence and surprise have been associated with 
differences in memory, particularly for naturalistic events, is not well-characterized. This event thus provided a unique opportunity to characterize the extent to which variability in emotional valence and surprise were associated with changes in the phenomenology of autobiographical memory for a consequential public event.

As anticipated, emotional responses to the election outcome varied strongly as a function of political affiliation, with Clinton supporters reporting negative emotional responses, Trump supporters reporting positive emotional responses, and thirdparty/non-voters reporting a mildly-negative emotional response. Interestingly, surprised individuals reported greater changes in experienced emotion with the election event, with surprised Trump supporters reporting a greater increase in positive affect and decrease in negative affect with the outcome than non-surprised Trump supporters (as well as observations of the reverse pattern in Clinton supporters, although this is tentative given the small number of non-surprised Clinton supporters recruited). These effects are consistent with recent findings suggesting that mood might reflect prediction error (i.e., the difference between actual and expected outcome), with surprises, either positive or negative, contributing to larger fluctuations in mood (Eldar et al., 2016).

Despite these differences in emotional response, objective memory measures (quantity and consistency) did not vary as a function of political affiliation or surprise. (Note that while Negative Affect significantly predicted memory quantity when added to the Affiliation model, this was driven by the quadratic term, not the linear term, of this predictor, suggesting that memory quantity may have increased with emotion intensity, but did not differ with valence.) Interestingly, information quantity and consistency significantly increased over time instead of decreasing, in contrast to prior observations 
from the autobiographical memory literature (Kensinger \& Schacter, 2006; Raw et al., 2020; Talarico \& Rubin, 2003). When interpreting our consistency results relative to prior work, however, it is important to note that we only measured consistency at T2 and T3, relative to T1; global consistency scores at both $\mathrm{T} 2(M=0.58, S D=0.21)$ and T3 $(M$ $=0.61, S D=0.22)$ are well below a perfect score of 1 , indicating both memory decline relative to T1, and an increase from T2 to T3. Given that many studies of memory for public events assess memory at two timepoints or fewer (Botzung et al., 2010; Holland \& Kensinger, 2012; Kensinger \& Schacter, 2006; Talarico \& Rubin, 2003), this threetimepoint design may be argued to enable more nuanced characterization of memory as well as potentially suggesting that memory decline may be non-linear over time. However, it is also important to note that in our study design, time elapsed since the event was confounded with number of studied retrieval attempts (i.e., all participants in our sample reported their personal memories for Election Night 2016 at T1 to provide a baseline to assess subsequent memory consistency against; then, for all returning participants, a second retrieval attempt was conducted at T2 and a third retrieval attempt was conducted at T3). Prior work in the memory literature has suggested that multiple retrieval attempts may be positively associated with subsequent memory performance: coined the "retrieval practice" effect, this phenomenon has been largely studied in educational contexts, where it has been used to advocate for frequent testing and assessment (i.e., required memory retrieval) as a mechanism for long-term retention of learned information (Roediger III \& Butler, 2011); however, note that increased retrieval practice has also been observed to increase false retrieval of related information as well as true retrieval (Mcdermott, 2006). Many studies investigating 
retrieval practice have used lists of words or facts as stimuli (akin to learning in classroom contexts); in contrast, investigations of the effects of multiple retrieval attempts on memory veridicality for episodic or autobiographical memories are more limited. Studies investigating the effect of repeated recall on memory for a complex, naturalistic (i.e., videotaped) event (Odinot \& Wolters, 2006; Odinot, Wolters, \& van Giezen, 2013) suggest that repeated recall may not significantly affect memory accuracy and confidence for the event in question (note that memory quantity was not analyzed as an outcome of interest in these prior works). Further, divergence of these results from observations in the retrieval practice literature have been suggested to be due to differences in memory assessment (recall vs. recognition) and stimuli (naturalistic vs. laboratory stimuli; (Odinot \& Wolters, 2006)). Given that our study likewise assessed memory recall for a naturalistic event, these prior observations suggest that our use of repeated retrieval attempts may not have significantly influenced memory performance over time; however, follow-up work should independently manipulate retention interval and number of retrieval attempts, as well as investigating previously observed differences in the effects of retrieval practice given varying stimuli and response modalities, to address these issues more definitively. The 2016 election may also have differed from many previously-studied public events potentially eliciting flashbulb memories in the ubiquity and intensity of subsequent media and social media coverage, which might have led to increased memory rehearsal (Marsh \& Rajaram, 2019), influencing subsequent memory performance. This possibility is addressed in more detail when discussing our memory rehearsal measures below. 
Subjective memory metrics including vividness and sensory processing declined over time overall, consistent with prior findings from the autobiographical memory literature (Janssen, Rubin, \& Jacques, 2011; Rubin et al., 2003; Rubin \& Schulkind, 1997) as well as recent experimental work using a novel paradigm to demonstrate decreased visual salience in memory recollection over time (Cooper, Kensinger, \& Ritchey, 2019). Further, while objective memory did not differ as a function of political affiliation and surprise, subjective memory varied robustly with these factors. First, Trump supporters reported higher memory confidence and belief that the event occurred the way they remember than Clinton supporters. Given that the election outcome was generally considered a positive emotional event by Trump supporters, this observation is consistent with a growing consensus that memory confidence may be greater for positive autobiographical events compared to negative (Holland \& Kensinger, 2012; Kensinger \& Schacter, 2006; Raw et al., 2020), which may be attributable to a greater willingness to endorse remembered items under positive versus negative affective states (Bowen, Marchesi, \& Kensinger, 2019; Levine \& Bluck, 2004). In addition to memory confidence, a number of additional differences in subjective memory experience were observed as a function of political affiliation. In general, thirdparty/non-voters differed from both Clinton and Trump supporters on these metrics, with limited differences observed between Clinton and Trump supporters. When adding Negative Affect as an additional predictor, robust quadratic effects were observed for many subjective memory outcomes, suggesting that these outcomes differed as a function of emotion intensity; additionally, significant effects of Negative Affect as a linear term in some models indicated the presence of valence effects on subjective 
memory that did not reach significance when examining group-level Political Affiliation alone. Third-party/non-voters reported emotional responses of significantly lower intensity than both Clinton and Trump supporters, and also reported decreased subjective vividness, event importance, and sensory processing. This is consistent with prior work suggesting that emotional intensity may be a more robust predictor of autobiographical memory experience than valence across a wide range of subjective memory properties (Talarico et al., 2004).

The role of emotional intensity and arousal in memory formation has become a topic of major importance in cognitive neuroscience, with several neuroimaging studies demonstrating associations between increased arousal, increased activity in the locus coeruleus-norepinephrine (LC-NE) neurotransmitter system, and increased memory performance, including enhanced vividness and confidence (Clewett et al., 2018; Mather \& Sutherland, 2011; Rimmele, Lackovic, Tobe, Leventhal, \& Phelps, 2016). However, memory enhancements for emotionally arousing or central items may potentially come at the expense of memory for peripheral details: this pattern has been conceptualized in terms of a competitive tradeoff, particularly for negatively-valenced information (Sakaki, Fryer, \& Mather, 2014). Consistent with this, work from the autobiographical memory literature that has argued that central, event-related details are remembered better in negative versus positive autobiographical memories (Berntsen, 2002), while memory for peripheral details or personal information may be superior for positively-valenced memories (Talarico, Berntsen, \& Rubin, 2009). Complementary work from the cognitive neuroscience literature suggests that memory encoding under positively- vs. negatively-valenced motivational states (e.g., reward 
versus punishment anticipation) may preferentially benefit encoding of contextual details or incidental information as integrative aspects of a memory episode, an effect that has been argued to be associated with dopaminergic input to the hippocampus (Murty \& Adcock, 2017). More broadly, mesolimbic dopamine has been linked to a number of states promoting memory formation - including reward-seeking, exploration, novelty and surprise -collectively argued to construe "behavioral activation", promoting integrative encoding of both item and context information, even in the presence of high emotional arousal and associated LC-NE activity (Clewett \& Murty, 2019). Given these findings, it was surprising that neither valence nor surprise were associated with differences in memory quantity or consistency in the present study.

Several features of the present study may have contributed to these null findings in objective memory, despite robust differences in subjective memory experience. By assessing memory for personal details of the evening of the event (e.g., "Where were you?", "What were you wearing?", etc.), we arguably assessed memory for peripheral details, as opposed to elements or items central to the election outcome itself. This contrasts with a prior study investigating memories for the 2008 presidential election outcome, which focused on election event details (e.g., percentage of votes earned by a given candidate, attire worn by the winning candidate and their family on Election Night) and reported valence differences in objective memory, with greater memory consistency observed in those for whom the 2008 election outcome was a negative event (Holland \& Kensinger, 2012). Future studies characterizing flashbulb memory for major public events could help account for these observed differences in valence effects on memory 
across studies by explicitly assessing both memory for central event details as well as peripheral personal details.

While many measures of subjective memory experience differed with intensity but not valence, some core differences were observed between Clinton and Trump supporters (who experienced the event as emotionally negative versus positive, respectively), as well as a function of individual-level emotional response. Trump supporters reported higher memory confidence and memory belief than Clinton supporters and third-party/non-voters. Trump supporters also reported a greater tendency to experience the memory as a coherent story, even though Clinton supporters reported higher memory vividness for activities and location on the night of the event. This pattern is consistent with prior research suggesting that memories have greater narrative coherence when positively versus negatively valenced (Talarico et al., 2004) and, with extremely intense negative memories, such as those associated with a traumatic event, memory details may be vividly experienced even when narrative coherence remains low (Van der Kolk \& Fisler, 1995). Additionally, even in the absence of significant differences as a function of Political Affiliation, adding Negative Affect as a predictor revealed that reported personal event importance, broader event importance, emotion intensity, and setting recall increased with negative affect. Our observation of increasing personal event importance with negative affect contradicts prior work examining memory for the 2008 American presidential election, where increasing event importance was associated with increasing positive affect (Holland \& Kensinger, 2012), but our observations of higher reported emotion intensity and setting recall with negative affect are consistent with prior characterizations of autobiographical memories for 
stressful events in individuals with post-traumatic stress disorder (Rubin, Dennis, \& Beckham, 2011). Given widespread characterization of Clinton's loss in the 2016 election as a collective trauma for supporters (Carmack \& DeGroot, 2018; Sondel, Baggett, \& Dunn, 2018), our observations of decreased narrative coherence as well as increased emotion intensity and setting recall reported by Clinton supporters and individuals experiencing negative affect may be interpreted as consistent with prior findings from the trauma literature.

We also observed that Clinton supporters reported higher memory rehearsal (in terms of thinking, consuming media coverage, and speaking about the event, measured via the ERQ) than Trump supporters or third-party/non-voters. Individual-level emotion responses further predicted valence differences in memory rehearsal, with increased rehearsal as a function of negative affect (in the three ERQ measures previously noted, as well as spoken rehearsal from the AMQ). Our observation of increased memory rehearsal with increasing negative affect diverges from prior studies of emotion and autobiographical memory rehearsal, which themselves have been mixed: two studies have suggested that positive memories are rehearsed more frequently than negative memories, particularly when negative memory reminders are avoidable (Bluck \& Li, 2001; Breslin \& Safer, 2011), while other studies have suggested no significant difference in positive versus negative memory rehearsal (Berntsen, 1998; Talarico et al., 2004). Arguably, the 2016 election outcome differs from most personal autobiographical events (and many events eliciting previously-studied flashbulb memories) in the extensive, intense, and sustained media (particularly Internet-based media) and social media coverage the event received, as well as the personal and public discussions it 
elicited for many Americans. Given this coverage and discussion, it is possible that memories of the 2016 election outcome may have been characterized by elevated levels of rehearsal generally relative to many previously-studied public events, which could have contributed to our observation of enhanced global memory consistency over time. Despite potentially high levels of rehearsal overall, differences in media and social media consumption between participants in our study could also have contributed to variability in memory and emotional responses over time. Mass media coverage has been previously shown to be associated with changes in political affiliation and perceptions of political candidates (DellaVigna \& Kaplan, 2007; Eberl, Wagner, \& Boomgaarden, 2017); the ease of access and volume of information (and misinformation) the Internet offers may accelerate these tendencies, especially given the rise of targeted media and social media content that may contribute to increased political polarization (Hong \& Kim, 2016; Jacobson, Myung, \& Johnson, 2016; Tewksbury \& Riles, 2015). In addition to consuming content, the Internet offers an increased ability to create content and share personal experiences with other users (i.e., through the use of social media platforms; Marsh \& Rajaram, 2019), which may have influenced memories of Election Night 2016 and emotional responses to the event, as well as encouraging the rise of political activism in those opposed to Trump's victory. Following the 2016 election, the American political left experienced a galvanization of grassroots activism and political activity, demonstrated by widespread attendance at the 2017 Women's Marches nationwide (estimated between 3 and 5 million people; Waddell, 2017) and the rise of anti-Trump opposition activist groups collectively termed 'The Resistance' (Meyer \& Tarrow, 2018). This upswing in political action following the 
2016 election may be interpreted as consistent with theoretical work positing that negative memories can serve as a directive to action (Rasmussen \& Berntsen, 2009), a tendency likely facilitated by the shared nature of the event. While the election outcome was experienced as a negative event for most Clinton supporters, it may thus differ from many previously-studied negative autobiographical events in terms of its public nature, shared emotional experience, and collective action as a response; these factors may have led to increased memory rehearsal. Interestingly, this also suggests the possibility of phenomenological differences in subjective memory experience for public, collectively-experienced and rehearsed emotional events, versus personal events. While we did not obtain detailed measures of media consumption or any measures of social media usage over time or motivation to activism in our participant sample, these potential sources of variability and contributions to emotion and memory for collectivelyexperienced events should be explored further in future research.

While our results suggest greater memory rehearsal with negative affect, this valence-related difference should be taken with caution, given that a highly similar measures of memory rehearsal from the AMQ (endorsing "I purposely thought about this event") did not differ between Clinton and Trump supporters or as a function of individual-level emotion response. Given that all three metrics of memory rehearsal from the ERQ (rating frequency of thought, media consumption, and speaking about the event) were consistent in revealing higher reported frequency in Clinton versus Trump supporters, and the AMQ rehearsal-talk measure ("I have talked about this event") was positively associated with increasing negative affect, it is possible that the AMQ rehearsal-thought measure tapped a slightly different construct of rehearsal. As 
opposed to our other measures of memory rehearsal, the wording of the AMQ rehearsal-thought measure ("I purposely thought about this event") may specifically assess voluntary autobiographical memory retrieval, although autobiographical memories may be retrieved in either a voluntary or involuntary manner (Berntsen, 1996; Berntsen \& Hall, 2004; Hall et al., 2014). While some studies of the AMQ's psychometric properties have been conducted (Fitzgerald \& Broadbridge, 2013), to our knowledge, the ERQ developed by Kensinger and Schacter (Kensinger \& Schacter, 2006) and adapted for use in the present study has not been characterized psychometrically or systematically compared with the AMQ.

Our study is also limited in its ability to characterize independent effects of political affiliation and surprise on memory performance, given the extremely small number of unsurprised Clinton supporters recruited ( $N=5$ at $T 1$, as opposed to $N=266$ surprised Clinton supporters at T1) and the small number of unsurprised third-party/nonvoters recruited ( $\mathrm{N}=16$ at $\mathrm{T} 1$, as opposed to $\mathrm{N}=81$ surprised third-party/non-voters at T1). While we did not set out to deliberately recruit either a nationally-representative sample nor a sample with equal numbers of participants in each of the cells of our $3 \times 2$ (Political Affiliation $x$ Surprise) factorial design, we did not anticipate the small number of participants recruited in these participant groups, particularly Clinton supporters. While many politically liberal media outlets had anticipated a Clinton victory (Francia, 2018), other liberal outlets anticipated a Trump victory (e.g., Michael Moore's July 2016 opinion piece "5 Reasons Why Trump Will Win”, https://michaelmoore.com/trumpwillwin/). Given such media coverage, we had hypothesized that a larger number of unsurprised Clinton supporters might be recruited in our sample. While our analytical approach focused on 
the use of multilevel models, which help protect against the heterogeneity of variance often present in unequal sample sizes (Singer \& Willet, 2003), we recognize that the great discrepancy in our sample sizes means that our models should be interpreted with caution. Future studies will need to address this issue by deliberately recruiting a more balanced sample for improved statistical robustness.

Finally, our study assessed participants' memories, expectations, and emotional responses to Election Night 2016 retroactively - our first wave of data collection was $\sim 2$ weeks following the election outcome, which could have led to potential bias or memory distortion. While, to our knowledge, retroactive evaluation of one's confidence in a future event has not been systematically evaluated, studies characterizing emotional experience as reported for a previous versus present moment have suggested a "memory-experience gap" - memories of prior experiences may systematically diverge from experience reported as it occurs (Hsee \& Hastie, 2006; Wirtz, Kruger, Scollon, \& Diener, 2003). Evidence exists in support of both negative memory biases (e.g., negative versus positive emotions are remembered as higher in intensity than when characterized in the present moment; Miron-Shatz, Stone, \& Kahneman, 2009) and positive memory biases (e.g., past events are recalled more favorably than they actually were; Adler \& Pansky, 2020; Kappes \& Crockett, 2016). While we are not able to disentangle potential contributions of retroactive negative or positive memory biases on participant self-reports in the present data, these potential influences should be kept in mind, and collecting prospective and present-moment data to characterize these relationships remains an important direction for future research. 
Taken together, our investigation of autobiographical memories for the evening of the 2016 American presidential election demonstrate that political affiliation and surprise acted as powerful modulators of emotional response to the event. As expected, Clinton supporters experienced the event as highly negative, Trump supporters experienced the event as highly positive, and third-party/non-voters experienced the event as moderately negative. Emotion intensity was higher in surprised versus unsurprised individuals. Despite these variations in emotion, political affiliation and surprise were not associated with significant differences in objective memory (although individual-level emotion responses suggested that emotion intensity was associated with increased memory quantity). Subjective memory was strongly influenced by political affiliation and surprise, with Clinton and Trump supporters reporting more vivid memories relative to third-party/non-voters, consistent with prior findings that emotional intensity may be a more important determinant of autobiographical memory experience than valence (Talarico et al., 2004). In addition to these group-level effects, examination of individuallevel emotion responses revealed higher reported emotion intensity, event importance, and setting recall as a function of negative affect. In contrast to these findings, we observed that Trump supporters reported greater confidence in their memories and a greater experience of story coherence, consistent with prior work suggesting greater memory confidence for positive versus negative memories and decreased narrative coherence in intensely negative and traumatic memories. Interestingly, Clinton supporters reported greater memory rehearsal than Trump supporters, a result that was amplified by follow-up analyses associating individual-level Negative Affect with increased memory rehearsal, contradicting prior literature suggesting higher rehearsal 
for positive memories. We suggest that this pattern might be specific to the public and heavily-discussed nature of the event, and its motivational significance given posited functions of negative memories as action directives (Rasmussen \& Berntsen, 2009), as reflected by increased political activity in the American public sphere in the aftermath of the 2016 election, particularly on the political left. In conclusion, this work indicates differences in subjective, but not objective, measures of autobiographical memory as a function of the intensity and valence of emotions and points to important directions for future work characterizing autobiographical memories, both personal and public, as well as their potential role in influencing large-scale human behavior.

\section{Acknowledgements}

This research was supported by Duke University. K.S.C. was supported by a postdoctoral fellowship from the Canadian Institutes for Health Research (MFE135441). We thank Kevin LaBar, David Rubin, and Kathleen Arnold for helpful suggestions during project development; Katherine Barnes, Natalia Espinosa, Sujal Manohar, and Cory Vandenberg, for assistance with data collection and analysis; and Holly Bowen, Kathryn Dickerson, and Timothy Sweeny for manuscript feedback. No conflict of interest is reported.

\section{Context of Research}

Investigations of so-called flashbulb memories have largely focused on memory for negative, unexpected events. By characterizing autobiographical memories for a public event varying in valence and surprise across perceivers, we advance a more 
comprehensive understanding of these memories, as well as linking autobiographical memory research to a growing literature regarding the impact of prediction errors and surprise on memory formation. Interestingly, our data suggest that subsequent memory rehearsal for a public, collectively-experienced event might differ from that for personal memories. Future work should explore the role of media coverage and consumption in shaping emotion and cognition for such collective events.

\section{$\underline{\text { References }}$}

Adler, O., \& Pansky, A. (2020). A "Rosy View" of the Past: Positive Memory Biases. In T. Aue \& H. Okon-Singer (Eds.), Cognitive Biases in Health and Psychiatric Disorders. Elsevier.

Axmacher, N., Cohen, M. X., Fell, J., Haupt, S., Dümpelmann, M., Elger, C. E., ... Ranganath, C. (2010). Intracranial EEG correlates of expectancy and memory formation in the human hippocampus and nucleus accumbens. Neuron, 65(4), $541-549$.

Beasley, T. M., \& Schumacker, R. E. (1995). Multiple regression approach to analyzing contingency tables: Post hoc and planned comparison procedures. The Journal of Experimental Education, 64(1), 79-93.

Berntsen, D. (1996). Involuntary autobiographical memories. Applied Cognitive Psychology, 10(5), 435-454.

Berntsen, D. (1998). Voluntary and involuntary access to autobiographical memory. Memory, 6(2), 113-141.

Berntsen, D. (2017). Flashbulb memories and social identity. In Flashbulb memories 
(pp. 198-216). Psychology Press.

Berntsen, D., \& Hall, N. M. (2004). The episodic nature of involuntary autobiographical memories. Memory \& Cognition, 32(5), 789-803.

Bluck, S., \& Li, K. Z. H. (2001). Predicting memory completeness and accuracy: Emotion and exposure in repeated autobiographical recall. Applied Cognitive Psychology: The Official Journal of the Society for Applied Research in Memory and Cognition, 15(2), 145-158.

Botzung, A., Rubin, D. C., Miles, A., Cabeza, R., \& LaBar, K. S. (2010). Mental hoop diaries: emotional memories of a college basketball game in rival fans. Journal of Neuroscience, 30(6), 2130-2137.

Bowen, H. J., Marchesi, M., \& Kensinger, E. (2019). Reward Motivation Influences Response Bias on a Recognition Memory Task.

Breslin, C. W., \& Safer, M. A. (2011). Effects of event valence on long-term memory for two baseball championship games. Psychological Science, 22(11), 1408-1412.

Brown, R., \& Kulik, J. (1977). Flashbulb memories. Cognition, 5(1), 73-99.

Bunzeck, N., \& Düzel, E. (2006). Absolute coding of stimulus novelty in the human substantia nigra/VTA. Neuron, 51(3), 369-379.

Carmack, H. J., \& DeGroot, J. M. (2018). Trauma metaphor use after Hillary Clinton's Loss in the 2016 Presidential Election. Journal of Loss and Trauma, 23(6), 468483.

Ceaser, J. W., Busch, A. E., \& Pitney Jr, J. J. (2019). Defying the Odds: The 2016 Elections and American Politics, Post 2018 Election Update. Rowman \& Littlefield. Chiew, K.S. (2021). Data repository for "Remembering Election Night 2016: Subjective 
but not objective metrics of autobiographical memory vary with political affiliation, affective valence, and surprise. Open Science Framework, https://osf.io/hkdjw/

Cillizza, C. (2016). President-elect Donald Trump's cataclysmic, history-making upset. The Washington Post. Retrieved from Https:/Www. Washingtonpost. Com/News/the-Fix/Wp/2016/11/09/How-Donald-Trump-Pulled-off-an-Upset-ofCataclysmic-Historic-Proportions.

Clewett, D., \& Murty, V. P. (2019). Echoes of emotions past: How neuromodulators determine what we recollect. Eneuro, 6(2).

Clewett, D., Schoeke, A., \& Mather, M. (2014). Locus coeruleus neuromodulation of memories encoded during negative or unexpected action outcomes. Neurobiology of Learning and Memory, 111, 65-70.

Clewett, D. V, Huang, R., Velasco, R., Lee, T.-H., \& Mather, M. (2018). Locus coeruleus activity strengthens prioritized memories under arousal. Journal of Neuroscience, 38(6), 1558-1574.

Cooper, R. A., Kensinger, E. A., \& Ritchey, M. (2019). Memories fade: the relationship between memory vividness and remembered visual salience. Psychological Science, 30(5), 657-668.

Craig, S. C., Martinez, M. D., Gainous, J., \& Kane, J. G. (2006). Winners, losers, and election context: Voter responses to the 2000 presidential election. Political Research Quarterly, 59(4), 579-592.

DellaVigna, S., \& Kaplan, E. (2007). The Fox News effect: Media bias and voting. The Quarterly Journal of Economics, 122(3), 1187-1234.

Eberl, J.-M., Wagner, M., \& Boomgaarden, H. G. (2017). Are perceptions of candidate 
traits shaped by the media? The effects of three types of media bias. The International Journal of Press/Politics, 22(1), 111-132.

Eldar, E., Rutledge, R. B., Dolan, R. J., \& Niv, Y. (2016). Mood as representation of momentum. Trends in Cognitive Sciences, 20(1), 15-24.

Faris, R., Roberts, H., Etling, B., Bourassa, N., Zuckerman, E., \& Benkler, Y. (2017). Partisanship, propaganda, and disinformation: Online media and the 2016 US presidential election. Berkman Klein Center Research Publication, 6.

Fitzgerald, J. M., \& Broadbridge, C. L. (2013). Latent constructs of the autobiographical memory questionnaire: A recollection-belief model of autobiographical experience. Memory, 21(2), 230-248.

Francia, P. L. (2018). Free media and Twitter in the 2016 presidential election: The unconventional campaign of Donald Trump. Social Science Computer Review, 36(4), 440-455.

Hall, S. A., Rubin, D. C., Miles, A., Davis, S. W., Wing, E. A., Cabeza, R., \& Berntsen, D. (2014). The neural basis of involuntary episodic memories. Journal of Cognitive Neuroscience, 26(10), 2385-2399.

Hendrickson, J., Sebastian, M., Bort, R., Storey, K., Joiner, W., \& Baird, R. P. (2017). The Untold Stories of Election Day 2016. Retrieved from https://www.esquire.com/news-politics/a13266971/election-2016-behind-thescenes/

Holland, A. C., \& Kensinger, E. A. (2012). Younger, middle-aged, and older adults' memories for the 2008 US Presidential Election. Journal of Applied Research in Memory and Cognition, 1(3), 163-170. 
Hong, S., \& Kim, S. H. (2016). Political polarization on twitter: Implications for the use of social media in digital governments. Government Information Quarterly, 33(4), 777782.

Hoyt, L. T., Zeiders, K. H., Chaku, N., Toomey, R. B., \& Nair, R. L. (2018). Young adults' psychological and physiological reactions to the 2016 US presidential election. Psychoneuroendocrinology, 92, 162-169.

Hsee, C. K., \& Hastie, R. (2006). Decision and experience: why don't we choose what makes us happy? Trends in Cognitive Sciences, 10(1), 31-37.

Jacobson, S., Myung, E., \& Johnson, S. L. (2016). Open media or echo chamber: The use of links in audience discussions on the Facebook pages of partisan news organizations. Information, Communication \& Society, 19(7), 875-891.

Janssen, S. M. J., Rubin, D. C., \& Jacques, P. L. S. (2011). The temporal distribution of autobiographical memory: changes in reliving and vividness over the life span do not explain the reminiscence bump. Memory \& Cognition, 39(1), 1-11.

Kappes, A., \& Crockett, M. J. (2016). The benefits and costs of a rose-colored hindsight. Trends in Cognitive Sciences, 20(9), 644-646.

Kawachi, I., \& Berkman, L. (2000). Social cohesion, social capital, and health. Social Epidemiology, 174(7).

Kensinger, E. A., \& Schacter, D. L. (2006). When the Red Sox shocked the Yankees: Comparing negative and positive memories. Psychonomic Bulletin \& Review, 13(5), 757-763. https://doi.org/10.3758/BF03193993

Levine, L., \& Bluck, S. (2004). Painting with broad strokes: Happiness and the malleability of event memory. Cognition and Emotion, 18(4), 559-574. 
Marsh, E. J., \& Rajaram, S. (2019). The digital expansion of the mind: Implications of internet usage for memory and cognition. Journal of Applied Research in Memory and Cognition, 8(1), 1-14.

Mather, M., \& Sutherland, M. R. (2011). Arousal-biased competition in perception and memory. Perspectives on Psychological Science, 6(2), 114-133.

Mcdermott, K. B. (2006). Paradoxical effects of testing: Repeated retrieval attempts enhance the likelihood of later accurate and false recall. Memory \& Cognition, 34(2), 261-267.

Meyer, D. S., \& Tarrow, S. (2018). The Resistance: The Dawn of the Anti-Trump Opposition Movement. Oxford University Press.

Miron-Shatz, T., Stone, A., \& Kahneman, D. (2009). Memories of yesterday's emotions: Does the valence of experience affect the memory-experience gap? Emotion, 9(6), 885.

Murty, V P, LaBar, K. S., \& Adcock, R. A. (2016). Distinct medial temporal networks encode surprise during motivation by reward versus punishment. Neurobiol Learn Mem. https://doi.org/10.1016/j.nlm.2016.01.018

Murty, Vishnu P, \& Adcock, R. A. (2017). Distinct medial temporal lobe network states as neural contexts for motivated memory formation. In D. E. Hannula \& C. Duff, Melissa (Eds.), The hippocampus from cells to systems (pp. 467-501). Cold Spring, New York: Springer International Publishing.

Neisser, U., \& Harsch, N. (1992). Phantom flashbulbs: False recollections of hearing the news about Challenger.

Newport, F. (2013). Democrats racially diverse; Republicans mostly White. Gallup 
Politics: Http://Www. Gallup. Com/Poll/160373/Democrats-Racially-DiverseRepublicans-Mostly-White. Aspx.

Odinot, G., \& Wolters, G. (2006). Repeated recall, retention interval and the accuracyconfidence relation in eyewitness memory. Applied Cognitive Psychology, 20(7), 973-985.

Odinot, G., Wolters, G., \& van Giezen, A. (2013). Accuracy, confidence and consistency in repeated recall of events. Psychology, Crime \& Law, 19(7), 629-642.

Otto, A. R., \& Eichstaedt, J. C. (2018). Real-world unexpected outcomes predict citylevel mood states and risk-taking behavior. PloS One, 13(11).

Rahn, W. M., Kroeger, B., \& Kite, C. M. (1996). A framework for the study of public mood. Political Psychology, 29-58.

Rasmussen, A. S., \& Berntsen, D. (2009). Emotional valence and the functions. Memory \& Cognition, 37(4), 477-492.

Raw, J., Rorke, A., ELLIS, J. A. N. N., Murayama, K., \& Sakaki, M. (2020). Memory of the UK's 2016 EU Referendum: The effects of valence on the long-term measures of a flashbulb memory.

Rimmele, U., Lackovic, S. F., Tobe, R. H., Leventhal, B. L., \& Phelps, E. A. (2016). Beta-adrenergic blockade at memory encoding, but not retrieval, decreases the subjective sense of recollection. Journal of Cognitive Neuroscience, 28(6), 895907.

Roediger III, H. L., \& Butler, A. C. (2011). The critical role of retrieval practice in longterm retention. Trends in Cognitive Sciences, 15(1), 20-27.

Rouhani, N., Norman, K. A., \& Niv, Y. (2018). Dissociable effects of surprising rewards 
on learning and memory. Journal of Experimental Psychology: Learning, Memory, and Cognition, 44(9), 1430.

Rubin, D. C., Dennis, M. F., \& Beckham, J. C. (2011). Autobiographical memory for stressful events: The role of autobiographical memory in posttraumatic stress disorder. Consciousness and Cognition, 20(3), 840-856.

Rubin, D. C., Schrauf, R. W., \& Greenberg, D. L. (2003). Belief and recollection of autobiographical memories. Memory \& Cognition, 31(6), 887-901.

Rubin, D. C., \& Schulkind, M. D. (1997). The distribution of autobiographical memories across the lifespan. Memory \& Cognition, 25(6), 859-866.

Rubin, D. C., \& Siegler, I. C. (2004). Facets of personality and the phenomenology of autobiographical memory. Applied Cognitive Psychology: The Official Journal of the Society for Applied Research in Memory and Cognition, 18(7), 913-930.

Sakaki, M., Fryer, K., \& Mather, M. (2014). Emotion strengthens high-priority memory traces but weakens low-priority memory traces. Psychological Science, 25(2), 387395.

Schill, D., \& Kirk, R. (2017). Angry, passionate, and divided: Undecided voters and the 2016 presidential election. American Behavioral Scientist, 61(9), 1056-1076.

Schultz, W., Dayan, P., \& Montague, P. R. (1997). A neural substrate of prediction and reward. Science, 275(5306), 1593-1599. Retrieved from http://www.ncbi.nlm.nih.gov/entrez/query.fcgi?cmd=Retrieve\&db=PubMed\&dopt=Ci tation\&list_uids $=9054347$

Singer, J. A., \& Willet, J. B. (2003). Applied Longitudinal Data Analysis: Oxford University press. New York. 
Sondel, B., Baggett, H. C., \& Dunn, A. H. (2018). "For millions of people, this is real trauma": A pedagogy of political trauma in the wake of the 2016 US Presidential election. Teaching and Teacher Education, 70, 175-185.

Talarico, J. M., LaBar, K. S., \& Rubin, D. C. (2004). Emotional intensity predicts autobiographical memory experience. Memory \& Cognition, 32(7), 1118-1132.

Talarico, J. M., \& Rubin, D. C. (2003). Confidence, not consistency, characterizes flashbulb memories. Psychological Science, 14(5), 455-461.

Tewksbury, D., \& Riles, J. M. (2015). Polarization as a Function of Citizen Predispositions and Exposure to News on the Internet. Journal of Broadcasting \& Electronic Media, 59(3), 381-398.

Valentino, N. A., King, J. L., \& Hill, W. W. (2017). Polling and prediction in the 2016 presidential election. Computer, 50(5), 110-115.

Van der Kolk, B. A., \& Fisler, R. (1995). Dissociation and the fragmentary nature of traumatic memories: Overview and exploratory study. Journal of Traumatic Stress, 8(4), 505-525.

Villano, W. J., Otto, A. R., Ezie, C. E., Gillis, R., \& Heller, A. S. (2020). Temporal dynamics of real-world emotion are more strongly linked to prediction error than outcome. Journal of Experimental Psychology: General.

Wirtz, D., Kruger, J., Scollon, C. N., \& Diener, E. (2003). What to do on spring break? The role of predicted, on-line, and remembered experience in future choice. Psychological Science, 14(5), 520-524.

Wittmann, B. C., Bunzeck, N., Dolan, R. J., \& Düzel, E. (2007). Anticipation of novelty recruits reward system and hippocampus while promoting recollection. 
Neuroimage, 38(1), 194-202.

\section{Figure Captions}

Figure 1. Study design and participant sample at each timepoint.

Figure 2. Reported affect outcomes and changes in affect as a function of Political Affiliation and Surprise, as reported at Time 1: (a) Positive and (b) Negative affect outcomes after the election event; (c) changes in positive affect and (d) changes in negative affect. For Figure 2c, a positive score indicates increased positive affect and a negative score indicates decreased positive affect; for Figure 2d, a positive score indicates increased negative affect and a negative score indicates decreased negative affect.

Figure 3. Summary of significant effects, corrected for familywise error, or Political Affiliation, Surprise, and Time on objective and subjective measures of memory from the $E R Q$ and $A M Q$.

Figure 4. Individual measures of (a) memory quantity, (b) memory consistency, and (c) memory confidence visualized as a function of Political Affilaition, Surprise, and Time. Average values for each affiliation group (collapsed across surprise conditions) as a function of time are superimposed in black. 


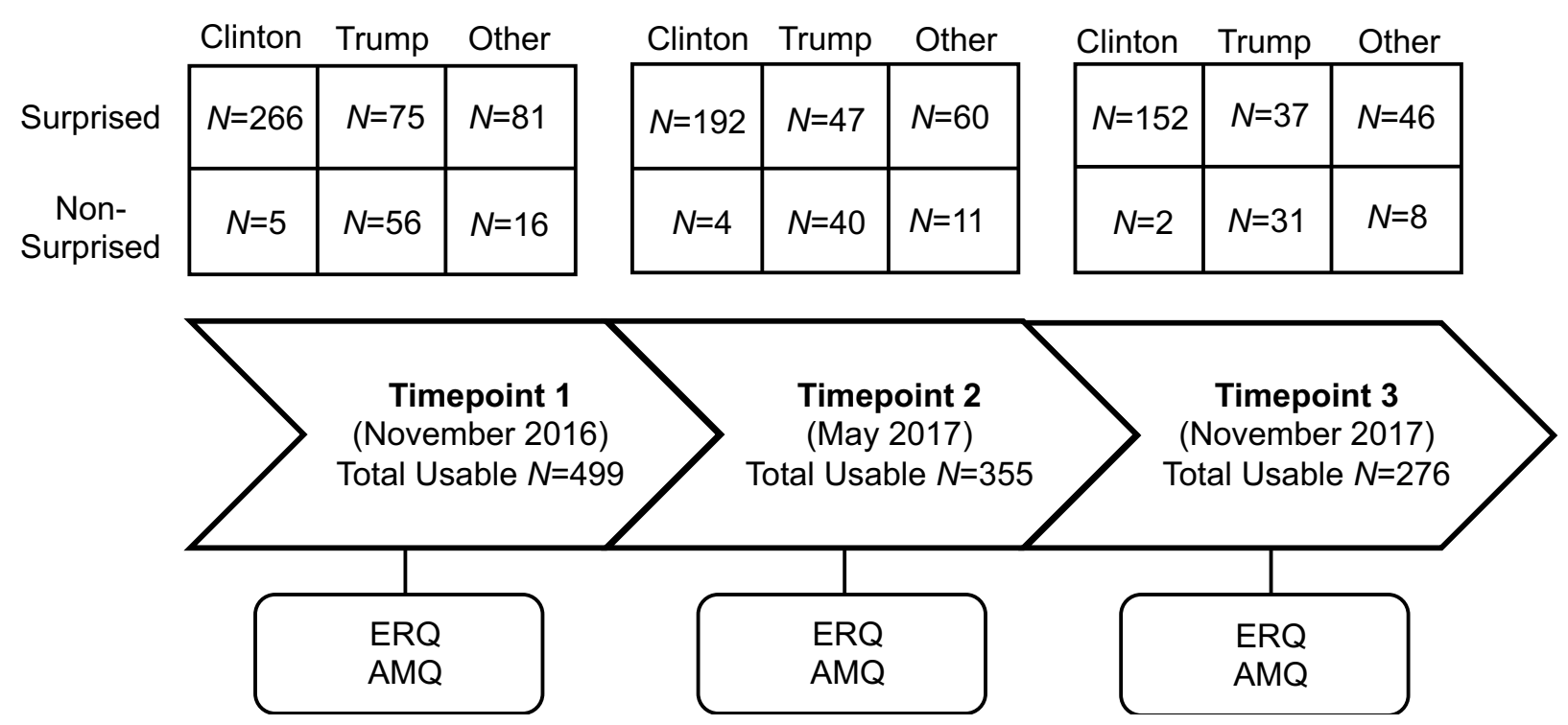

Figure 1

(a)

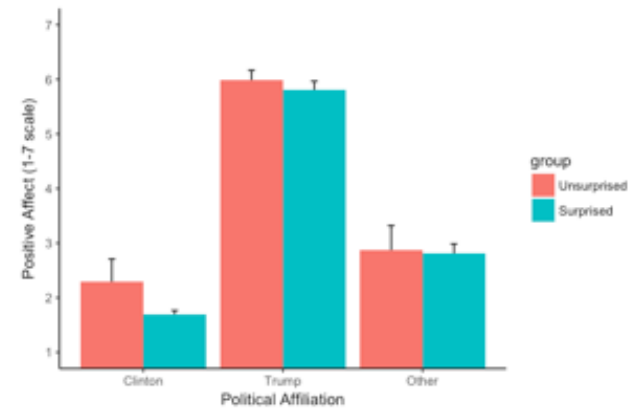

(c)

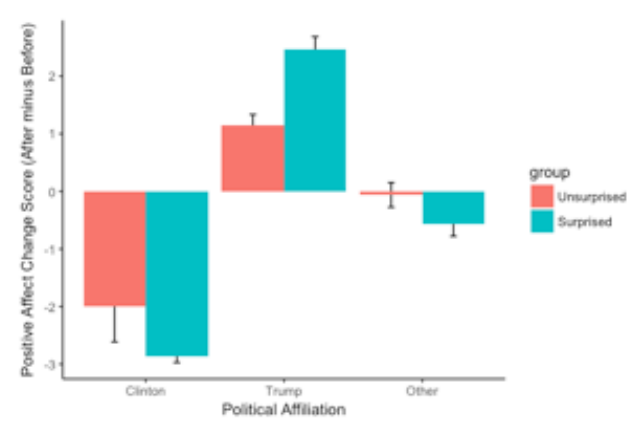

(b)

(d)
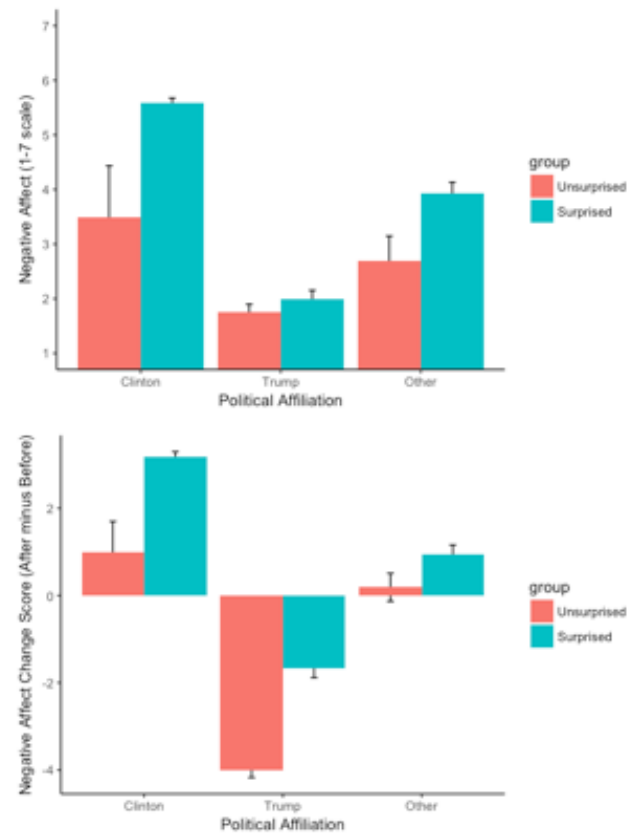

Figure 2 


\section{Objective Memory Measures}

\section{$\uparrow$ Time}

Subjective Memory Measures

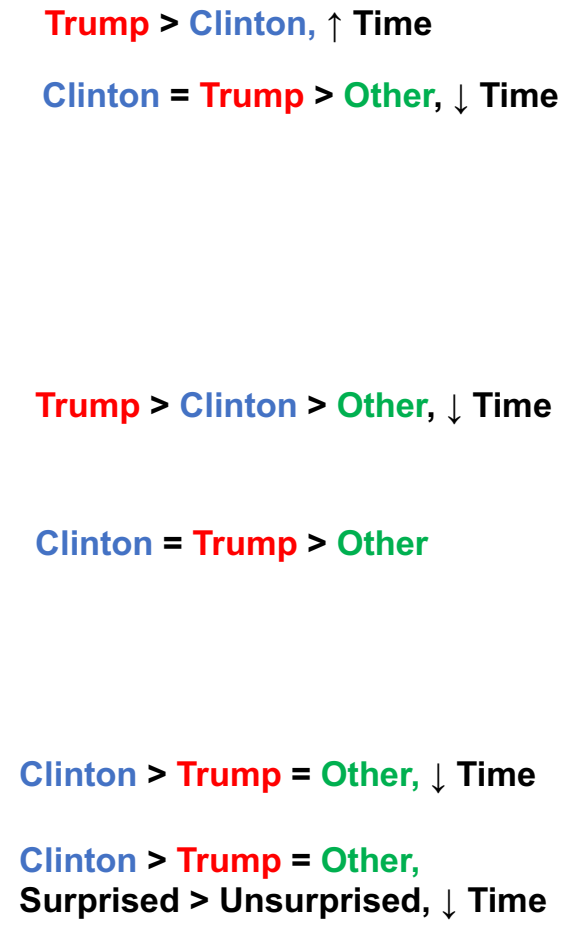

Figure 3
Memory Quantity

Memory Consistency

Memory Confidence

$E R Q$ Subjective memory vividness

ERQ Broader importance

AMQ Visual

AMQ Hearing

AMQ Importance

AMQ Rehearsal (Thought)

AMQ Rehearsal (Talk)

ERQ Subjective memory vividness for activities/location AMQ Belief

AMQ Story

ERQ Emotion intensity

ERQ Personal importance

AMQ Reliving

AMQ Setting

AMQ In-Words

ERQ Frequency of speaking

ERQ Frequency of thought

ERQ Frequency of media consumption 
(a)

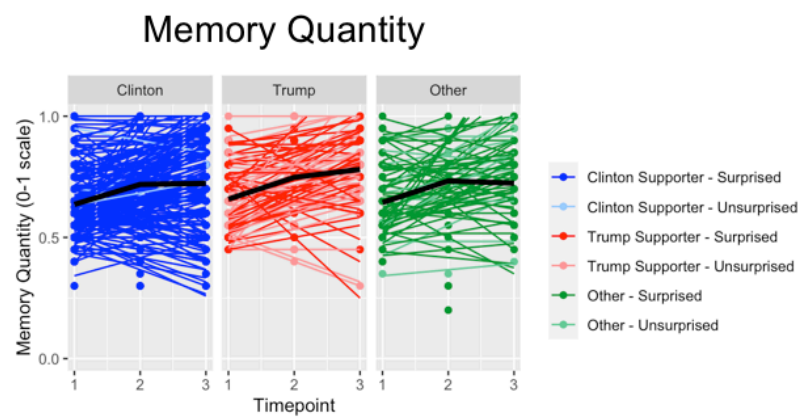

(b)

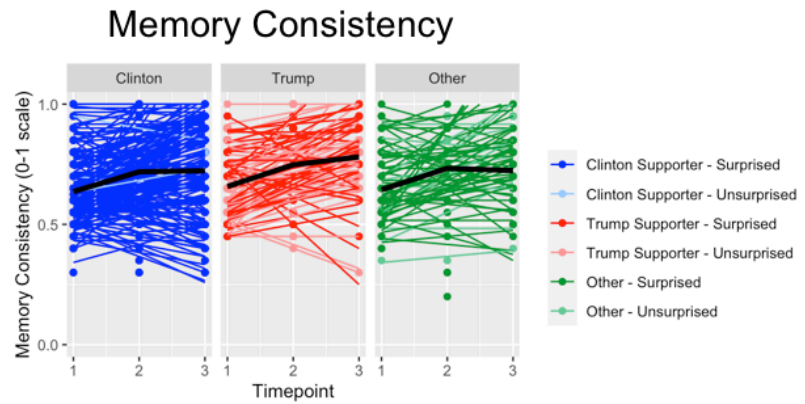

(c)

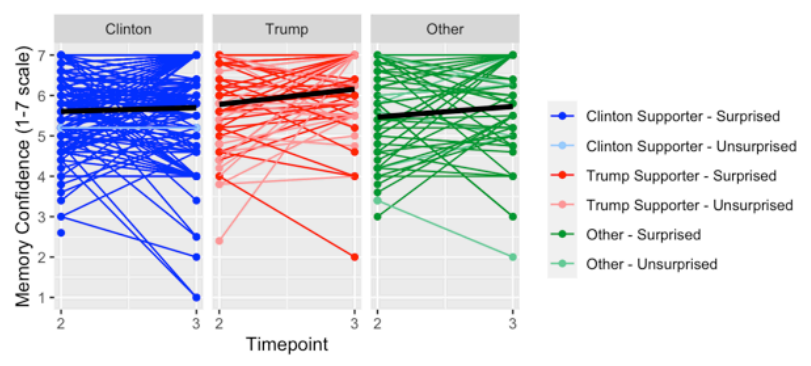

Figure 4 


\begin{tabular}{|c|c|c|c|c|c|c|c|c|c|c|c|c|c|c|c|c|c|c|}
\hline & \multicolumn{6}{|c|}{ Clinton Supporters } & \multicolumn{6}{|c|}{ Trump Supporters } & \multicolumn{6}{|c|}{ Third-Party/Non-Voters } \\
\hline & \multicolumn{3}{|c|}{ Surprised } & \multicolumn{3}{|c|}{ Not-Surprised } & \multicolumn{3}{|c|}{ Surprised } & \multicolumn{3}{|c|}{ Not-Surprised } & \multicolumn{3}{|c|}{ Surprised } & \multicolumn{3}{|c|}{ Not-Surprised } \\
\hline & T1 & T2 & T3 & T1 & T2 & T3 & T1 & T2 & T3 & T1 & T2 & T3 & T1 & T2 & T3 & T1 & T2 & T3 \\
\hline Usable $\mathbf{N}$ & 266 & 192 & 152 & 5 & 4 & 2 & 75 & 47 & 37 & 56 & 40 & 31 & 81 & 60 & 46 & 16 & 11 & 8 \\
\hline \multicolumn{19}{|l|}{ Gender } \\
\hline Male & 129 & 92 & 72 & 1 & 0 & 0 & 44 & 31 & 26 & 39 & 29 & 25 & 55 & 40 & 31 & 11 & 8 & 7 \\
\hline Female & 134 & 98 & 80 & 4 & 4 & 2 & 31 & 16 & 11 & 17 & 11 & 6 & 26 & 20 & 15 & 5 & 3 & 1 \\
\hline Other & 3 & 2 & 0 & 0 & 0 & 0 & 0 & 0 & 0 & 0 & 0 & 0 & 0 & 0 & 0 & 0 & 0 & 0 \\
\hline $\begin{array}{l}\text { Mean Age } \\
\text { (SD) }\end{array}$ & $\begin{array}{l}35.8 \\
(10.4) \\
\end{array}$ & $\begin{array}{l}36.6 \\
(10.8) \\
\end{array}$ & $\begin{array}{l}37.2 \\
(10.7) \\
\end{array}$ & $\begin{array}{l}38.8 \\
(11.9) \\
\end{array}$ & $\begin{array}{l}40.8 \\
(12.8) \\
\end{array}$ & $\begin{array}{l}48.5 \\
(13.4) \\
\end{array}$ & $\begin{array}{l}35.8 \\
(10.8) \\
\end{array}$ & $\begin{array}{l}37.9 \\
(10.1) \\
\end{array}$ & $\begin{array}{l}37.5 \\
(11.7) \\
\end{array}$ & $\begin{array}{l}37.5 \\
(10.1) \\
\end{array}$ & $\begin{array}{l}38.0 \\
(10.1) \\
\end{array}$ & $\begin{array}{l}37.6 \\
(10.7) \\
\end{array}$ & $\begin{array}{l}35.6 \\
(11.4) \\
\end{array}$ & $\begin{array}{l}36.6 \\
(11.7) \\
\end{array}$ & $\begin{array}{l}37.7 \\
(12.3) \\
\end{array}$ & $\begin{array}{l}28.5 \\
(5.9) \\
\end{array}$ & $\begin{array}{l}27.0 \\
(4.2) \\
\end{array}$ & $\begin{array}{l}26.7 \\
(4.8) \\
\end{array}$ \\
\hline $\begin{array}{l}\text { Mean Years of } \\
\text { Education } \\
\text { (SD) }\end{array}$ & $\begin{array}{l}15.5 \\
(2.0)\end{array}$ & $\begin{array}{l}15.6 \\
(2.0)\end{array}$ & $\begin{array}{l}15.7 \\
(2.0)\end{array}$ & $\begin{array}{l}14.4 \\
(2.1)\end{array}$ & $\begin{array}{l}14.0 \\
(2.2)\end{array}$ & $\begin{array}{l}13.0 \\
(1.4)\end{array}$ & $\begin{array}{l}14.6 \\
(2.0)\end{array}$ & $\begin{array}{l}14.9 \\
(1.9)\end{array}$ & $\begin{array}{l}14.9 \\
(2.1)\end{array}$ & $\begin{array}{l}14.4 \\
(1.8)\end{array}$ & $\begin{array}{l}14.5 \\
(1.9)\end{array}$ & $\begin{array}{l}14.4 \\
(1.9)\end{array}$ & $\begin{array}{l}14.9 \\
(2.0)\end{array}$ & $\begin{array}{l}15.0 \\
(2.0)\end{array}$ & $\begin{array}{l}15.2 \\
(2.0)\end{array}$ & $\begin{array}{l}13.9 \\
(1.5)\end{array}$ & $\begin{array}{l}14.0 \\
(1.5)\end{array}$ & $\begin{array}{l}13.6 \\
(1.4)\end{array}$ \\
\hline \multicolumn{19}{|l|}{ Race/Ethnicity } \\
\hline White & 196 & 143 & 117 & 4 & 4 & 2 & 68 & 42 & 33 & 50 & 38 & 29 & 69 & 50 & 38 & 12 & 10 & 8 \\
\hline Black & 30 & 24 & 18 & 1 & 0 & 0 & 1 & 1 & 1 & 2 & 1 & 1 & 4 & 4 & 3 & 2 & 0 & 0 \\
\hline Asian & 17 & 12 & 10 & 0 & 0 & 0 & 4 & 3 & 3 & 0 & 0 & 0 & 4 & 2 & 2 & 1 & 0 & 0 \\
\hline $\begin{array}{l}\text { American } \\
\text { Indian } \\
\end{array}$ & 4 & 4 & 2 & 0 & 0 & 0 & 0 & 0 & 0 & 1 & 0 & 0 & 1 & 1 & 1 & 0 & 0 & 0 \\
\hline $\begin{array}{c}\text { Pacific } \\
\text { Islander }\end{array}$ & 1 & 0 & 0 & 0 & 0 & 0 & 0 & 0 & 0 & 0 & 0 & 0 & 0 & 0 & 0 & 0 & 0 & 0 \\
\hline Other & 8 & 4 & 3 & 0 & 0 & 0 & 0 & 0 & 0 & 0 & 0 & 0 & 0 & 0 & 0 & 0 & 0 & 0 \\
\hline $\begin{array}{l}\text { More than } \\
\text { one race }\end{array}$ & 10 & 5 & 2 & 0 & 0 & 0 & 2 & 1 & 0 & 1 & 0 & 0 & 3 & 3 & 2 & 1 & 1 & 0 \\
\hline Unspecified & 0 & 0 & 0 & 0 & 0 & 0 & 0 & 0 & 0 & 2 & 1 & 1 & 0 & 0 & 0 & 0 & 0 & 0 \\
\hline
\end{tabular}

Table 1. Sample demographics at each of the three timepoints of the study. 
Appendix 1: Event-Related Questionnaire. Note that not all questions were analyzed in the present study.

Did you watch Election Night 2016 on TV/internet? $\quad$ Y/N

Did you vote in the 2016 U.S. election? $\quad$ Y/N

Who did you vote for? $\quad$ Clinton Trump Other None

Did your vote match the majority vote in your state of residence? $\mathrm{Y} / \mathrm{N}$

\section{Personal Detail Questions:}

Where were you?

Who were you with?

What were you wearing?

What were you eating/drinking?

What did you do after the event?

Do you remember any other information about what you were doing (or your surroundings) during the event?

At Phase 2 and 3, participants also rated their confidence to each of their answers to Personal Detail Questions on a 1-7 scale (1=guessing and 7=extremely confident).

\section{Event Expectation Questions}

Who did you expect to win the election? Clinton Other

How certain did you subjectively feel of your expected outcome? (1-7 scale)

How happy did you feel the day before Election Night? (1-7 scale)

The day after Election Night? (1-7 scale)

How sad did you feel the day before Election Night? (1-7 scale)

The day after Election Night? (1-7 scale)

How excited did you feel the day before Election Night? (1-7 scale)

The day after Election Night? (1-7 scale)

How afraid did you feel the day before Election Night? (1-7 scale)

The day after Election Night? (1-7 scale)

How angry did you feel the day before Election Night? (1-7 scale)

The day after Election Night? (1-7 scale)

How surprised did you feel about the election outcome the day after Election Night? (1-7 scale)

Do you recall a specific moment during Election Night that you realized that your outcome expectation was going to come true or not come true? If so, please describe that specific moment in as much detail as possible.

What time did you go to bed on Election Night? How confident are you? (1-7 scale)

Please tell us any more detail about your memory for where you were and what you were doing Election Night 2016 that you wish.

\section{Assessment of Memory Vividness}

How vividly do you remember the event? (1-7 scale)

How vividly do you remember your activities and location during the event (1-7 scale)

\section{Assessments of Emotional Importance}

What was the intensity of your emotional reaction to the event? (1-7 scale)

Was your reaction positive or negative? (1-7 scale)

What was the personal importance of the event? (1-7 scale)

What was the broader importance of the event? (1-7 scale)

How surprising was the outcome of the event? (1-7 scale) 
What emotions were generated for you by this event (list all that apply)? (1-7 scale)

(only collected in Phase 2 and 3) Have your emotions about election outcome changed since the event occurred in November 2016? (1-7 scale; $1=$ much more negative, $4=$ no change, $7=$ much more positive)

(only collected in Phase 2 and 3 ) Why have your emotions changed or not changed?

Please tell us any more detail about your emotional reaction to the event that you wish.

\section{Assessment of Rehearsal}

How frequently have you thought about the election outcome since it occurred? (1-7 scale)

How frequently have you spoken about the election outcome since it occurred? (1-7 scale)

How frequently have you watched/read/listened to media coverage about this event? (1-7 scale)

What is the primary medium through which you get coverage about this event? (Internet, TV, radio, newspapers, etc.)

What are the primary media sources through which you get coverage about this event? (CNN, NBC, specific newspapers or websites, etc.)

Please tell us any more detail about your thoughts, media consumption, and speaking about this event in its aftermath that you wish.

\section{Group Affiliation and Political Activity}

Please describe your political party affiliation

Democrat (1-7 scale)

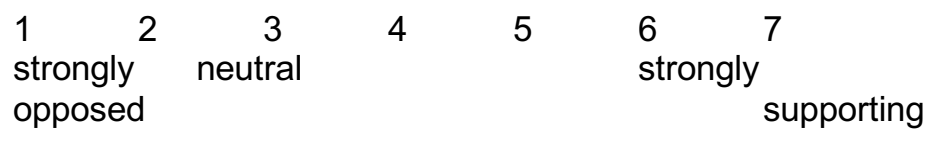

Republican (1-7 scale)

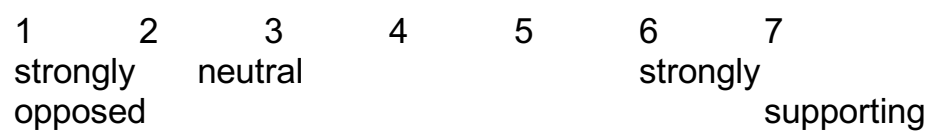

Third Party (1-7 scale)

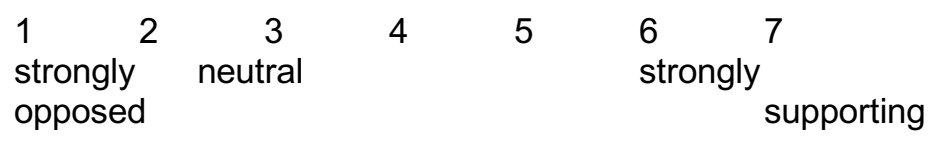

Please tell us any more information about your political affiliation that you wish.

\section{Political Activity Questions (only collected in Phase 2 and 3)}

Have you participated in any organized political events since election night (November 8 2016)? For example, demonstrations, rallies, protests, community town halls, community meetings, advocacy? If yes, please describe.

How does your political activity post-election compare to your political activity pre-election? (1-7 scale, where $1=$ huge decrease, $4=$ no change, $7=$ huge increase) 
Appendix 2: Autobiographical Memory Questionnaire (adapted from Rubin, Schrauf, \& Greenberg, 2003)

\begin{tabular}{|c|c|}
\hline Variable & Brief description of rating scales \\
\hline \multicolumn{2}{|r|}{ Metacognitive judgments } \\
\hline Reliving & I feel as though I am reliving it ( $1=$ not at all, $7=$ completely $)$ \\
\hline Belief & $\begin{array}{l}\text { Things really occurred the way I remember ( } 1=100 \% \text { imaginary, } \\
7=100 \% \text { real) }\end{array}$ \\
\hline \multicolumn{2}{|r|}{ Component processes } \\
\hline Visual & I can see it in my mind $(1=$ not at all, $7=$ completely $)$ \\
\hline Setting & I know the setting where it occurred $(1=$ not at all, $7=$ completely $)$ \\
\hline Hearing & I can hear it in my mind $(1=$ not at all, $7=$ completely $)$ \\
\hline In words & The memory is in words ( $1=$ not at all, $7=$ completely $)$ \\
\hline Story & The memory is a coherent story ( $1=$ not at all, $7=$ completely $)$ \\
\hline \multicolumn{2}{|r|}{ Reported properties of events or memories } \\
\hline Importance & $\begin{array}{l}\text { This event is a central part of my life story }(1=\text { not at all, } 7= \\
\text { completely) }\end{array}$ \\
\hline $\begin{array}{l}\text { Rehearsal - } \\
\text { thought }\end{array}$ & I purposely thought about this event $(1=$ not at all, $7=$ very often $)$ \\
\hline Rehearsal - & I have talked about this event $(1=$ not at all, $7=$ very often $)$ \\
\hline
\end{tabular}


Supplementary Tables A. Results of mixed linear models predicting ERQ metrics of autobiographical memory as predicted by fixed effects of (Political) Affiliation, Surprise, and Time, and interactions between them. For each dependent variable, the model building and comparison process is presented, followed by model output for final models. For models with Affiliation as a fixed effect, the model is also presented with the composite Negative Affect measure (which is mean-centered in the model including both linear and quadratic terms) added as a fixed effect. For models that are significantly better than baseline, the model is also presented with Gender and Years of Education added as fixed effects.

Statistically significant effects are noted ( ${ }^{*}$ at alpha criterion of $p=.05$ for planned contrasts, ${ }^{* *}$ at alpha criterion of $p=.003$ correcting for familywise error) as revealed via comparison of model stipulated versus baseline model indicated.

$\mathrm{RE}=$ random effect; FE = fixed effect; AIC = Aikake Information Criterion; BIC = Bayesian Information Criterion; LL = LogLikelihood; df = degrees of freedom; ME = main effect; LRT = Likelihood Ratio Test

\section{SA1. Memory Detail Quantity}

\begin{tabular}{|c|c|c|c|c|c|c|c|c|c|c|}
\hline \multirow[t]{2}{*}{ Model Specification } & \multirow{2}{*}{$\begin{array}{l}\text { Baseline } \\
\text { Model }\end{array}$} & \multirow{2}{*}{$\begin{array}{l}\text { Fixed } \\
\text { Effects } \\
\text { Added }\end{array}$} & \multirow{2}{*}{$\begin{array}{l}\text { Random } \\
\text { Effect (of } \\
\text { Subject) }\end{array}$} & \multicolumn{4}{|l|}{ Model Fit } & \multicolumn{3}{|c|}{ LRT } \\
\hline & & & & AIC & BIC & LL & df & df & $\begin{array}{l}\text { Likelihood } \\
\text { Ratio }\end{array}$ & $\begin{array}{l}\text { LRT } p- \\
\text { value }\end{array}$ \\
\hline Null (RE only) & -- & -- & Intercepts & -1093.518 & -1078.449 & 549.759 & 3 & & & \\
\hline Affiliation & Null & Affiliation & Intercepts & -1092.392 & -1067.278 & 551.196 & 5 & 2 & 2.875 & 0.238 \\
\hline Surprise & Null & Surprise & Intercepts & -1091.519 & -1071.427 & 549.759 & 4 & 1 & 0.001 & 0.974 \\
\hline Time* & Null & Time & Intercepts & -1214.004 & -1193.912 & 611.002 & 4 & 1 & 122.486 & $<.001$ \\
\hline $\begin{array}{l}\text { Affiliation }+ \text { Neg Affect (linear } \\
\text { term alone) }\end{array}$ & Affiliation & Neg Affect & Intercepts & -1091.380 & -1061.243 & 551.690 & 6 & 1 & 0.988 & 0.320 \\
\hline $\begin{array}{l}\text { Affiliation + Neg Affect + (Neg } \\
\text { Affect) }^{2} \text { (linear and quadratic } \\
\text { terms) }^{*}\end{array}$ & Affiliation & $\begin{array}{l}\text { Neg Affect } \\
+(\text { Neg } \\
{\text { Affect })^{2}}\end{array}$ & Intercepts & -1094.709 & -1059.549 & 554.354 & 7 & 2 & 6.317 & 0.043 \\
\hline Time + Gender & Time & Gender & Intercepts & -1202.532 & -1177.503 & 606.266 & 5 & 1 & 0.599 & 0.439 \\
\hline Time + Years of Education & Time & Years Ed. & Intercepts & -1202.020 & -1176.991 & 606.010 & 5 & 1 & 0.087 & 0.768 \\
\hline
\end{tabular}

Final Model: Time

\begin{tabular}{|l|l|l|}
\hline Fixed Effects & Estimate & SE \\
\hline & 0.603 & 0.009 \\
\hline Intercept & 0.049 & 0.004 \\
\hline Time & Variance \\
\hline \multicolumn{2}{|l|}{} \\
\hline \multicolumn{2}{|l|}{} \\
\hline Random Effects & 0.012 & SD \\
\hline Model Fit & Marginal & 0.108 \\
\hline & 0.063 & Conditional \\
\hline $\mathbf{R}^{\mathbf{2}}$ & & 0.526 \\
\hline
\end{tabular}

\begin{tabular}{|l|l|l|}
\hline $\mathbf{9 5 \%} \mathbf{C l}$ & $\mathbf{t}$ & $\mathbf{p}$ \\
\hline $0.584-0.621$ & 63.567 & $<.001$ \\
\hline $0.041-0.058$ & 11.486 & $<.001$ \\
\hline
\end{tabular}


Final Model: Affiliate + Neg Affect $+(\text { Neg Affect })^{2}$ (linear and quadratic terms)

\begin{tabular}{|c|c|c|}
\hline \multicolumn{3}{|l|}{ Fixed Effects } \\
\hline & Estimate & SE \\
\hline Intercept & 0.659 & 0.012 \\
\hline $\begin{array}{l}\text { Affiliation } \\
\text { (Clinton - Trump) }\end{array}$ & 0.026 & 0.025 \\
\hline $\begin{array}{l}\text { Affiliation } \\
\text { (Clinton - Other) }\end{array}$ & 0.017 & 0.018 \\
\hline $\begin{array}{l}\text { Affiliation } \\
\text { (Trump - Other) }\end{array}$ & -0.009 & 0.023 \\
\hline Neg Affect & 0.006 & 0.005 \\
\hline$(\text { Neg Affect) })^{2}$ & 0.004 & 0.002 \\
\hline \multicolumn{3}{|l|}{ Random Effects } \\
\hline & Variance & SD \\
\hline Subject & 0.011 & 0.105 \\
\hline \multicolumn{3}{|l|}{ Model Fit } \\
\hline & Marginal & Conditional \\
\hline $\mathbf{R}^{2}$ & 0.013 & 0.446 \\
\hline
\end{tabular}

\begin{tabular}{|l|l|l|}
\hline $\mathbf{9 5 \%} \mathbf{C l}$ & $\mathbf{t}$ & $\mathbf{p}$ \\
\hline $0.635-0.683$ & 53.940 & $<.001$ \\
\hline$-0.022-0.075$ & 1.065 & 0.287 \\
\hline$-0.018-0.052$ & 0.975 & 0.330 \\
\hline$-0.054-0.036$ & -0.395 & 0.693 \\
\hline$-0.003-0.016$ & 1.249 & 0.212 \\
\hline $0.001-0.008$ & 2.308 & 0.021 \\
\hline
\end{tabular}




\section{SA2. Memory Consistency}

\begin{tabular}{|c|c|c|c|c|c|c|c|c|c|c|}
\hline \multirow[t]{2}{*}{ Model Specification } & \multirow{2}{*}{$\begin{array}{l}\text { Baseline } \\
\text { Model }\end{array}$} & \multirow{2}{*}{$\begin{array}{l}\text { Fixed } \\
\text { Effects } \\
\text { Added } \\
\end{array}$} & \multirow{2}{*}{$\begin{array}{l}\text { Random } \\
\text { Effect (of } \\
\text { Subject) } \\
\end{array}$} & \multicolumn{4}{|l|}{ Model Fit } & \multicolumn{3}{|c|}{ LRT } \\
\hline & & & & AIC & BIC & LL & df & df & $\begin{array}{l}\text { Likelihood } \\
\text { Ratio }\end{array}$ & $\begin{array}{l}\text { LRT } p- \\
\text { value }\end{array}$ \\
\hline Null (RE only) & $\begin{array}{ll}- \\
\end{array}$ & -- & Intercepts & -196.271 & -182.958 & 101.135 & 3 & & & \\
\hline Affiliation & Null & Affiliation & Intercepts & -192.606 & -170.417 & 101.303 & 5 & 2 & 0.335 & 0.846 \\
\hline Surprise & Null & Surprise & Intercepts & -194.271 & -176.520 & 101.136 & 4 & 1 & 0.000 & 0.997 \\
\hline Time* & Null & Time & Intercepts & -199.046 & -181.295 & 103.523 & 4 & 1 & 4.775 & 0.029 \\
\hline $\begin{array}{l}\text { Affiliation }+ \text { Neg Affect (linear } \\
\text { term alone) }\end{array}$ & Affiliation & Neg Affect & Intercepts & -190.890 & -164.264 & 101.445 & 6 & 1 & 0.284 & 0.594 \\
\hline $\begin{array}{l}\text { Affiliation + Neg Affect + (Neg } \\
\text { Affect) }^{2} \text { (linear and quadratic } \\
\text { terms) }\end{array}$ & Affiliation & $\begin{array}{l}\text { Neg Affect + } \\
(\text { Neg } \\
\text { Affect })^{\wedge} 2\end{array}$ & Intercepts & -192.823 & -161.759 & 103.412 & 7 & 2 & 1.573 & 0.210 \\
\hline Time + Gender & Time & Gender & Intercepts & -198.542 & -176.426 & 104.271 & 5 & 1 & 0.045 & 0.832 \\
\hline Time + Years of Education & Time & Years Ed. & Intercepts & -198.537 & -176.421 & 104.269 & 5 & 1 & 0.040 & 0.841 \\
\hline
\end{tabular}

\section{Final Model: Time}

\section{Fixed Effects}

\begin{tabular}{|l|l|l|}
\hline & Estimate & SE \\
\hline Intercept & 0.516 & 0.036 \\
\hline Time & 0.031 & 0.014 \\
\hline \multicolumn{2}{|l|}{} \\
\hline Random Effects & Variance & SD \\
\hline \multicolumn{2}{|l|}{} \\
\hline Subject & 0.029 & 0.171 \\
\hline Model Fit & Marginal & Conditional \\
\hline \multicolumn{2}{|l|}{} \\
\hline $\mathbf{R}^{\mathbf{2}}$ & 0.005 & 0.343 \\
\hline
\end{tabular}

\begin{tabular}{|l|l|l|}
\hline $\mathbf{9 5 \%} \mathbf{C l}$ & $\mathbf{t}$ & $\mathbf{p}$ \\
\hline $0.446-0.586$ & 14.527 & $<.001$ \\
\hline $0.003-0.059$ & 2.188 & 0.030 \\
\hline
\end{tabular}




\section{SA3. Memory Confidence}

\begin{tabular}{|c|c|c|c|c|c|c|c|c|c|c|}
\hline \multirow[t]{2}{*}{ Model Specification } & \multirow{2}{*}{$\begin{array}{l}\text { Baseline } \\
\text { Model }\end{array}$} & \multirow{2}{*}{$\begin{array}{l}\text { Fixed } \\
\text { Effects } \\
\text { Added }\end{array}$} & \multirow{2}{*}{$\begin{array}{l}\text { Random } \\
\text { Effect (of } \\
\text { Subject) }\end{array}$} & \multicolumn{4}{|l|}{ Model Fit } & \multicolumn{3}{|c|}{ LRT } \\
\hline & & & & AIC & BIC & LL & df & df & $\begin{array}{l}\text { Likelihood } \\
\text { Ratio }\end{array}$ & $\begin{array}{l}\text { LRT } p \\
\text { value }\end{array}$ \\
\hline Null (RE only) & -- & -- & Intercepts & 1857.757 & 1871.032 & -925.879 & 3 & & & \\
\hline Affiliation* & Null & Affiliation & Intercepts & 1854.347 & 1876.471 & -922.173 & 5 & 2 & 7.411 & 0.025 \\
\hline Surprise & Null & Surprise & Intercepts & 1858.591 & 1876.291 & -925.296 & 4 & 1 & 1.166 & 0.280 \\
\hline Time* & Null & Time & Intercepts & 1853.850 & 1871.549 & -922.925 & 4 & 1 & 5.907 & 0.015 \\
\hline Affiliation $x$ Time & $\begin{array}{l}\text { Affiliation + } \\
\text { Time ME }\end{array}$ & $\begin{array}{l}\text { Affiliation } x \\
\text { Time }\end{array}$ & Intercepts & 1851.119 & 1886.518 & -917.560 & 8 & 2 & 3.233 & 0.199 \\
\hline $\begin{array}{l}\text { Affiliation + Neg Affect (linear } \\
\text { term alone) }\end{array}$ & Affiliation & Neg Affect & Intercepts & 1855.167 & 1881.716 & -921.584 & 6 & 1 & 1.180 & 0.278 \\
\hline $\begin{array}{l}\text { Affiliation + Neg Affect + (Neg } \\
\text { Affect) })^{2} \text { (linear and quadratic } \\
\text { terms)* }\end{array}$ & Affiliation & $\begin{array}{l}\text { Neg Affect + } \\
(\text { Neg } \\
\text { Affect)^2 }\end{array}$ & Intercepts & 1847.925 & 1878.899 & -916.962 & 7 & 2 & 10.422 & 0.006 \\
\hline Affiliation + Gender & Affiliation & Gender & Intercepts & 1830.087 & 1856.548 & -909.044 & 6 & 1 & 0.658 & 0.417 \\
\hline Affiliation + Years of Education & Affiliation & Years Ed. & Intercepts & 1830.079 & 1856.540 & -909.039 & 6 & 1 & 0.667 & 0.414 \\
\hline Time + Gender & Time & Gender & Intercepts & 1829.708 & 1851.759 & -909.854 & 5 & 1 & 1.152 & 0.283 \\
\hline Time + Years of Education & Time & Years Ed. & Intercepts & 1829.487 & 1851.538 & -909.744 & 5 & 1 & 1.373 & 0.241 \\
\hline
\end{tabular}

Final Model: Affiliation

\begin{tabular}{|l|l|l|l|l|l|}
\hline Fixed Effects & Estimate & SE & $\mathbf{9 5 \%}$ Cl & t & P \\
\hline Intercept & 5.618 & 0.069 & $5.482-5.754$ & 80.875 \\
\hline Clinton - Trump & 0.311 & 0.125 & $0.065-0.557$ & 2.478 \\
\hline Clinton - Other & -0.051 & 0.134 & $-0.313-0.212$ & -0.381 \\
\hline Trump - Other & -0.362 & 0.155 & $-0.666--0.058$ & -2.337 & 0.014 \\
\hline
\end{tabular}

\begin{tabular}{|l|l|l|}
\hline \multicolumn{2}{|l|}{ Random Effects } & Variance \\
\hline & 0.482 & SD \\
\hline Subject & Marginal & 0.695 \\
\hline Model Fit & 0.016 & Conditional \\
\hline & & 0.397 \\
\hline $\mathbf{R}^{2}$ &
\end{tabular}

Final Model: Time

\section{Fixed Effects}

\begin{tabular}{|l|l|l|l|l|l|}
\hline Fixed Effects & Estimate & SE & $\mathbf{9 5 \%}$ Cl & t & $\mathbf{P}$ \\
\hline Intercept & 5.256 & 0.183 & $4.896-5.615$ & 28.723 \\
\hline Time & 0.177 & 0.073 & $0.034-0.320$ & 2.434 \\
\hline
\end{tabular}

\section{Random Effects}




\begin{tabular}{|c|c|c|}
\hline & Variance & SD \\
\hline Subject & 0.503 & 0.709 \\
\hline \multicolumn{3}{|c|}{ Model Fit } \\
\hline & Marginal & Conditional \\
\hline $\mathbf{R}^{2}$ & 0.006 & 0.404 \\
\hline
\end{tabular}

Final Model: Affiliate + Neg Affect + (Neg Affect) ${ }^{2}$ (linear and quadratic terms) Fixed Effects

\begin{tabular}{|l|l|l|l|l|l|}
\hline & Estimate & SE & $\mathbf{9 5 \%}$ Cl & $\mathbf{~}$ \\
\hline Intercept & 5.385 & 0.104 & $5.181-5.588$ & 51.786 \\
\hline $\begin{array}{l}\text { Affiliation } \\
\text { (Clinton - Trump) }\end{array}$ & 0.296 & 0.212 & $-0.119-0.710$ & 1.397 \\
\hline $\begin{array}{l}\text { Affiliation } \\
\text { (Clinton - Other) }\end{array}$ & 0.058 & 0.150 & $-0.236-0.352$ & 0.386 \\
\hline $\begin{array}{l}\text { Affiliation } \\
\text { (Trump - Other) }\end{array}$ & -0.238 & 0.191 & $-0.612-0.137$ & -1.241 \\
\hline Neg Affect & 0.057 & 0.040 & 0.700 & \\
\hline (Neg Affect) $^{2}$ & 0.050 & 0.016 & 0.0215 & 0.136 \\
\end{tabular}

\begin{tabular}{|c|c|c|}
\hline \multicolumn{3}{|c|}{ Random Effects } \\
\hline & Variance & SD \\
\hline Subject & 0.457 & 0.676 \\
\hline \multicolumn{3}{|c|}{ Model Fit } \\
\hline & Marginal & Conditional \\
\hline $\mathbf{R}^{2}$ & 0.037 & 0.398 \\
\hline
\end{tabular}




\section{SA4. ERQ: Subjective Memory Vividness}

\begin{tabular}{|c|c|c|c|c|c|c|c|c|c|c|}
\hline \multirow[t]{2}{*}{ Model Specification } & \multirow{2}{*}{$\begin{array}{l}\text { Baseline } \\
\text { Model }\end{array}$} & \multirow{2}{*}{$\begin{array}{l}\text { Fixed } \\
\text { Effects } \\
\text { Added }\end{array}$} & \multirow{2}{*}{$\begin{array}{l}\text { Random } \\
\text { Effect (of } \\
\text { Subject) } \\
\end{array}$} & \multicolumn{4}{|l|}{ Model Fit } & \multicolumn{3}{|c|}{ LRT } \\
\hline & & & & AIC & BIC & LL & df & df & $\begin{array}{l}\text { Likelihood } \\
\text { Ratio }\end{array}$ & $\begin{array}{l}\text { LRT } p- \\
\text { value }\end{array}$ \\
\hline Null (RE only) & -- & -- & Intercepts & 3995.007 & 4010.086 & -1994.504 & 3 & & & \\
\hline Affiliation ${ }^{* *}$ & Null & Affiliation & Intercepts & 3975.423 & 4000.555 & -1982.711 & 5 & 2 & 23.584 & $<.001$ \\
\hline Surprise & Null & Surprise & Intercepts & 3996.664 & 4016.770 & -1994.332 & 4 & 1 & 0.343 & 0.558 \\
\hline Time & Null & Time & Intercepts & 3981.429 & 4001.535 & -1986.715 & 4 & 1 & 15.578 & $<.001$ \\
\hline Affiliation $\times$ Time & $\begin{array}{l}\text { Affiliation + } \\
\text { Time ME }\end{array}$ & $\begin{array}{l}\text { Affiliation } \mathrm{x} \\
\text { Time }\end{array}$ & Intercepts & 3963.978 & 4004.189 & -1973.989 & 8 & 2 & 2.129 & 0.345 \\
\hline $\begin{array}{l}\text { Affiliation + Neg Affect (linear } \\
\text { term alone) }\end{array}$ & Affiliation & Neg Affect & Intercepts & 3976.318 & 4006.476 & -1982.159 & 6 & 1 & 1.105 & 0.293 \\
\hline $\begin{array}{l}\text { Affiliation + Neg Affect }+(\text { Neg } \\
\text { Affect) }^{2} \text { (linear and quadratic } \\
\text { terms) })^{* *}\end{array}$ & Affiliation & $\begin{array}{l}\text { Neg Affect + } \\
(\text { Neg } \\
\text { Affect) })^{\wedge} 2\end{array}$ & Intercepts & 3959.785 & 3994.970 & -1972.892 & 7 & 2 & 19.638 & $<.001$ \\
\hline Affiliation + Gender & Affiliation & Gender & Intercepts & 3915.734 & 3945.791 & -1951.867 & 6 & 1 & 2.217 & 0.137 \\
\hline Affiliation + Years of Education & Affiliation & Years Ed. & Intercepts & 3917.951 & 3948.007 & -1952.975 & 6 & 1 & 0.000 & 0.983 \\
\hline Time + Gender & Time & Gender & Intercepts & 3921.601 & 3946.648 & -1955.801 & 5 & 1 & 2.813 & 0.094 \\
\hline Time + Years of Education & Time & Years Ed. & Intercepts & 3924.358 & 3949.405 & -1957.179 & 5 & 1 & 0.056 & 0.813 \\
\hline
\end{tabular}

Final Model: Affiliation

\begin{tabular}{|l|l|l|l|l|l|}
\hline Fixed Effects & Estimate & SE & $\mathbf{9 5 \%}$ Cl & t \\
\hline Intercept & 5.237 & 0.069 & $5.101-5.374$ & $\mathbf{p}$ \\
\hline Clinton - Trump & 0.194 & 0.123 & $-0.048-0.435$ & 1.408 \\
\hline Clinton - Other & -0.540 & 0.135 & $-0.804--0.275$ & -4.004 \\
\hline Trump - Other & -0.733 & 0.154 & $-1.035--0.431$ & -4.760 & 0.117 \\
\hline
\end{tabular}

\begin{tabular}{|l|l|l|}
\hline \multicolumn{2}{|l|}{ Random Effects } & Variance \\
\hline & 0.587 & SD \\
\hline Subject & Marginal & 0.766 \\
\hline Model Fit & 0.030 & Conditional \\
\hline & & 0.301 \\
\hline $\mathbf{R}^{2}$ &
\end{tabular}

Final Model: Time

\section{Fixed Effects}

\begin{tabular}{|l|l|l|l|l|l|}
\hline Fixed Effects & Estimate & SE & $\mathbf{9 5 \%}$ Cl & t & P \\
\hline & 5.503 & 0.097 & $5.313-5.693$ & 56.808 \\
\hline Intercept & -0.186 & 0.047 & $-0.278--0.094$ & -3.962 \\
\hline Time & & $<.001$ & $<1$ \\
\hline
\end{tabular}

\section{Random Effects}




\begin{tabular}{|c|c|c|}
\hline & Variance & SD \\
\hline Subject & 0.662 & 0.814 \\
\hline \multicolumn{3}{|c|}{ Model Fit } \\
\hline & Marginal & Conditional \\
\hline $\mathbf{R}^{2}$ & 0.010 & 0.316 \\
\hline
\end{tabular}

Final Model: Affiliate + Neg Affect + (Neg Affect) ${ }^{2}$ (linear and quadratic terms) Fixed Effects

\begin{tabular}{|l|l|l|l|l|}
\hline & Estimate & SE & $95 \%$ Cl & $\mathbf{t}$ \\
\hline Intercept & 4.930 & 0.102 & $4.731-5.129$ & 48.479 \\
\hline $\begin{array}{l}\text { Affiliation } \\
\text { (Clinton - Trump) }\end{array}$ & 0.139 & 0.207 & $-0.267-0.545$ & 0.670 \\
\hline $\begin{array}{l}\text { Affiliation } \\
\text { (Clinton - Other) }\end{array}$ & -0.401 & 0.148 & $-0.692--0.111$ & -2.712 \\
\hline $\begin{array}{l}\text { Affiliation } \\
\text { (Trump - Other) }\end{array}$ & -0.540 & 0.190 & $-0.914--0.167$ & -2.837 \\
\hline Neg Affect & 0.072 & 0.040 & 0.001 & \\
\hline (Neg Affect) $^{2}$ & 0.069 & 0.016 & $0.007-0.150$ & 1.784 \\
\hline
\end{tabular}

\begin{tabular}{|l|l|l|}
\hline \multicolumn{2}{|l|}{ Random Effects } & Variance \\
\hline & 0.531 & SD \\
\hline Subject & Marginal & 0.729 \\
\hline Model Fit & 0.053 & Conditional \\
\hline \multicolumn{2}{|l|}{} \\
\hline $\mathbf{R}^{\mathbf{2}}$ & 0.299 \\
\hline
\end{tabular}




\section{SA5. Subjective Memory Vividness for Activities and Location}

\begin{tabular}{|c|c|c|c|c|c|c|c|c|c|c|}
\hline \multirow[t]{2}{*}{ Model Specification } & \multirow{2}{*}{$\begin{array}{l}\text { Baseline } \\
\text { Model }\end{array}$} & \multirow{2}{*}{$\begin{array}{l}\text { Fixed } \\
\text { Effects } \\
\text { Added }\end{array}$} & \multirow{2}{*}{$\begin{array}{l}\text { Random } \\
\text { Effect (of } \\
\text { Subject) }\end{array}$} & \multicolumn{4}{|l|}{ Model Fit } & \multicolumn{3}{|c|}{ LRT } \\
\hline & & & & AIC & BIC & LL & df & df & $\begin{array}{l}\text { Likelihood } \\
\text { Ratio }\end{array}$ & $\begin{array}{l}\text { LRT p- } \\
\text { value }\end{array}$ \\
\hline Null (RE only) & -- & -- & Intercepts & 4058.625 & 4073.702 & -2026.313 & 3 & & & \\
\hline Affiliation $^{* *}$ & Null & Affiliation & Intercepts & 4033.932 & 4059.060 & -2011.966 & 5 & 2 & 28.693 & $<.001$ \\
\hline Surprise & Null & Surprise & Intercepts & 4060.621 & 4080.723 & -2026.311 & 4 & 1 & 0.004 & 0.948 \\
\hline Time ${ }^{* *}$ & Null & Time & Intercepts & 4041.376 & 4061.478 & -2016.688 & 4 & 1 & 19.249 & $<.001$ \\
\hline Affiliation $x$ Time & $\begin{array}{l}\text { Affiliation + } \\
\text { Time ME }\end{array}$ & $\begin{array}{l}\text { Affiliation } x \\
\text { Time }\end{array}$ & Intercepts & 4017.798 & 4058.003 & -2000.899 & 8 & 2 & 3.194 & 0.203 \\
\hline $\begin{array}{l}\text { Affiliation + Neg Affect (linear } \\
\text { term alone) }\end{array}$ & Affiliation & Neg Affect & Intercepts & 4034.688 & 4064.841 & -2011.344 & 6 & 1 & 1.245 & 0.265 \\
\hline $\begin{array}{l}\text { Affiliation + Neg Affect + (Neg } \\
\text { Affect) })^{2} \text { (linear and quadratic } \\
\text { terms) }\end{array}$ & Affiliation & $\begin{array}{l}\text { Neg Affect + } \\
(\text { Neg } \\
\text { Affect)^2 }\end{array}$ & Intercepts & 4024.029 & 4059.208 & -2005.014 & 7 & 2 & 13.903 & 0.001 \\
\hline Affiliation + Gender & Affiliation & Gender & Intercepts & 3971.504 & 4001.555 & -1979.752 & 6 & 1 & 1.852 & 0.174 \\
\hline Affiliation + Years of Education & Affiliation & Years Ed. & Intercepts & 3972.726 & 4002.777 & -1980.363 & 6 & 1 & 0.630 & 0.427 \\
\hline Time + Gender & Time & Gender & Intercepts & 3977.679 & 4002.722 & -1983.840 & 5 & 1 & 2.363 & 0.124 \\
\hline Time + Years of Education & Time & Years Ed. & Intercepts & 3979.780 & 4004.823 & -1984.890 & 5 & 1 & 0.262 & 0.609 \\
\hline
\end{tabular}

\section{Final Model: Affiliation}

\begin{tabular}{|l|l|l|l|l|l|}
\hline Fixed Effects & Estimate & SE & $\mathbf{9 5 \%}$ Cl & t & P \\
\hline & 5.277 & 0.069 & $5.141-5.414$ & 75.966 \\
\hline Intercept & 0.256 & 0.123 & $0.014-0.498$ & 2.076 \\
\hline Clinton - Trump & -0.567 & 0.135 & $-0.831--0.303$ & -4.209 \\
\hline Clinton - Other & -0.823 & 0.154 & $-1.126--0.521$ & -5.345 & 0.038 \\
\hline Trump - Other & & $<.001$ & $<.001$ \\
\hline
\end{tabular}

\begin{tabular}{|l|l|l|}
\hline \multicolumn{2}{|l|}{ Random Effects } & Variance \\
\hline & 0.524 & SD \\
\hline Subject & Marginal & 0.724 \\
\hline Model Fit & 0.035 & Conditional \\
\hline \multicolumn{2}{|l|}{} & 0.266 \\
\hline $\mathbf{R}^{2}$ &
\end{tabular}

Final Model: Time

\section{Fixed Effects}

\begin{tabular}{|l|l|l|l|l|l|}
\hline Fixed Effects & Estimate & SE & $\mathbf{9 5 \%}$ Cl & t & p \\
\hline Intercept & 5.607 & 0.100 & $5.410-5.804$ & 55.931 \\
\hline Time & -0.215 & 0.049 & $-0.311--0.120$ & -4.408 & $<01$ \\
\hline
\end{tabular}

\section{Random Effects}




\begin{tabular}{|c|c|c|}
\hline & Variance & SD \\
\hline Subject & 0.613 & 0.783 \\
\hline \multicolumn{3}{|c|}{ Model Fit } \\
\hline & Marginal & Conditional \\
\hline $\mathbf{R}^{2}$ & 0.013 & 0.284 \\
\hline
\end{tabular}

Final Model: Affiliate + Neg Affect + (Neg Affect) ${ }^{2}$ (linear and quadratic terms) Fixed Effects

\begin{tabular}{|l|l|l|l|l|l|}
\hline & Estimate & SE & $95 \%$ Cl & t \\
\hline Intercept & 5.012 & 0.103 & $4.811-5.213$ & 48.880 \\
\hline $\begin{array}{l}\text { Affiliation } \\
\text { (Clinton - Trump) }\end{array}$ & 0.241 & 0.209 & $-0.169-0.650$ & 1.152 \\
\hline $\begin{array}{l}\text { Affiliation } \\
\text { (Clinton - Other) }\end{array}$ & -0.440 & 0.149 & $-0.733--0.147$ & -2.949 \\
\hline $\begin{array}{l}\text { Affiliation } \\
\text { (Trump - Other) }\end{array}$ & -0.941 & 0.179 & $-1.057--0.304$ & -0.250 \\
\hline Neg Affect & 0.067 & 0.040 & 0.003 & -0.247 \\
\hline (Neg Affect) $^{2}$ & 0.057 & 0.016 & $0.025-0.089$ & 1.659 & 3.520 \\
\hline
\end{tabular}

\begin{tabular}{|l|l|l|}
\hline \multicolumn{2}{|l|}{ Random Effects } & Variance \\
\hline & 0.488 & SD \\
\hline Subject & Marginal & 0.699 \\
\hline Model Fit & 0.051 & Conditional \\
\hline \multicolumn{2}{|l|}{} \\
\hline $\mathbf{R}^{\mathbf{2}}$ & 0.266 \\
\hline
\end{tabular}




\section{SA6. Emotion Intensity}

\begin{tabular}{|c|c|c|c|c|c|c|c|c|c|c|}
\hline \multirow[t]{2}{*}{ Model Specification } & \multirow{2}{*}{$\begin{array}{l}\text { Baseline } \\
\text { Model }\end{array}$} & \multirow{2}{*}{$\begin{array}{l}\text { Fixed } \\
\text { Effects } \\
\text { Added } \\
\end{array}$} & \multirow{2}{*}{$\begin{array}{l}\text { Random } \\
\text { Effect (of } \\
\text { Subject) }\end{array}$} & \multicolumn{4}{|l|}{ Model Fit } & \multicolumn{3}{|c|}{ LRT } \\
\hline & & & & AIC & BIC & LL & df & df & $\begin{array}{l}\text { Likelihood } \\
\text { Ratio }\end{array}$ & $\begin{array}{l}\text { LRT p- } \\
\text { value }\end{array}$ \\
\hline Null (RE only) & -- & -- & Intercepts & 4154.294 & 4169.365 & -2074.147 & 3 & & & \\
\hline Affiliation $^{* *}$ & Null & Affiliation & Intercepts & 4115.906 & 4141.025 & -2052.953 & 5 & 2 & 42.388 & $<.001$ \\
\hline Surprise & Null & Surprise & Intercepts & 4154.634 & 4174.729 & -2073.317 & 4 & 1 & 1.659 & 0.198 \\
\hline Time & Null & Time & Intercepts & 4152.330 & 4172.425 & -2072.165 & 4 & 1 & 3.964 & 0.047 \\
\hline $\begin{array}{l}\text { Affiliation }+ \text { Neg Affect (linear } \\
\text { term alone) }\end{array}$ & Affiliation & Neg Affect & Intercepts & 4092.880 & 4123.023 & -2040.440 & 6 & 1 & 25.026 & $<.001$ \\
\hline $\begin{array}{l}\text { Affiliation + Neg Affect + (Neg } \\
\text { Affect) }{ }^{2} \text { (linear and quadratic } \\
\text { terms) }\end{array}$ & Affiliation & $\begin{array}{l}\text { Neg Affect + } \\
\text { (Neg } \\
\text { Affect)^2 }\end{array}$ & Intercepts & 4009.136 & 4044.302 & -1997.568 & 7 & 2 & 110.771 & $<.001$ \\
\hline Affiliation + Gender ${ }^{* *}$ & Affiliation & Gender & Intercepts & 4028.043 & 4058.083 & -2008.022 & 6 & 1 & 15.138 & $<.001$ \\
\hline Affiliation + Years of Education & Affiliation & Years Ed. & Intercepts & 4041.919 & 4071.959 & -2014.959 & 6 & 1 & 1.262 & 0.261 \\
\hline
\end{tabular}

\section{Final Model: Affiliation}

\section{Fixed Effects}

\begin{tabular}{|l|l|l|}
\hline & Estimate & SE \\
\hline Intercept & 5.237 & 0.073 \\
\hline Clinton - Trump & -0.015 & 0.130 \\
\hline Clinton - Other & -0.906 & 0.142 \\
\hline Trump - Other & -0.891 & 0.162 \\
\hline \multicolumn{2}{|l}{} \\
\hline Random Effects & Variance & SD \\
\hline \multicolumn{2}{|l|}{} \\
\hline Subject & 0.616 & 0.785 \\
\hline Model Fit & Marginal & Conditional \\
\hline & 0.052 & 0.297 \\
\hline $\mathbf{R}^{\mathbf{2}}$ &
\end{tabular}

Final Model: Affiliate + Neg Affect (linear term alone)

\begin{tabular}{|c|c|c|c|c|c|}
\hline \multicolumn{6}{|l|}{ Fixed Effects } \\
\hline & Estimate & SE & $95 \% \mathrm{Cl}$ & $\mathbf{t}$ & $p$ \\
\hline Intercept & 3.984 & 0.257 & $3.480-4.488$ & 15.500 & $<.001$ \\
\hline $\begin{array}{l}\text { Affiliation } \\
\text { (Clinton - Trump) }\end{array}$ & 0.832 & 0.210 & $0.421-1.244$ & 3.969 & $<.001$ \\
\hline $\begin{array}{l}\text { Affiliation } \\
\text { (Clinton - Other) }\end{array}$ & -0.550 & 0.155 & $-0.853--0.246$ & -3.549 & $<.001$ \\
\hline $\begin{array}{l}\text { Affiliation } \\
\text { (Trump - Other) }\end{array}$ & -1.382 & 0.186 & $-1.746--1.018$ & -7.446 & $<.001$ \\
\hline Neg Affect & 0.214 & 0.042 & $0.131-0.297$ & 5.067 & $<.001$ \\
\hline
\end{tabular}




\begin{tabular}{|l|l|l|}
\hline Random Effects & \multicolumn{2}{l|}{} \\
\hline & Variance & SD \\
\hline Subject & 0.542 & 0.736 \\
\hline Model Fit & Marginal & Conditional \\
\hline \multicolumn{2}{|l|}{} & 0.296 \\
\hline $\mathbf{R}^{\mathbf{2}}$ & 0.081 & \\
\hline
\end{tabular}

Final Model: Affiliate + Neg Affect + (Neg Affect) ${ }^{2}$ (linear and quadratic terms)

\begin{tabular}{|l|l|l|l|l|l|}
\hline Fixed Effects & Estimate & SE & $\mathbf{9 5 \%}$ CI & $\mathbf{~}$ \\
\hline & 4.436 & 0.096 & $4.248-4.625$ & 46.032 \\
\hline $\begin{array}{l}\text { Affiliation } \\
\text { (Clinton - Trump) }\end{array}$ & 0.234 & 0.196 & $-0.151-0.619$ & 1.192 \\
\hline $\begin{array}{l}\text { Affiliation } \\
\text { (Clinton - Other) }\end{array}$ & -0.438 & 0.140 & $-0.712--0.163$ & -.001 \\
\hline $\begin{array}{l}\text { Affiliation } \\
\text { (Trump - Other) }\end{array}$ & -0.672 & 0.180 & $-1.025--0.318$ & -3.234 \\
\hline Neg Affect & 0.250 & 0.038 & 0.002 & -325 \\
\hline (Neg Affect) $^{2}$ & 0.151 & 0.015 & $0.176-0.325$ & 6.592 \\
\hline
\end{tabular}

\begin{tabular}{|l|l|l|}
\hline Random Effects & \multicolumn{2}{|l|}{} \\
\hline & Variance & SD \\
\hline Subject & 0.295 & 0.543 \\
\hline Model Fit & Marginal & Conditional \\
\hline \multicolumn{2}{|l|}{} \\
\hline $\mathbf{R}^{\mathbf{2}}$ & 0.167 & 0.284 \\
\hline
\end{tabular}

Final Model: Affiliation + Gender

Fixed Effects

\begin{tabular}{|l|l|l|l|l|l|}
\hline Fixed Effects & Estimate & SE & $\mathbf{9 5 \%}$ Cl & $\mathbf{~}$ \\
\hline & 5.032 & 0.093 & $4.851-5.214$ & 54.312 \\
\hline Intercept & 0.049 & 0.131 & $-0.207-0.305$ & 0.378 \\
$\begin{array}{l}\text { Affiliation } \\
\text { (Clinton - Trump) }\end{array}$ & -0.834 & 0.142 & $-1.113--0.556$ & -5.871 \\
\hline $\begin{array}{l}\text { Affiliation } \\
\text { (Clinton - Other) }\end{array}$ & -0.884 & 0.161 & $-1.199--0.569$ & -5.503 \\
\hline $\begin{array}{l}\text { Affiliation } \\
\text { (Trump - Other) }\end{array}$ & 0.433 & 0.110 & $0.216-0.650$ & 3.920 \\
\hline Gender & & $<.001$ & $<01$ \\
\hline
\end{tabular}

\section{Random Effects}


Subject

Model Fit

0.572

0.756

\begin{tabular}{|l|l|} 
& \\
\hline & Marginal \\
\hline
\end{tabular}

0.072

Conditional

0.300 


\section{SA7. Personal Importance}

\begin{tabular}{|c|c|c|c|c|c|c|c|c|c|c|}
\hline \multirow[t]{2}{*}{ Model Specification } & \multirow{2}{*}{$\begin{array}{l}\text { Baseline } \\
\text { Model }\end{array}$} & \multirow{2}{*}{$\begin{array}{l}\text { Fixed } \\
\text { Effects } \\
\text { Added }\end{array}$} & \multirow{2}{*}{$\begin{array}{l}\text { Random } \\
\text { Effect (of } \\
\text { Subject) }\end{array}$} & \multicolumn{4}{|l|}{ Model Fit } & \multicolumn{3}{|c|}{ LRT } \\
\hline & & & & AIC & BIC & LL & df & df & $\begin{array}{l}\text { Likelihood } \\
\text { Ratio }\end{array}$ & $\begin{array}{l}\text { LRT } p- \\
\text { value }\end{array}$ \\
\hline Null (RE only) & -- & -- & Intercepts & 4275.357 & 4290.423 & -2134.679 & 3 & & & \\
\hline Affiliation $^{\star *}$ & Null & Affiliation & Intercepts & 4237.971 & 4263.081 & -2113.985 & 5 & 2 & 41.386 & $<.001$ \\
\hline Surprise & Null & Surprise & Intercepts & 4275.868 & 4295.956 & -2113.934 & 4 & 1 & 1.489 & 0.222 \\
\hline Time & Null & Time & Intercepts & 4270.818 & 4290.906 & -2131.409 & 4 & 1 & 6.539 & 0.011 \\
\hline $\begin{array}{l}\text { Affiliation }+ \text { Neg Affect (linear } \\
\text { term alone) }\end{array}$ & Affiliation & Neg Affect & Intercepts & 4226.901 & 4257.033 & -2107.450 & 6 & 1 & 13.070 & $<.001$ \\
\hline $\begin{array}{l}\text { Affiliation + Neg Affect + (Neg } \\
\text { Affect) }{ }^{* *} \text { (linear and quadratic } \\
\text { terms) }\end{array}$ & Affiliation & $\begin{array}{l}\text { Neg Affect }+ \\
\text { (Neg } \\
\text { Affect)^2 }\end{array}$ & Intercepts & 4174.720 & 4209.874 & -2080.360 & 7 & 2 & 67.251 & $<.001$ \\
\hline Affiliation + Gender ${ }^{* *}$ & Affiliation & Gender & Intercepts & 4156.594 & 4186.623 & -2072.297 & 6 & 1 & 12.814 & $<.001$ \\
\hline Affiliation + Years of Education & Affiliation & Years Ed. & Intercepts & 4169.334 & 4199.363 & -2078.667 & 6 & 1 & 0.074 & 0.786 \\
\hline
\end{tabular}

\section{Final Model: Affiliation}

\section{Fixed Effects}

\begin{tabular}{|l|l|l|l|l|l|} 
& Estimate & SE & $\mathbf{9 5 \%}$ Cl & t & $\mathbf{p}$ \\
\hline Intercept & 4.953 & 0.075 & $4.806-5.099$ & 66.207 \\
\hline Clinton - Trump & 0.109 & 0.133 & $-0.152-0.371$ & 0.823 \\
\hline Clinton - Other & -0.869 & 0.145 & $-1.154--0.585$ & -001 \\
\hline Trump - Other & -0.979 & 0.166 & $-1.304--0.653$ & -598 & -5.900 \\
\hline
\end{tabular}

\begin{tabular}{|c|c|c|}
\hline \multicolumn{3}{|c|}{ Random Effects } \\
\hline & Variance & SD \\
\hline Subject & 0.536 & 0.732 \\
\hline \multicolumn{3}{|c|}{ Model Fit } \\
\hline & Marginal & Conditional \\
\hline $\mathbf{R}^{2}$ & 0.048 & 0.243 \\
\hline
\end{tabular}

Final Model: Affiliate + Neg Affect (linear term alone)

\begin{tabular}{|c|c|c|c|c|c|}
\hline \multicolumn{6}{|l|}{ Fixed Effects } \\
\hline & Estimate & SE & $95 \% \mathrm{Cl}$ & $\mathbf{t}$ & $p$ \\
\hline Intercept & 4.023 & 0.266 & $3.502-4.544$ & 15.138 & $<.001$ \\
\hline $\begin{array}{l}\text { Affiliation } \\
\text { (Clinton - Trump) }\end{array}$ & 0.738 & 0.217 & $0.313-1.164$ & 3.402 & 0.001 \\
\hline $\begin{array}{l}\text { Affiliation } \\
\text { (Clinton - Other) }\end{array}$ & -0.606 & 0.160 & $-0.920--0.292$ & -3.782 & $<.001$ \\
\hline $\begin{array}{l}\text { Affiliation } \\
\text { (Trump - Other) }\end{array}$ & -1.344 & 0.192 & $-1.721--0.968$ & -7.001 & $<.001$ \\
\hline Neg Affect & 0.159 & 0.044 & $0.073-0.244$ & 3.635 & $<.001$ \\
\hline
\end{tabular}




\begin{tabular}{|l|l|l|}
\hline Random Effects & \multicolumn{2}{l|}{} \\
\hline & Variance & SD \\
\hline Subject & 0.496 & 0.705 \\
\hline Model Fit & Marginal & Conditional \\
\hline \multicolumn{2}{|l|}{} & 0.243 \\
\hline $\mathbf{R}^{\mathbf{2}}$ & 0.063 & \\
\hline
\end{tabular}

Final Model: Affiliate + Neg Affect + (Neg Affect) ${ }^{2}$ (linear and quadratic terms)

\begin{tabular}{|c|c|c|}
\hline \multicolumn{3}{|l|}{ Fixed Effects } \\
\hline & Estimate & SE \\
\hline Intercept & 4.312 & 0.103 \\
\hline $\begin{array}{l}\text { Affiliation } \\
\text { (Clinton - Trump) }\end{array}$ & 0.225 & 0.210 \\
\hline $\begin{array}{l}\text { Affiliation } \\
\text { (Clinton - Other) }\end{array}$ & -0.523 & 0.150 \\
\hline $\begin{array}{l}\text { Affiliation } \\
\text { (Trump - Other) }\end{array}$ & -0.749 & 0.193 \\
\hline Neg Affect & 0.186 & 0.041 \\
\hline$(\text { Neg Affect })^{2}$ & 0.127 & 0.016 \\
\hline \multicolumn{3}{|l|}{ Random Effects } \\
\hline & Variance & SD \\
\hline Subject & 0.316 & 0.562 \\
\hline \multicolumn{3}{|l|}{ Model Fit } \\
\hline & Marginal & Conditional \\
\hline $\mathbf{R}^{2}$ & 0.118 & 0.233 \\
\hline
\end{tabular}

Final Model: Affiliation + Gender

Fixed Effects

\begin{tabular}{|l|l|l|l|l|}
\hline Fixed Effects & Estimate & SE & $\mathbf{9 5 \%}$ Cl & $\mathbf{~}$ \\
\hline & 4.740 & 0.095 & $4.552-4.927$ & 49.666 \\
\hline Intercept & 0.197 & 0.135 & $-0.067-0.461$ & 1.462 \\
\hline $\begin{array}{l}\text { Affiliation } \\
\text { Clinton - Trump) }\end{array}$ & -0.784 & 0.146 & $-1.071--0.498$ & -5.365 \\
\hline $\begin{array}{l}\text { Affiliation } \\
\text { Clinton - Other) }\end{array}$ & -0.981 & 0.165 & $-1.305--0.657$ & -5.935 \\
\hline $\begin{array}{l}\text { Affiliation } \\
\text { (Trump - Other) }\end{array}$ & 0.409 & 0.114 & $0.186-0.632$ & 3.596 \\
\hline Gender & & $<.001$ & $<.001$ \\
\hline
\end{tabular}

\section{Random Effects}

\begin{tabular}{|l|l|l|}
\hline $\mathbf{9 5 \%} \mathbf{C l}$ & $\mathbf{t}$ & $\mathbf{p}$ \\
\hline $4.110-4.515$ & 47.706 & $<.001$ \\
\hline$-0.187-0.638$ & 1.071 & 0.285 \\
\hline$-0.818--0.229$ & -3.486 & 0.001 \\
\hline$-1.128--0.370$ & -3.876 & $<.001$ \\
\hline $0.106-0.266$ & 4.573 & $<.001$ \\
\hline $0.094-0.159$ & 7.701 & $<.001$ \\
\hline
\end{tabular}


Subject Model Fit
0.511

Marginal

0.063

Conditional 0.248 


\section{SA8. Broader Importance}

\begin{tabular}{|c|c|c|c|c|c|c|c|c|c|c|}
\hline \multirow[t]{2}{*}{ Model Specification } & \multirow{2}{*}{$\begin{array}{l}\text { Baseline } \\
\text { Model }\end{array}$} & \multirow{2}{*}{$\begin{array}{l}\text { Fixed } \\
\text { Effects } \\
\text { Added }\end{array}$} & \multirow{2}{*}{$\begin{array}{l}\text { Random } \\
\text { Effect (of } \\
\text { Subject) }\end{array}$} & \multicolumn{4}{|l|}{ Model Fit } & \multicolumn{3}{|c|}{ LRT } \\
\hline & & & & AIC & BIC & LL & df & df & $\begin{array}{l}\text { Likelihood } \\
\text { Ratio }\end{array}$ & $\begin{array}{l}\text { LRT } p- \\
\text { value }\end{array}$ \\
\hline Null (RE only) & -- & -- & Intercepts & 3826.294 & 3841.365 & -1910.147 & 3 & & & \\
\hline Affiliation $^{* *}$ & Null & Affiliation & Intercepts & 3807.174 & 3832.292 & -1898.587 & 5 & 2 & 23.120 & $<.001$ \\
\hline Surprise & Null & Surprise & Intercepts & 3827.956 & 3848.051 & -1909.978 & 4 & 1 & 0.338 & 0.561 \\
\hline Time ${ }^{* *}$ & Null & Time & Intercepts & 3811.115 & 3831.210 & -1901.558 & 4 & 1 & 17.178 & $<.001$ \\
\hline Affiliation $\times$ Time & $\begin{array}{l}\text { Affiliation + } \\
\text { Time ME }\end{array}$ & $\begin{array}{l}\text { Affiliation } x \\
\text { Time }\end{array}$ & Intercepts & 3786.898 & 3827.088 & -1885.449 & 8 & 2 & 8.868 & 0.012 \\
\hline $\begin{array}{l}\text { Affiliation + Neg Affect (linear } \\
\text { term alone) }\end{array}$ & Affiliation & Neg Affect & Intercepts & 3794.025 & 3824.167 & -1891.012 & 6 & 1 & 15.149 & $<.001$ \\
\hline $\begin{array}{l}\text { Affiliation + Neg Affect + (Neg } \\
\text { Affect) })^{2} \text { (linear and quadratic } \\
\text { terms) }\end{array}$ & Affiliation & $\begin{array}{l}\text { Neg Affect + } \\
(\text { Neg } \\
\text { Affect)^2 }\end{array}$ & Intercepts & 3763.758 & 3798.924 & -1874.879 & 7 & 2 & 47.416 & $<.001$ \\
\hline Affiliation + Gender & Affiliation & Gender & Intercepts & 3736.625 & 3766.665 & -1862.312 & 6 & 1 & 8.273 & 0.004 \\
\hline Affiliation + Years of Education & Affiliation & Years Ed. & Intercepts & 3742.720 & 3772.760 & -1865.360 & 6 & 1 & 2.178 & 0.140 \\
\hline Time + Gender** & Time & Gender & Intercepts & 3739.365 & 3764.398 & -1864.682 & 5 & 1 & 11.883 & 0.001 \\
\hline Time + Years of Education & Time & Years Ed. & Intercepts & 3746.422 & 3771.456 & -1868.211 & 5 & 1 & 4.826 & 0.028 \\
\hline
\end{tabular}

Final Model: Affiliation

\begin{tabular}{|l|l|l|l|l|l|}
\hline Fixed Effects & Estimate & SE & $\mathbf{9 5 \%}$ Cl & t \\
\hline Intercept & 5.887 & 0.066 & $5.757-6.016$ & 89.012 \\
\hline Clinton - Trump & -0.132 & 0.117 & $-0.362-0.098$ & -1.129 \\
\hline Clinton - Other & -0.624 & 0.128 & $-0.875--0.372$ & -4.866 \\
\hline Trump - Other & -0.491 & 0.146 & $-0.778--0.204$ & -3.356 & 0.260 \\
\hline
\end{tabular}

\begin{tabular}{|l|l|l|}
\hline \multicolumn{2}{|l|}{ Random Effects } & Variance \\
\hline & 0.568 & SD \\
\hline Subject & Marginal & 0.754 \\
\hline Model Fit & 0.030 & Conditional \\
\hline & & 0.329 \\
\hline $\mathbf{R}^{2}$ &
\end{tabular}

Final Model: Time

\section{\begin{tabular}{l} 
Final Model: Tim \\
\hline Fixed Effects
\end{tabular}}

\begin{tabular}{|l|l|l|l|l|l|}
\hline Fixed Effects & Estimate & SE & $\mathbf{9 5 \%}$ Cl & t & p \\
\hline Intercept & 6.042 & 0.090 & $5.865-6.219$ & 67.131 \\
\hline Time & -0.180 & 0.043 & $-0.265--0.095$ & -4.159 \\
\hline
\end{tabular}

\section{Random Effects}




\begin{tabular}{|c|c|c|}
\hline & Variance & SD \\
\hline Subject & 0.633 & 0.795 \\
\hline \multicolumn{3}{|c|}{ Model Fit } \\
\hline & Marginal & Conditional \\
\hline $\mathbf{R}^{2}$ & 0.011 & 0.344 \\
\hline
\end{tabular}

Final Model: Affiliate + Neg Affect (linear term alone) Fixed Effects

\begin{tabular}{|l|l|l|}
\hline & Estimate & SE \\
\hline Intercept & 5.002 & 0.235 \\
\hline $\begin{array}{l}\text { Affiliation } \\
\text { (Clinton - Trump) }\end{array}$ & 0.465 & 0.192 \\
\hline $\begin{array}{l}\text { Affiliation } \\
\text { (Clinton - Other) }\end{array}$ & -0.375 & 0.142 \\
\hline $\begin{array}{l}\text { Affiliation } \\
\text { (Trump - Other) }\end{array}$ & -0.839 & 0.169 \\
\hline Neg Affect & 0.151 & 0.039 \\
\hline \multicolumn{2}{|l|}{} \\
\hline Random Effects & Variance & SD \\
\hline \multicolumn{2}{|l|}{0.732} \\
\hline Subject & 0.536 & Conditional \\
\hline Model Fit & Marginal & 0.331 \\
\hline \multicolumn{2}{|l}{} \\
\hline
\end{tabular}

Final Model: Affiliate + Neg Affect + (Neg Affect) ${ }^{2}$ (linear and quadratic terms)

\begin{tabular}{|l|l|l|}
\hline Fixed Effects & Estimate & SE \\
\hline & 5.394 & 0.094 \\
\hline Intercept & 0.153 & 0.191 \\
\hline $\begin{array}{l}\text { Affiliation } \\
\text { (Clinton - Trump) }\end{array}$ & -0.307 & 0.137 \\
\hline $\begin{array}{l}\text { Affiliation } \\
\text { (Clinton - Other) }\end{array}$ & -0.460 & 0.176 \\
\hline $\begin{array}{l}\text { Affiliation } \\
\text { (Trump - Other) }\end{array}$ & 0.178 & 0.037 \\
\hline Neg Affect & 0.085 & 0.015 \\
\hline (Neg Affect) & & \\
\hline & & \\
\hline Random Effects & Variance & SD \\
\hline & 0.455 & 0.675 \\
\hline Subject & \multicolumn{2}{|l|}{} \\
\hline Model Fit &
\end{tabular}

\begin{tabular}{|l|l|l|}
\hline $\mathbf{9 5 \%} \mathbf{C l}$ & $\mathbf{t}$ & $\mathbf{p}$ \\
\hline $4.541-5.463$ & 21.275 & $<.001$ \\
\hline $0.089-0.840$ & 2.426 & 0.016 \\
\hline$-0.652--0.097$ & -2.647 & 0.008 \\
\hline$-1.172--0.507$ & -4.953 & $<.001$ \\
\hline $0.075-0.227$ & 3.912 & $<.001$ \\
\hline
\end{tabular}

\begin{tabular}{|l|l|l|}
\hline $\mathbf{9 5 \%} \mathbf{C l}$ & $\mathbf{t}$ & $\mathbf{p}$ \\
\hline $5.210-5.578$ & 57.402 & $<.001$ \\
\hline$-0.222-0.528$ & 0.801 & 0.423 \\
\hline$-0.575--0.039$ & -2.248 & 0.025 \\
\hline$-0.805--0.116$ & -2.621 & 0.009 \\
\hline $0.106-0.251$ & 4.813 & $<.001$ \\
\hline $0.055-0.114$ & 5.664 & $<.001$ \\
\hline
\end{tabular}

Model Fit 


\begin{tabular}{|l|l|l|}
\hline & Marginal & Conditional \\
\hline $\mathbf{R}^{2}$ & 0.087 & 0.327 \\
\hline
\end{tabular}

Final Model: Time + Gender Fixed Effects

\begin{tabular}{|c|c|c|}
\hline & Estimate & SE \\
\hline Intercept & 5.883 & 0.101 \\
\hline Time & -0.171 & 0.044 \\
\hline Gender & 0.349 & 0.101 \\
\hline \multicolumn{3}{|c|}{ Random Effects } \\
\hline & Variance & SD \\
\hline Subject & 0.606 & 0.779 \\
\hline \multicolumn{3}{|c|}{ Model Fit } \\
\hline & Marginal & Conditional \\
\hline $\mathbf{R}^{2}$ & 0.026 & 0.344 \\
\hline
\end{tabular}

\section{$\mathbf{9 5 \%} \mathrm{Cl}$}

$5.683-6.081$

$-0.257--0.086$

$0.151-0.547$

t

58.215

$-3.936$

3.466

p

$<.001$

$<.001$

1




\section{SA9. Frequency of Thought}

\begin{tabular}{|c|c|c|c|c|c|c|c|c|c|c|}
\hline \multirow[t]{2}{*}{ Model Specification } & \multirow{2}{*}{$\begin{array}{l}\text { Baseline } \\
\text { Model }\end{array}$} & \multirow{2}{*}{$\begin{array}{l}\text { Fixed } \\
\text { Effects } \\
\text { Added }\end{array}$} & \multirow{2}{*}{$\begin{array}{l}\text { Random } \\
\text { Effect (of } \\
\text { Subject) }\end{array}$} & \multicolumn{4}{|l|}{ Model Fit } & \multicolumn{3}{|c|}{ LRT } \\
\hline & & & & AIC & BIC & LL & df & df & $\begin{array}{l}\text { Likelihood } \\
\text { Ratio }\end{array}$ & $\begin{array}{l}\text { LRT p- } \\
\text { value }\end{array}$ \\
\hline Null (RE only) & -- & -- & Intercepts & 4195.837 & 4210.918 & -2094.918 & 3 & & & \\
\hline Affiliation $^{\star *}$ & Null & Affiliation & Intercepts & 4173.199 & 4198.336 & -2081.600 & 5 & 2 & 26.637 & $<.001$ \\
\hline Surprise $^{* *}$ & Null & Surprise & Intercepts & 4182.338 & 4202.447 & -2087.169 & 4 & 1 & 15.498 & $<.001$ \\
\hline Time & Null & Time & Intercepts & 4172.895 & 4193.004 & -2082.447 & 4 & 1 & 24.942 & $<.001$ \\
\hline Affiliation $x$ Time & $\begin{array}{l}\text { Affiliation + } \\
\text { Time ME }\end{array}$ & $\begin{array}{l}\text { Affiliation } \mathrm{x} \\
\text { Time }\end{array}$ & Intercepts & 4151.802 & 4191.921 & -2067.851 & 8 & 2 & 2.061 & 0.357 \\
\hline Affiliation $\times$ Surprise & $\begin{array}{l}\text { Affiliation + } \\
\text { Surprise ME }\end{array}$ & $\begin{array}{l}\text { Affiliation } x \\
\text { Surprise ME }\end{array}$ & Intercepts & 4165.620 & 4205.839 & -2074.810 & 8 & 2 & 6.732 & 0.035 \\
\hline Surprise $\mathrm{x}$ Time & $\begin{array}{l}\text { Surprise + } \\
\text { Time ME }\end{array}$ & $\begin{array}{l}\text { Surprise } \mathrm{x} \\
\text { Time ME }\end{array}$ & Intercepts & 4160.789 & 4190.953 & -2074.394 & 8 & 2 & 0.362 & 0.548 \\
\hline $\begin{array}{l}\text { Affiliation }+ \text { Neg Affect (linear } \\
\text { term alone) }\end{array}$ & Affiliation & Neg Affect & Intercepts & 4151.254 & 4181.418 & -2069.627 & 6 & 1 & 23.945 & $<.001$ \\
\hline $\begin{array}{l}\text { Affiliation + Neg Affect + (Neg } \\
\text { Affect) }^{2} \text { (linear and quadratic } \\
\text { terms) }\end{array}$ & Affiliation & $\begin{array}{l}\text { Neg Affect + } \\
(\text { Neg } \\
\text { Affect)^2 }\end{array}$ & Intercepts & 4137.106 & 4172.298 & -2061.553 & 7 & 2 & 40.093 & $<.001$ \\
\hline Affiliation + Gender & Affiliation & Gender & Intercepts & 4097.597 & 4127.659 & -2042.799 & 6 & 1 & 3.303 & 0.069 \\
\hline Affiliation + Years of Education & Affiliation & Years Ed. & Intercepts & 4100.482 & 4130.544 & -2044.241 & 6 & 1 & 0.419 & 0.518 \\
\hline Surprise + Gender & Surprise & Gender & Intercepts & 4104.435 & 4129.486 & -2047.217 & 5 & 1 & 5.460 & 0.020 \\
\hline Surprise + Years of Education & Surprise & Years Ed. & Intercepts & 4109.782 & 4134.833 & -2049.891 & 5 & 1 & 0.113 & 0.736 \\
\hline Time + Gender & Time & Gender & Intercepts & 4095.057 & 4120.108 & -2042.528 & 5 & 1 & 6.567 & 0.010 \\
\hline Time + Years of Education & Time & Years Ed. & Intercepts & 4101.388 & 4126.439 & -2045.694 & 5 & 1 & 0.236 & 0.627 \\
\hline
\end{tabular}

Final Model: Affiliation Fixed Effects

\begin{tabular}{|l|l|l|l|l|l|}
\hline Fixed Effects & Estimate & SE & $\mathbf{9 5 \%} \mathbf{C l}$ & $\mathbf{t}$ & $\mathbf{p}$ \\
\hline Intercept & 4.431 & 0.077 & $4.280-4.582$ & 57.614 \\
\hline Clinton - Trump & -0.466 & 0.137 & $-0.734--0.199$ & -3.417 \\
\hline Clinton - Other & -0.714 & 0.149 & $-1.006--0.421$ & -4.791 \\
\hline Trump - Other & 0.247 & 0.170 & $-0.087-0.582$ & 1.453 \\
\hline
\end{tabular}

\begin{tabular}{|c|c|c|}
\hline \multicolumn{3}{|c|}{ Random Effects } \\
\hline & Variance & SD \\
\hline Subject & 0.761 & 0.872 \\
\hline \multicolumn{3}{|c|}{ Model Fit } \\
\hline & Marginal & Conditional \\
\hline $\mathbf{R}^{2}$ & 0.034 & 0.326 \\
\hline
\end{tabular}


Final Model: Surprise Fixed Effects

\begin{tabular}{|c|c|c|}
\hline & Estimate & SE \\
\hline Intercept & 3.635 & 0.147 \\
\hline Surprise & 0.634 & 0.160 \\
\hline \multicolumn{3}{|c|}{ Random Effects } \\
\hline & Variance & SD \\
\hline Subject & .804 & .897 \\
\hline \multicolumn{3}{|l|}{ Model Fit } \\
\hline & Marginal & Conditional \\
\hline $\mathbf{R}^{2}$ & 0.020 & 0.328 \\
\hline
\end{tabular}

Final Model: Time

\begin{tabular}{|l|l|l|}
\hline Fixed Effects & Estimate & SE \\
\hline & 4.610 & 0.105 \\
\hline Intercept & -0.253 & 0.050 \\
\hline Surprise & Variance \\
\hline \multicolumn{2}{|l|}{} \\
\hline Random Effects & 0.874 & SD \\
\hline & & 0.935 \\
\hline Subject & Marginal \\
\hline Model Fit & 0.016 & Conditional \\
\hline & $\mathbf{R}^{\mathbf{2}}$ & 0.351 \\
\hline
\end{tabular}

\begin{tabular}{|l|l|l|}
\hline $\mathbf{9 5 \%} \mathbf{C l}$ & $\mathbf{t}$ & $\mathbf{p}$ \\
\hline $3.346-3.923$ & 24.721 & $<.001$ \\
\hline $0.320-0.948$ & 3.966 & $<.001$ \\
\hline
\end{tabular}

.001

Final Model: Affiliate + Neg Affect (linear term alone)

Fixed Effects

\begin{tabular}{|l|l|l|}
\hline & Estimate & SE \\
\hline Intercept & 3.145 & 0.270 \\
\hline $\begin{array}{l}\text { Affiliation } \\
\text { (Clinton - Trump) }\end{array}$ & 0.401 & 0.220 \\
\hline $\begin{array}{l}\text { Affiliation } \\
\text { (Clinton - Other) }\end{array}$ & -0.349 & 0.163 \\
\hline $\begin{array}{l}\text { Affiliation } \\
\text { (Trump - Other) }\end{array}$ & -0.750 & 0.195 \\
\hline Neg Affect & 0.219 & 0.044 \\
\hline & \multicolumn{2}{|l|}{} \\
\hline Random Effects & Variance \\
\hline & 0.681 & SD \\
\hline Subject & 0.825 \\
\hline Model Fit & \\
\hline
\end{tabular}

\begin{tabular}{|l|l|l|}
\hline $\mathbf{9 5 \%} \mathbf{C l}$ & $\mathbf{t}$ & $\mathbf{p}$ \\
\hline $4.404-4.816$ & 43.969 & $<.001$ \\
\hline$-0.352--0.154$ & -5.029 & $<.001$ \\
\hline
\end{tabular}




\begin{tabular}{|l|l|l|}
\hline & Marginal & Conditional \\
\hline $\mathbf{R}^{\mathbf{2}}$ & 0.064 & 0.325 \\
\hline
\end{tabular}

Final Model: Affiliate + Neg Affect + (Neg Affect) ${ }^{2}$ (linear and quadratic terms)

\begin{tabular}{|l|l|l|l|l|l|}
\hline Fixed Effects & Estimate & SE & $\mathbf{9 5 \%}$ CI & $\mathbf{p}$ \\
\hline Intercept & 3.904 & 0.110 & $3.689-4.119$ & 35.571 \\
\hline $\begin{array}{l}\text { Affiliation } \\
\text { (Clinton - Trump) }\end{array}$ & 0.097 & 0.223 & $-0.341-0.535$ & 0.433 \\
\hline $\begin{array}{l}\text { Affiliation } \\
\text { (Clinton - Other) }\end{array}$ & -0.304 & 0.160 & $-0.617-0.009$ & -1.905 \\
\hline $\begin{array}{l}\text { Affiliation } \\
\text { (Trump - Other) }\end{array}$ & -0.401 & 0.205 & $-0.803-0.001$ & -1.955 \\
\hline Neg Affect & 0.234 & 0.043 & 0.665 & \\
\hline (Neg Affect) & 0.072 & 0.017 & $0.149-0.319$ & 5.410 \\
\hline
\end{tabular}

\begin{tabular}{|c|c|c|}
\hline \multicolumn{3}{|c|}{ Random Effects } \\
\hline & Variance & SD \\
\hline Subject & 0.617 & 0.786 \\
\hline \multicolumn{3}{|c|}{ Model Fit } \\
\hline & Marginal & Conditional \\
\hline $\mathbf{R}^{2}$ & 0.083 & 0.320 \\
\hline
\end{tabular}




\section{SA10. Frequency of Media Consumption}

\begin{tabular}{|c|c|c|c|c|c|c|c|c|c|c|}
\hline \multirow[t]{2}{*}{ Model Specification } & \multirow{2}{*}{$\begin{array}{l}\text { Baseline } \\
\text { Model }\end{array}$} & \multirow{2}{*}{$\begin{array}{l}\text { Fixed } \\
\text { Effects } \\
\text { Added }\end{array}$} & \multirow{2}{*}{$\begin{array}{l}\text { Random } \\
\text { Effect (of } \\
\text { Subject) }\end{array}$} & \multicolumn{4}{|l|}{ Model Fit } & \multicolumn{3}{|c|}{ LRT } \\
\hline & & & & AIC & BIC & LL & df & df & $\begin{array}{l}\text { Likelihood } \\
\text { Ratio }\end{array}$ & $\begin{array}{l}\text { LRT p- } \\
\text { value }\end{array}$ \\
\hline Null (RE only) & -- & -- & Intercepts & 4383.300 & 4398.379 & -2188.650 & 3 & & & \\
\hline Affiliation $^{\star *}$ & Null & Affiliation & Intercepts & 4366.116 & 4391.248 & -2170.058 & 5 & 2 & 21.184 & $<.001$ \\
\hline Surprise $^{* *}$ & Null & Surprise & Intercepts & 4374.882 & 4394.988 & -2183.441 & 4 & 1 & 10.418 & 0.001 \\
\hline Time & Null & Time & Intercepts & 4368.063 & 4388.169 & -2180.032 & 4 & 1 & 17.237 & $<.001$ \\
\hline Affiliation $x$ Time & $\begin{array}{l}\text { Affiliation + } \\
\text { Time ME }\end{array}$ & $\begin{array}{l}\text { Affiliation } x \\
\text { Time }\end{array}$ & Intercepts & 4348.993 & 4389.204 & -2166.496 & 8 & 2 & 5.689 & 0.058 \\
\hline Affiliation $\times$ Surprise & $\begin{array}{l}\text { Affiliation + } \\
\text { Surprise ME }\end{array}$ & $\begin{array}{l}\text { Affiliation } x \\
\text { Surprise }\end{array}$ & Intercepts & 4363.950 & 4404.161 & -2173.975 & 8 & 2 & 3.434 & 0.180 \\
\hline Surprise $\mathrm{x}$ Time & $\begin{array}{l}\text { Surprise + } \\
\text { Time ME }\end{array}$ & $\begin{array}{l}\text { Surprise } x \\
\text { Time }\end{array}$ & Intercepts & 4359.529 & 4389.688 & -2173.765 & 8 & 2 & 2.078 & 0.149 \\
\hline $\begin{array}{l}\text { Affiliation }+ \text { Neg Affect (linear } \\
\text { term alone) }\end{array}$ & Affiliation & Neg Affect & Intercepts & 4350.075 & 4380.233 & -2169.037 & 6 & 1 & 18.041 & $<.001$ \\
\hline $\begin{array}{l}\text { Affiliation + Neg Affect + (Neg } \\
\text { Affect) }^{2} \text { (linear and quadratic } \\
\text { terms) }\end{array}$ & Affiliation & $\begin{array}{l}\text { Neg Affect + } \\
(\text { Neg } \\
\text { Affect)^2 }\end{array}$ & Intercepts & 4335.302 & 4370.487 & -2160.651 & 7 & 2 & 34.814 & $<.001$ \\
\hline Affiliation + Gender & Affiliation & Gender & Intercepts & 4296.084 & 4326.141 & -2142.042 & 6 & 1 & 2.412 & 0.120 \\
\hline Affiliation + Years of Education & Affiliation & Years Ed. & Intercepts & 4298.045 & 4328.101 & -2143.022 & 6 & 1 & 0.452 & 0.501 \\
\hline Surprise + Gender & Surprise & Gender & Intercepts & 4303.314 & 4328.361 & -2146.657 & 5 & 1 & 4.233 & 0.040 \\
\hline Surprise + Years of Education & Surprise & Years Ed. & Intercepts & 4306.638 & 4331.685 & -2148.319 & 5 & 1 & 0.909 & 0.340 \\
\hline Time + Gender & Time & Gender & Intercepts & 4295.396 & 4320.443 & -2142.698 & 5 & 1 & 4.975 & 0.026 \\
\hline Time + Years of Education & Time & Years Ed. & Intercepts & 4297.810 & 4322.857 & -2143.905 & 5 & 1 & 2.562 & 0.110 \\
\hline
\end{tabular}

Final Model: Affiliation Fixed Effects

\begin{tabular}{|l|l|l|l|l|l|}
\hline Fixed Effects & Estimate & SE & $\mathbf{9 5 \%} \mathbf{C l}$ & $\mathbf{t}$ & $\mathbf{p}$ \\
\hline Intercept & 4.598 & 0.081 & $4.439-4.756$ & 57.006 \\
\hline Clinton - Trump & -0.384 & 0.143 & $-0.665--0.103$ & -2.679 \\
\hline Clinton - Other & -0.690 & 0.156 & $-0.997--0.383$ & -4.407 \\
\hline Trump - Other & -0.306 & 0.179 & $-0.657-0.045$ & -1.708 & 0.008 \\
\hline
\end{tabular}

\begin{tabular}{|c|c|c|}
\hline \multicolumn{3}{|c|}{ Random Effects } \\
\hline & Variance & SD \\
\hline Subject & 0.718 & 0.848 \\
\hline \multicolumn{3}{|c|}{ Model Fit } \\
\hline & Marginal & Conditional \\
\hline $\mathbf{R}^{2}$ & 0.026 & 0.265 \\
\hline
\end{tabular}


Final Model: Surprise Fixed Effects

\begin{tabular}{|l|l|l|}
\hline & Estimate & SE \\
\hline Intercept & 3.904 & 0.154 \\
\hline Time & 0.542 & 0.167 \\
\hline \multicolumn{2}{|l|}{} \\
\hline Random Effects & Variance & SD \\
\hline \multicolumn{2}{|l|}{} \\
\hline Subject & 0.748 & 0.865 \\
\hline Model Fit & Marginal & Conditional \\
\hline & 0.013 & 0.262 \\
\hline $\mathbf{R}^{2}$ & & \\
\hline
\end{tabular}

Final Model: Time

\begin{tabular}{|l|l|l|l|l|}
\hline Fixed Effects & Estimate & SE & $\mathbf{9 5 \%} \mathbf{C l}$ & $\mathbf{~}$ \\
\hline & 4.774 & 0.116 & $4.547-5.000$ & $\mathbf{p}$ \\
\hline Intercept & -0.235 & 0.056 & $-0.346--0.125$ & -.314 \\
\hline Time & & $<.183$ & $<01$ \\
\hline
\end{tabular}

\begin{tabular}{|l|l|l|}
\hline Random Effects & Variance & SD \\
\hline & 0.829 & 0.910 \\
\hline Subject & Marginal & Conditional \\
\hline Model Fit & 0.012 & 0.287 \\
\hline \multicolumn{2}{|l|}{} \\
\hline $\mathbf{R}^{\mathbf{2}}$ &
\end{tabular}

Final Model: Affiliate + Neg Affect (linear term alone)

Fixed Effects

\begin{tabular}{|c|c|c|}
\hline & Estimate & SE \\
\hline Intercept & 3.423 & 0.285 \\
\hline $\begin{array}{l}\text { Affiliation } \\
\text { (Clinton - Trump) }\end{array}$ & 0.410 & 0.233 \\
\hline $\begin{array}{l}\text { Affiliation } \\
\text { (Clinton - Other) }\end{array}$ & -0.356 & 0.172 \\
\hline $\begin{array}{l}\text { Affiliation } \\
\text { (Trump - Other) }\end{array}$ & -0.766 & 0.206 \\
\hline Neg Affect & 0.200 & 0.047 \\
\hline \multicolumn{3}{|l|}{ Random Effects } \\
\hline & Variance & SD \\
\hline Subject & 0.654 & 0.809 \\
\hline Model Fit & & \\
\hline
\end{tabular}

\begin{tabular}{|l|l|l|}
\hline $\mathbf{9 5 \%} \mathbf{C l}$ & $\mathbf{t}$ & $\mathbf{p}$ \\
\hline $3.603-4.206$ & 25.398 & $<.001$ \\
\hline $0.214-0.870$ & 3.246 & 0.001 \\
\hline
\end{tabular}




\begin{tabular}{|l|l|l|}
\hline & Marginal & Conditional \\
\hline $\mathbf{R}^{\mathbf{2}}$ & 0.047 & 0.264 \\
\hline
\end{tabular}

Final Model: Affiliate + Neg Affect + (Neg Affect) ${ }^{2}$ (linear and quadratic terms)

\begin{tabular}{|l|l|l|l|l|l|}
\hline Fixed Effects & Estimate & SE & $\mathbf{9 5 \%}$ CI & t \\
\hline Intercept & 4.079 & 0.116 & $3.850-4.307$ & 35.016 \\
\hline $\begin{array}{l}\text { Affiliation } \\
\text { Clinton - Trump) }\end{array}$ & 0.107 & 0.237 & $-0.358-0.572$ & 0.453 \\
\hline $\begin{array}{l}\text { Affiliation } \\
\text { (Clinton - Other) }\end{array}$ & -0.301 & 0.169 & $-0.633-0.031$ & -1.776 \\
\hline $\begin{array}{l}\text { Affiliation } \\
\text { (Trump-Other) }\end{array}$ & -0.408 & 0.218 & $-0.836-0.019$ & -1.873 \\
\hline Neg Affect & 0.219 & 0.046 & 0.651 & \\
\hline (Neg Affect) $^{2}$ & 0.076 & 0.019 & $0.129-0.309$ & 4.778 \\
\hline
\end{tabular}

\begin{tabular}{|c|c|c|}
\hline \multicolumn{3}{|c|}{ Random Effects } \\
\hline & Variance & SD \\
\hline Subject & 0.601 & 0.775 \\
\hline \multicolumn{3}{|c|}{ Model Fit } \\
\hline & Marginal & Conditional \\
\hline $\mathbf{R}^{2}$ & 0.065 & 0.265 \\
\hline
\end{tabular}




\section{SA11. Frequency of Speaking}

\begin{tabular}{|c|c|c|c|c|c|c|c|c|c|c|}
\hline \multirow[t]{2}{*}{ Model Specification } & \multirow{2}{*}{$\begin{array}{l}\text { Baseline } \\
\text { Model }\end{array}$} & \multirow{2}{*}{$\begin{array}{l}\text { Fixed } \\
\text { Effects } \\
\text { Added }\end{array}$} & \multirow{2}{*}{$\begin{array}{l}\text { Random } \\
\text { Effect (of } \\
\text { Subject) }\end{array}$} & \multicolumn{4}{|l|}{ Model Fit } & \multicolumn{3}{|c|}{ LRT } \\
\hline & & & & AIC & $\mathrm{BIC}$ & LL & df & df & $\begin{array}{l}\text { Likelihood } \\
\text { Ratio }\end{array}$ & $\begin{array}{l}\text { LRT } p \text { - } \\
\text { value }\end{array}$ \\
\hline Null (RE only) & -- & -- & Intercepts & 4186.507 & 4201.586 & -2090.253 & 3 & & & \\
\hline Affiliation $^{* *}$ & Null & Affiliation & Intercepts & 4173.473 & 4198.605 & -2081.736 & 5 & 2 & 17.034 & $<.001$ \\
\hline Surprise & Null & Surprise & Intercepts & 4181.401 & 4201.507 & -2086.701 & 4 & 1 & 7.105 & 0.008 \\
\hline Time $^{* *}$ & Null & Time & Intercepts & 4179.377 & 4199.483 & -2085.689 & 4 & 1 & 9.129 & 0.003 \\
\hline Affiliation $x$ Time & $\begin{array}{l}\text { Affiliation + } \\
\text { Time ME }\end{array}$ & $\begin{array}{l}\text { Affiliation } x \\
\text { Time }\end{array}$ & Intercepts & 4163.458 & 4203.670 & -2073.729 & 8 & 2 & 6.752 & 0.034 \\
\hline $\begin{array}{l}\text { Affiliation }+ \text { Neg Affect (linear } \\
\text { term alone) }\end{array}$ & Affiliation & Neg Affect & Intercepts & 4154.239 & 4184.398 & -2071.120 & 6 & 1 & 21.234 & $<.001$ \\
\hline $\begin{array}{l}\text { Affiliation + Neg Affect + (Neg } \\
\text { Affect) }^{2} \text { (linear and quadratic } \\
\text { terms) }\end{array}$ & Affiliation & $\begin{array}{l}\text { Neg Affect + } \\
\text { (Neg } \\
\text { Affect)^2 }\end{array}$ & Intercepts & 4131.828 & 4167.013 & -2058.914 & 7 & 2 & 45.645 & $<.001$ \\
\hline Affiliation + Gender & Affiliation & Gender & Intercepts & 4096.150 & 4126.207 & -2042.075 & 6 & 1 & 6.822 & 0.009 \\
\hline Affiliation + Years of Education & Affiliation & Years Ed. & Intercepts & 4102.791 & 4132.848 & -2045.396 & 6 & 1 & 0.181 & 0.670 \\
\hline Time + Gender** & Time & Gender & Intercepts & 4098.825 & 4123.872 & -2044.412 & 5 & 1 & 10.176 & 0.001 \\
\hline Time + Years of Education & Time & Years Ed. & Intercepts & 4107.552 & 4132.599 & -2048.776 & 5 & 1 & 1.449 & 0.229 \\
\hline
\end{tabular}

Final Model: Affiliation

\begin{tabular}{|l|l|l|l|l|l|}
\hline Fixed Effects & Estimate & SE & $\mathbf{9 5 \%}$ Cl & t & P \\
\hline & 4.239 & 0.078 & $4.087-4.391$ & 54.658 \\
\hline Intercept & -0.312 & 0.138 & $-0.582--0.042$ & -2.264 \\
\hline Clinton - Trump & -0.603 & 0.150 & $-0.898--0.308$ & -4.008 \\
\hline Clinton - Other & -0.292 & 0.172 & $-0.629-0.046$ & -001 \\
\hline Trump - Other & & -1.696 & $<.024$ \\
\hline
\end{tabular}

\begin{tabular}{|l|l|l|}
\hline \multicolumn{2}{|l|}{ Random Effects } & Variance \\
\hline & 0.792 & SD \\
\hline Subject & Marginal & 0.890 \\
\hline Model Fit & 0.022 & Conditional \\
\hline & & 0.327 \\
\hline $\mathbf{R}^{2}$ &
\end{tabular}

Final Model: Time

\section{Fixed Effects}

\begin{tabular}{|l|l|l|l|l|l|}
\hline Fixed Effects & Estimate & SE & $\mathbf{9 5 \%}$ Cl & t & $\mathbf{p}$ \\
\hline Intercept & 4.307 & 0.105 & $4.100-4.513$ & 40.865 \\
\hline Time & -0.153 & 0.051 & $-0.253--0.054$ & -3.028 & $<$ \\
\hline
\end{tabular}

\section{Random Effects}




\begin{tabular}{|l|l|l|}
\hline & Variance & SD \\
\hline Subject & 0.868 & 0.932 \\
\hline Model Fit & Marginal & Conditional \\
\hline & 0.006 & 0.340 \\
\hline $\mathbf{R}^{\mathbf{2}}$ &
\end{tabular}

Final Model: Affiliate + Neg Affect (linear term alone) Fixed Effects

\begin{tabular}{|c|c|c|}
\hline & Estimate & SE \\
\hline Intercept & 3.016 & 0.273 \\
\hline $\begin{array}{l}\text { Affiliation } \\
\text { (Clinton - Trump) }\end{array}$ & 0.513 & 0.223 \\
\hline $\begin{array}{l}\text { Affiliation } \\
\text { (Clinton - Other) }\end{array}$ & -0.259 & 0.165 \\
\hline $\begin{array}{l}\text { Affiliation } \\
\text { (Trump - Other) }\end{array}$ & -0.772 & 0.197 \\
\hline Neg Affect & 0.209 & 0.045 \\
\hline \multicolumn{3}{|l|}{ Random Effects } \\
\hline & Variance & SD \\
\hline Subject & 0.717 & 0.847 \\
\hline \multicolumn{3}{|l|}{ Model Fit } \\
\hline & Marginal & Conditional \\
\hline $\mathbf{R}^{2}$ & 0.049 & 0.326 \\
\hline
\end{tabular}

Final Model: Affiliate + Neg Affect $+(\text { Neg Affect })^{2}$ (linear and quadratic terms)

\begin{tabular}{|l|l|l|l|l|l|}
\hline Fixed Effects & Estimate & SE & $\mathbf{9 5 \%}$ Cl & t \\
\hline Intercept & 3.671 & 0.110 & $3.455-3.888$ & 33.245 \\
\hline $\begin{array}{l}\text { Affiliation } \\
\text { (Clinton - Trump) }\end{array}$ & 0.146 & 0.225 & $-0.295-0.587$ & 0.650 \\
\hline $\begin{array}{l}\text { Affiliation } \\
\text { (Clinton - Other) }\end{array}$ & -0.202 & 0.161 & $-0.517-0.113$ & -1.257 \\
\hline $\begin{array}{l}\text { Affiliation } \\
\text { (Trump - Other) }\end{array}$ & -0.348 & 0.207 & $-0.754-0.057$ & -1.685 \\
\hline Neg Affect & 0.228 & 0.044 & 0.209 & 0.093 \\
\hline (Neg Affect) & & 0.089 & 0.018 & $0.054-0.123$ & 5.232 \\
\hline
\end{tabular}

\begin{tabular}{|c|c|c|}
\hline \multicolumn{3}{|c|}{ Random Effects } \\
\hline & Variance & SD \\
\hline Subject & 0.643 & 0.802 \\
\hline
\end{tabular}

\begin{tabular}{|l|l|l|}
\hline $\mathbf{9 5 \%} \mathbf{C l}$ & $\mathbf{t}$ & $\mathbf{p}$ \\
\hline $2.481-3.552$ & 11.041 & $<.001$ \\
\hline $0.076-0.950$ & 2.304 & 0.022 \\
\hline$-0.582-0.064$ & -1.573 & 0.116 \\
\hline$-1.159--0.385$ & -3.916 & $<.001$ \\
\hline $0.121-0.297$ & 4.659 & $<.001$ \\
\hline
\end{tabular}

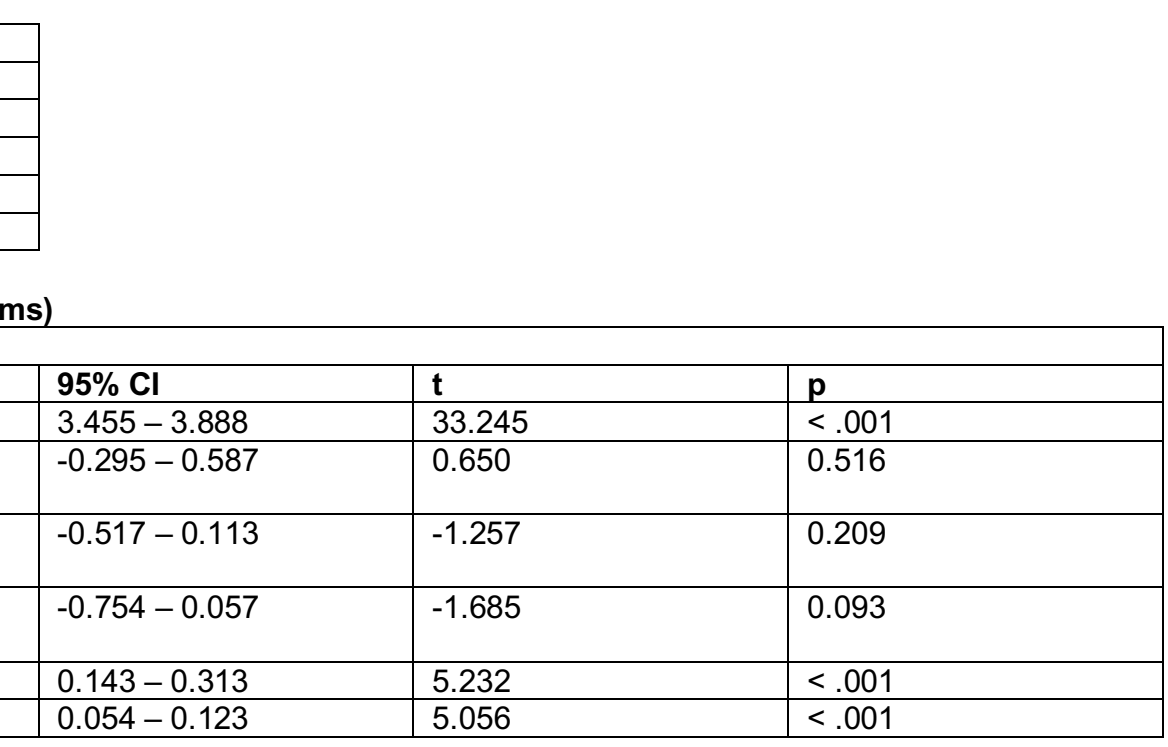




\begin{tabular}{|l|l|l|}
\hline & Marginal & Conditional \\
\hline $\mathbf{R}^{2}$ & 0.078 & 0.326 \\
\hline
\end{tabular}

Final Model: Time + Gender Fixed Effects

\begin{tabular}{|c|c|c|}
\hline \multicolumn{3}{|c|}{ FIXea Emects } \\
\hline 然 & Estimate & SE \\
\hline Intercept & 4.124 & 0.118 \\
\hline Time & -0.141 & 0.051 \\
\hline Gender & 0.378 & 0.118 \\
\hline \multicolumn{3}{|c|}{ Random Effects } \\
\hline & Variance & SD \\
\hline Subject & 0.827 & 0.909 \\
\hline \multicolumn{3}{|l|}{ Model Fit } \\
\hline & Marginal & Conditional \\
\hline $\mathbf{R}^{2}$ & 0.019 & 0.338 \\
\hline
\end{tabular}

\begin{tabular}{|l|l|l}
\hline $\mathbf{9 5 \%} \mathbf{C l}$ & $\mathbf{t}$ & $\mathbf{p}$ \\
\hline $3.892-4.356$ & 34.891 & $<.001$ \\
$-0.241--0.041$ & -2.762 & 0.006 \\
\hline $0.147-0.609$ & 3.209 & 0.001
\end{tabular}


Supplementary Tables B. Results of mixed linear models predicting AMQ metrics of autobiographical memory as predicted by fixed effects of (Political) Affiliation, Surprise, and Time, and interactions between them. For each dependent variable, the model building and comparison process is presented, followed by model output for final models. For models with Affiliation as a fixed effect, the model is also presented with the composite Negative Affect measure (which is mean-centered in the model including both linear and quadratic terms) added as a fixed effect. For models that are significantly better than baseline, the model is also presented with Gender and Years of Education added as fixed effects.

Statistically significant effects are noted ( ${ }^{*}$ at alpha criterion of $p=.05$ for planned contrasts, ${ }^{* *}$ at alpha criterion of $p=.003$ correcting for familywise error) as revealed via comparison of model stipulated versus baseline model indicated.

$\mathrm{RE}=$ random effect; FE = fixed effect; AIC = Aikake Information Criterion; BIC = Bayesian Information Criterion; LL = LogLikelihood; df = degrees of freedom; ME = main effect; LRT = Likelihood Ratio Test

\section{SB1. AMQ: Reliving}

\begin{tabular}{|c|c|c|c|c|c|c|c|c|c|c|}
\hline \multirow[t]{2}{*}{ Model Specification } & \multirow{2}{*}{$\begin{array}{l}\text { Baseline } \\
\text { Model }\end{array}$} & \multirow{2}{*}{$\begin{array}{l}\text { Fixed } \\
\text { Effects } \\
\text { Added }\end{array}$} & \multirow{2}{*}{$\begin{array}{l}\text { Random } \\
\text { Effect (of } \\
\text { Subject) }\end{array}$} & \multicolumn{4}{|l|}{ Model Fit } & \multicolumn{3}{|c|}{ LRT } \\
\hline & & & & AIC & BIC & LL & df & df & $\begin{array}{l}\text { Likelihood } \\
\text { Ratio }\end{array}$ & $\begin{array}{l}\text { LRT } p- \\
\text { value }\end{array}$ \\
\hline Null (RE only) & -- & -- & Intercepts & 4283.865 & 4298.939 & -2138.932 & 3 & & & \\
\hline Affiliation $^{* *}$ & Null & Affiliation & Intercepts & 4254.366 & 4279.489 & -2122.183 & 5 & 2 & 33.499 & $<.001$ \\
\hline Surprise & Null & Surprise & Intercepts & 4283.489 & 4303.587 & -2137.744 & 4 & 1 & 2.376 & 0.123 \\
\hline Time & Null & Time & Intercepts & 4279.235 & 4299.334 & -2135.617 & 4 & 1 & 6.630 & 0.010 \\
\hline $\begin{array}{l}\text { Affiliation }+ \text { Neg Affect (linear } \\
\text { term alone) }\end{array}$ & Affiliation & Neg Affect & Intercepts & 4248.269 & 4278.416 & -2118.134 & 6 & 1 & 8.097 & 0.004 \\
\hline $\begin{array}{l}\text { Affiliation + Neg Affect + (Neg } \\
\text { Affect) }^{2} \text { (linear and quadratic } \\
\text { terms) }\end{array}$ & Affiliation & $\begin{array}{l}\text { Neg Affect + } \\
(\text { Neg } \\
\text { Affect })^{\wedge} 2\end{array}$ & Intercepts & 4227.352 & 4262.524 & -2106.676 & 7 & 2 & 31.014 & $<.001$ \\
\hline Affiliation + Gender & Affiliation & Gender & Intercepts & 4173.751 & 4203.797 & -2080.876 & 6 & 1 & 4.427 & 0.035 \\
\hline Affiliation + Years of Education & Affiliation & Years Ed. & Intercepts & 4174.869 & 4204.915 & -2081.435 & 6 & 1 & 3.309 & 0.069 \\
\hline
\end{tabular}

Final Model: Affiliation

\begin{tabular}{|c|c|c|}
\hline \multicolumn{3}{|l|}{ Fixed Effects } \\
\hline & Estimate & SE \\
\hline Intercept & 4.014 & 0.095 \\
\hline Clinton - Trump & 0.202 & 0.169 \\
\hline Clinton - Other & -0.956 & 0.185 \\
\hline Trump - Other & -1.158 & 0.211 \\
\hline \multicolumn{3}{|l|}{ Random Effects } \\
\hline & Variance & SD \\
\hline Subject & 1.716 & 1.310 \\
\hline
\end{tabular}




\begin{tabular}{|l|l|l|}
\hline & Marginal & Conditional \\
\hline $\mathbf{R}^{2}$ & 0.051 & 0.562 \\
\hline
\end{tabular}

Final Model: Affiliate + Neg Affect + (Neg Affect) ${ }^{2}$ (linear and quadratic terms)

\begin{tabular}{|l|l|l|l|l|l|}
\hline Fixed Effects & \multicolumn{5}{l|}{} \\
\hline & Estimate & SE & $\mathbf{9 5 \%}$ Cl & t & P \\
\hline Intercept & 3.448 & 0.138 & $3.178-3.718$ & 25.020 & $<.001$ \\
\hline $\begin{array}{l}\text { Affiliation } \\
\text { (Clinton - Trump) }\end{array}$ & 0.421 & 0.280 & $-0.128-0.971$ & 1.503 & 0.134 \\
\hline $\begin{array}{l}\text { Affiliation } \\
\text { (Clinton - Other) }\end{array}$ & -0.617 & 0.201 & $-1.011--0.222$ & -3.064 & \\
\hline $\begin{array}{l}\text { Affiliation } \\
\text { (Trump-Other) }\end{array}$ & -1.038 & 0.259 & $-1.545--0.531$ & -4.013 & 0.002 \\
\hline Neg Affect & 0.188 & 0.055 & $0.081-0.295$ & 3.441 & $<.001$ \\
\hline (Neg Affect) & 0.106 & 0.022 & $0.063-0.149$ & 4.829 & 0.001 \\
\hline
\end{tabular}

\begin{tabular}{|c|c|c|}
\hline \multicolumn{3}{|c|}{ Random Effects } \\
\hline & Variance & SD \\
\hline Subject & 1.570 & 1.253 \\
\hline \multicolumn{3}{|c|}{ Model Fit } \\
\hline & Marginal & Conditional \\
\hline $\mathbf{R}^{2}$ & 0.096 & 0.562 \\
\hline
\end{tabular}




\section{SB2. AMQ: Belief}

\begin{tabular}{|c|c|c|c|c|c|c|c|c|c|c|}
\hline \multirow[t]{2}{*}{ Model Specification } & \multirow{2}{*}{$\begin{array}{l}\text { Baseline } \\
\text { Model }\end{array}$} & \multirow{2}{*}{$\begin{array}{l}\text { Fixed } \\
\text { Effects } \\
\text { Added }\end{array}$} & \multirow{2}{*}{$\begin{array}{l}\text { Random } \\
\text { Effect (of } \\
\text { Subject) }\end{array}$} & \multicolumn{4}{|l|}{ Model Fit } & \multicolumn{3}{|c|}{ LRT } \\
\hline & & & & AIC & BIC & LL & df & df & $\begin{array}{l}\text { Likelihood } \\
\text { Ratio }\end{array}$ & $\begin{array}{l}\text { LRT } p- \\
\text { value }\end{array}$ \\
\hline Null (RE only) & $\begin{array}{ll}- \\
\end{array}$ & -- & Intercepts & 3762.188 & 3777.262 & -1878.094 & 3 & & & \\
\hline Affiliation $^{* *}$ & Null & Affiliation & Intercepts & 3745.319 & 3770.443 & -1867.660 & 5 & 2 & 20.868 & $<.001$ \\
\hline Surprise & Null & Surprise & Intercepts & 3764.169 & 3784.268 & -1878.085 & 4 & 1 & 0.018 & 0.892 \\
\hline Time $^{* *}$ & Null & Time & Intercepts & 3730.910 & 3751.009 & -1861.455 & 4 & 1 & 33.278 & $<.001$ \\
\hline Affiliation $x$ Time & $\begin{array}{l}\text { Affiliation + } \\
\text { Time ME }\end{array}$ & $\begin{array}{l}\text { Affiliation } x \\
\text { Time }\end{array}$ & Intercepts & 3713.426 & 3753.623 & -1848.713 & 8 & 2 & 5.265 & 0.072 \\
\hline $\begin{array}{l}\text { Affiliation + Neg Affect (linear } \\
\text { term alone) }\end{array}$ & Affiliation & Neg Affect & Intercepts & 3741.149 & 3771.297 & -1864.575 & 6 & 1 & 6.170 & 0.013 \\
\hline $\begin{array}{l}\text { Affiliation + Neg Affect + (Neg } \\
\text { Affect) })^{2} \text { (linear and quadratic } \\
\text { terms) }\end{array}$ & Affiliation & $\begin{array}{l}\text { Neg Affect + } \\
(\text { Neg } \\
\text { Affect)^2 }\end{array}$ & Intercepts & 3701.142 & 3736.314 & -1843.571 & 7 & 2 & 48.178 & $<.001$ \\
\hline Affiliation + Gender & Affiliation & Gender & Intercepts & 3665.134 & 3695.179 & -1826.567 & 6 & 1 & 8.392 & 0.004 \\
\hline Affiliation + Years of Education & Affiliation & Years Ed. & Intercepts & 3673.020 & 3703.065 & -1830.510 & 6 & 1 & 0.506 & 0.477 \\
\hline Time + Gender & Time & Gender & Intercepts & 3650.185 & 3675.223 & -1820.093 & 5 & 1 & 8.494 & 0.004 \\
\hline Time + Years of Education & Time & Years Ed. & Intercepts & 3658.002 & 3683.040 & -1824.001 & 5 & 1 & 0.677 & 0.411 \\
\hline
\end{tabular}

Final Model: Affiliation

\begin{tabular}{|l|l|l|l|l|l|}
\hline Fixed Effects & Estimate & SE & $\mathbf{9 5 \%}$ Cl & t & P \\
\hline & 5.448 & 0.072 & $5.307-5.590$ & 75.658 \\
\hline Intercept & 0.327 & 0.127 & $0.077-0.577$ & 2.565 \\
\hline Clinton - Trump & -0.408 & 0.140 & $-0.682--0.133$ & -2.913 \\
\hline Clinton - Other & -0.734 & 0.159 & $-1.047--0.421$ & -4.604 & 0.011 \\
\hline Trump - Other & & 0.004 & $<.001$ \\
\hline
\end{tabular}

\begin{tabular}{|l|l|l|}
\hline \multicolumn{2}{|l|}{ Random Effects } & Variance \\
\hline & 0.896 & SD \\
\hline Subject & Marginal & 0.947 \\
\hline Model Fit & 0.030 & Conditional \\
\hline \multicolumn{2}{|l|}{} & 0.484 \\
\hline $\mathbf{R}^{2}$ &
\end{tabular}

Final Model: Time

\section{Fixed Effects}

\begin{tabular}{|l|l|l|l|l|l|}
\hline Fixed Effects & Estimate & SE & $\mathbf{9 5 \%}$ Cl & t & P \\
\hline & 5.838 & 0.086 & $5.670-6.006$ & 68.274 \\
\hline Intercept & -0.226 & 0.039 & $-0.302--0.150$ & -5.842 \\
\hline Time & & $<.001$ & $<1$ \\
\hline
\end{tabular}

\section{Random Effects}




\begin{tabular}{|c|c|c|}
\hline & Variance & SD \\
\hline Subject & 0.977 & 0.989 \\
\hline \multicolumn{3}{|c|}{ Model Fit } \\
\hline & Marginal & Conditional \\
\hline $\mathbf{R}^{2}$ & 0.017 & 0.511 \\
\hline
\end{tabular}

Final Model: Affiliate + Neg Affect + (Neg Affect) ${ }^{2}$ (linear and quadratic terms) Fixed Effects

\begin{tabular}{|l|l|l|l|l|l|}
\hline & Estimate & SE & $\mathbf{9 5 \%}$ Cl & $\mathbf{~}$ \\
\hline Intercept & 4.944 & 0.102 & $4.744-5.143$ & 48.545 \\
\hline $\begin{array}{l}\text { Affiliation } \\
\text { (Clinton - Trump) }\end{array}$ & 0.331 & 0.207 & $-0.075-0.738$ & 1.599 \\
\hline $\begin{array}{l}\text { Affiliation } \\
\text { (Clinton - Other) }\end{array}$ & -0.153 & 0.149 & $-0.444-0.138$ & -1.029 \\
\hline $\begin{array}{l}\text { Affiliation } \\
\text { (Trump - Other) }\end{array}$ & -0.484 & 0.191 & $-0.858--0.110$ & -2.536 \\
\hline Neg Affect & 0.135 & 0.040 & 0.304 & \\
\hline (Neg Affect) $^{2}$ & 0.107 & 0.016 & $0.056-0.214$ & 3.349 \\
\hline
\end{tabular}

\begin{tabular}{|c|c|c|}
\hline \multicolumn{3}{|c|}{ Random Effects } \\
\hline & Variance & SD \\
\hline Subject & 0.753 & 0.868 \\
\hline \multicolumn{3}{|c|}{ Model Fit } \\
\hline & Marginal & Conditional \\
\hline $\mathbf{R}^{2}$ & 0.096 & 0.479 \\
\hline
\end{tabular}




\section{SB3. AMQ: Visual}

\begin{tabular}{|c|c|c|c|c|c|c|c|c|c|c|}
\hline \multirow[t]{2}{*}{ Model Specification } & \multirow{2}{*}{$\begin{array}{l}\text { Baseline } \\
\text { Model }\end{array}$} & \multirow{2}{*}{$\begin{array}{l}\text { Fixed } \\
\text { Effects } \\
\text { Added }\end{array}$} & \multirow{2}{*}{$\begin{array}{l}\text { Random } \\
\text { Effect (of } \\
\text { Subject) }\end{array}$} & \multicolumn{4}{|l|}{ Model Fit } & \multicolumn{3}{|c|}{ LRT } \\
\hline & & & & AIC & BIC & LL & df & df & $\begin{array}{l}\text { Likelihood } \\
\text { Ratio }\end{array}$ & $\begin{array}{l}\text { LRT } p- \\
\text { value }\end{array}$ \\
\hline Null (RE only) & -- & -- & Intercepts & 3815.398 & 3830.472 & -1904.699 & 3 & & & \\
\hline Affiliation ${ }^{* *}$ & Null & Affiliation & Intercepts & 3787.900 & 3813.023 & -1888.950 & 5 & 2 & 31.499 & $<.001$ \\
\hline Surprise & Null & Surprise & Intercepts & 3814.861 & 3834.959 & -1903.430 & 4 & 1 & 2.538 & 0.111 \\
\hline Time $^{* *}$ & Null & Time & Intercepts & 3801.590 & 3821.689 & -1896.795 & 4 & 1 & 15.808 & $<.001$ \\
\hline Affiliation $x$ Time & $\begin{array}{l}\text { Affiliation + } \\
\text { Time ME }\end{array}$ & $\begin{array}{l}\text { Affiliation } x \\
\text { Time }\end{array}$ & Intercepts & 3777.613 & 3817.811 & -1880.807 & 8 & 2 & 0.876 & 0.645 \\
\hline $\begin{array}{l}\text { Affiliation }+ \text { Neg Affect (linear } \\
\text { term alone) }\end{array}$ & Affiliation & Neg Affect & Intercepts & 3784.417 & 3814.565 & -1886.209 & 6 & 1 & 5.483 & 0.019 \\
\hline $\begin{array}{l}\text { Affiliation + Neg Affect + (Neg } \\
\text { Affect) }^{2} \text { (linear and quadratic } \\
\text { terms) }\end{array}$ & Affiliation & $\begin{array}{l}\text { Neg Affect + } \\
(\text { Neg } \\
\text { Affect })^{\wedge} 2\end{array}$ & Intercepts & 3743.957 & 3779.130 & -1864.978 & 7 & 2 & 47.943 & $<.001$ \\
\hline Affiliation + Gender & Affiliation & Gender & Intercepts & 3707.247 & 3737.292 & -1847.623 & 6 & 1 & 4.697 & 0.030 \\
\hline Affiliation + Years of Education & Affiliation & Years Ed. & Intercepts & 3709.500 & 3739.545 & -1848.750 & 6 & 1 & 2.444 & 0.118 \\
\hline Time + Gender & Time & Gender & Intercepts & 3719.755 & 3744.793 & -1854.878 & 5 & 1 & 6.296 & 0.012 \\
\hline Time + Years of Education & Time & Years Ed. & Intercepts & 3722.661 & 3747.699 & -1856.331 & 5 & 1 & 3.390 & 0.066 \\
\hline
\end{tabular}

Final Model: Affiliation

\begin{tabular}{|l|l|l|l|l|l|}
\hline Fixed Effects & Estimate & SE & $\mathbf{9 5 \%}$ Cl & t & P \\
\hline & 5.401 & 0.076 & $5.252-5.551$ & 71.011 \\
\hline Intercept & 0.235 & 0.134 & $-0.028-0.499$ & 1.750 \\
\hline Clinton - Trump & -0.690 & 0.148 & $-0.980--0.400$ & -4.667 \\
\hline Clinton - Other & -0.925 & 0.168 & $-1.256--0.595$ & -001 & 0.081 \\
\hline Trump - Other & & $<.494$ & $<.001$ \\
\hline
\end{tabular}

\begin{tabular}{|l|l|l|}
\hline \multicolumn{2}{|l|}{ Random Effects } & Variance \\
\hline & 1.061 & SD \\
\hline Subject & Marginal & 1.030 \\
\hline Model Fit & 0.047 & Conditional \\
\hline \multicolumn{2}{|l|}{} & 0.538 \\
\hline $\mathbf{R}^{2}$ &
\end{tabular}

Final Model: Time

Fixed Effects

\begin{tabular}{|l|l|l|l|l|l|}
\hline Fixed Effects & Estimate & SE & $\mathbf{9 5 \%}$ Cl & t \\
\hline Intercept & 5.592 & 0.088 & $5.419-5.765$ & 63.420 \\
\hline Time & -0.157 & 0.039 & $-0.233--0.080$ & -3.997 \\
\hline
\end{tabular}




\begin{tabular}{|l|l|l|}
\hline Random Effects & \multicolumn{2}{l|}{} \\
\hline & Variance & SD \\
\hline Subject & 1.168 & 1.081 \\
\hline Model Fit & Marginal & Conditional \\
\hline & 0.007 & 0.547 \\
\hline $\mathbf{R}^{\mathbf{2}}$ & &
\end{tabular}

Final Model: Affiliate + Neg Affect + (Neg Affect) ${ }^{2}$ (linear and quadratic terms)

Fixed Effects

\begin{tabular}{|l|l|l|l|l|l|}
\hline \multicolumn{2}{|l|}{ Fixed Effects } & Estimate & SE & $\mathbf{9 5 \%}$ Cl & $\mathbf{~}$ \\
\hline Intercept & 4.876 & 0.108 & $4.665-5.088$ & 45.206 \\
\hline $\begin{array}{l}\text { Affiliation } \\
\text { (Clinton - Trump) }\end{array}$ & 0.208 & 0.220 & $-0.222-0.638$ & 0.948 \\
\hline $\begin{array}{l}\text { Affiliation } \\
\text { (Clinton - Other) }\end{array}$ & -0.433 & 0.157 & $-0.742--0.125$ & -2.751 \\
\hline $\begin{array}{l}\text { Affiliation } \\
\text { (Trump - Other) }\end{array}$ & -0.641 & 0.202 & $-1.038--0.245$ & -3.169 \\
\hline Neg Affect & 0.136 & 0.043 & $0.052-0.219$ & 0.006 \\
\hline (Neg Affect) $^{2}$ & 0.114 & 0.017 & $0.080-0.148$ & 3.175 \\
\hline
\end{tabular}

\begin{tabular}{|l|l|l|}
\hline Random Effects & \multicolumn{2}{l|}{} \\
\hline & Variance & SD \\
\hline Subject & 0.913 & 0.956 \\
\hline Model Fit & Marginal & Conditional \\
\hline \multicolumn{2}{|l|}{} & 0.536 \\
\hline $\mathbf{R}^{\mathbf{2}}$ & 0.113 &
\end{tabular}




\section{SB4. AMQ: Setting}

\begin{tabular}{|c|c|c|c|c|c|c|c|c|c|c|}
\hline \multirow[t]{2}{*}{ Model Specification } & \multirow{2}{*}{$\begin{array}{l}\text { Baseline } \\
\text { Model }\end{array}$} & \multirow{2}{*}{$\begin{array}{l}\text { Fixed } \\
\text { Effects } \\
\text { Added }\end{array}$} & \multirow{2}{*}{$\begin{array}{l}\text { Random } \\
\text { Effect (of } \\
\text { Subject) }\end{array}$} & \multicolumn{4}{|l|}{ Model Fit } & \multicolumn{3}{|c|}{ LRT } \\
\hline & & & & AIC & BIC & LL & df & df & $\begin{array}{l}\text { Likelihood } \\
\text { Ratio }\end{array}$ & $\begin{array}{l}\text { LRT } p- \\
\text { value }\end{array}$ \\
\hline Null (RE only) & -- & -- & Intercepts & 3842.558 & 3857.638 & -1918.279 & 3 & & & \\
\hline Affiliation** & Null & Affiliation & Intercepts & 3832.231 & 3857.363 & -1911.115 & 5 & 2 & 14.328 & 0.001 \\
\hline Surprise & Null & Surprise & Intercepts & 3840.978 & 3861.084 & -1916.489 & 4 & 1 & 3.580 & 0.059 \\
\hline Time & Null & Time & Intercepts & 3844.543 & 3864.648 & -1918.271 & 4 & 1 & 0.016 & 0.901 \\
\hline $\begin{array}{l}\text { Affiliation }+ \text { Neg Affect (linear } \\
\text { term alone) }\end{array}$ & Affiliation & Neg Affect & Intercepts & 3824.398 & 3854.557 & -1906.199 & 6 & 1 & 9.833 & 0.002 \\
\hline $\begin{array}{l}\text { Affiliation + Neg Affect + (Neg } \\
\text { Affect) }^{2} \text { (linear and quadratic } \\
\text { terms) }\end{array}$ & Affiliation & $\begin{array}{l}\text { Neg Affect + } \\
\text { (Neg } \\
\text { Affect)^2 }\end{array}$ & Intercepts & 3796.283 & 3831.468 & -1891.142 & 7 & 2 & 39.948 & $<.001$ \\
\hline Affiliation + Gender & Affiliation & Gender & Intercepts & 3732.676 & 3762.732 & -1860.338 & 6 & 1 & 8.377 & 0.004 \\
\hline Affiliation + Years of Education & Affiliation & Years Ed. & Intercepts & 3739.430 & 3769.487 & -1863.715 & 6 & 1 & 1.622 & 0.203 \\
\hline
\end{tabular}

\section{Final Model: Affiliation}

\section{Fixed Effects}

\begin{tabular}{|l|l|l|}
\hline & Estimate & SE \\
\hline Intercept & 5.893 & 0.070 \\
\hline Clinton - Trump & 0.094 & 0.124 \\
\hline Clinton - Other & -0.453 & 0.135 \\
\hline Trump - Other & -0.546 & 0.155 \\
\hline \multicolumn{2}{|l}{} \\
\hline Random Effects & Variance & SD \\
\hline \multicolumn{2}{|l|}{} \\
\hline Subject & 0.733 & 0.856 \\
\hline Model Fit & Marginal & Conditional \\
\hline & 0.020 & 0.391 \\
\hline $\mathbf{R}^{\mathbf{2}}$ &
\end{tabular}

Final Model: Affiliate + Neg Affect (linear term alone)

\begin{tabular}{|c|c|c|c|c|c|}
\hline \multicolumn{6}{|l|}{ Fixed Effects } \\
\hline & Estimate & SE & $95 \% \mathrm{Cl}$ & $\mathbf{t}$ & $p$ \\
\hline Intercept & 5.140 & 0.250 & $4.650-5.629$ & 20.588 & $<.001$ \\
\hline $\begin{array}{l}\text { Affiliation } \\
\text { (Clinton - Trump) }\end{array}$ & 0.602 & 0.203 & $0.204-1.001$ & 2.964 & 0.003 \\
\hline $\begin{array}{l}\text { Affiliation } \\
\text { (Clinton - Other) }\end{array}$ & -0.239 & 0.150 & $-0.534-0.056$ & -1.591 & 0.112 \\
\hline $\begin{array}{l}\text { Affiliation } \\
\text { (Trump - Other) }\end{array}$ & -0.842 & 0.180 & $-1.194--0.489$ & -4.679 & $<.001$ \\
\hline Neg Affect & 0.129 & 0.041 & $0.048-0.209$ & 3.143 & 0.002 \\
\hline
\end{tabular}




\begin{tabular}{|l|l|l|}
\hline Random Effects & \multicolumn{2}{|l|}{} \\
\hline & Variance & SD \\
\hline Subject & 0.712 & 0.844 \\
\hline Model Fit & Marginal & Conditional \\
\hline \multicolumn{2}{|l|}{} & 0.393 \\
\hline $\mathbf{R}^{\mathbf{2}}$ & 0.033 & \\
\hline
\end{tabular}

Final Model: Affiliate + Neg Affect + (Neg Affect) ${ }^{2}$ (linear and quadratic terms)

\begin{tabular}{|l|l|l|l|l|l|}
\hline Fixed Effects & Estimate & SE & $\mathbf{9 5 \%}$ Cl & t \\
\hline Intercept & 5.424 & 0.100 & $5.227-5.621$ & 54.021 \\
\hline $\begin{array}{l}\text { Affiliation } \\
\text { (Clinton - Trump) }\end{array}$ & 0.270 & 0.204 & $-0.131-0.670$ & 1.320 \\
\hline $\begin{array}{l}\text { Affiliation } \\
\text { (Clinton - Other) }\end{array}$ & -0.170 & 0.146 & $-0.457-0.117$ & -1.162 \\
\hline $\begin{array}{l}\text { Affiliation } \\
\text { (Trump- Other) }\end{array}$ & -0.440 & 0.188 & $-0.808--0.071$ & -2.340 \\
\hline Neg Affect & 0.155 & 0.040 & $0.077-0.232$ & 3.188 \\
\hline (Neg Affect) & 0.088 & 0.016 & $0.057-0.119$ & 0.020 \\
\hline
\end{tabular}

\begin{tabular}{|l|l|l|}
\hline Random Effects & \multicolumn{2}{|l|}{} \\
\hline & Variance & SD \\
\hline Subject & 0.639 & 0.799 \\
\hline Model Fit & Marginal & Conditional \\
\hline \multicolumn{2}{|l|}{} \\
\hline $\mathbf{R}^{\mathbf{2}}$ & 0.071 & 0.394 \\
\hline
\end{tabular}




\section{SB5. AMQ: Hearing}

\begin{tabular}{|c|c|c|c|c|c|c|c|c|c|c|}
\hline \multirow[t]{2}{*}{ Model Specification } & \multirow{2}{*}{$\begin{array}{l}\text { Baseline } \\
\text { Model }\end{array}$} & \multirow{2}{*}{$\begin{array}{l}\text { Fixed } \\
\text { Effects } \\
\text { Added }\end{array}$} & \multirow{2}{*}{$\begin{array}{l}\text { Random } \\
\text { Effect (of } \\
\text { Subject) }\end{array}$} & \multicolumn{4}{|l|}{ Model Fit } & \multicolumn{3}{|c|}{ LRT } \\
\hline & & & & AIC & BIC & LL & df & df & $\begin{array}{l}\text { Likelihood } \\
\text { Ratio }\end{array}$ & $\begin{array}{l}\text { LRT } p- \\
\text { value }\end{array}$ \\
\hline Null (RE only) & $\begin{array}{ll}- \\
\end{array}$ & -- & Intercepts & 4299.306 & 4314.385 & -2146.653 & 3 & & & \\
\hline Affiliation ${ }^{\star *}$ & Null & Affiliation & Intercepts & 4271.471 & 4296.603 & -2130.735 & 5 & 2 & 31.835 & $<.001$ \\
\hline Surprise & Null & Surprise & Intercepts & 4297.862 & 4317.968 & -2144.931 & 4 & 1 & 3.444 & 0.064 \\
\hline Time ${ }^{* \star}$ & Null & Time & Intercepts & 4270.760 & 4290.865 & -2131.380 & 4 & 1 & 30.546 & $<.001$ \\
\hline $\begin{array}{l}\text { Affiliation + Neg Affect (linear } \\
\text { term alone) }\end{array}$ & Affiliation & Neg Affect & Intercepts & 4269.291 & 4299.450 & -2128.646 & 6 & 1 & 4.180 & 0.041 \\
\hline $\begin{array}{l}\text { Affiliation + Neg Affect + (Neg } \\
\text { Affect) }^{2} \text { (linear and quadratic } \\
\text { terms) }\end{array}$ & Affiliation & $\begin{array}{l}\text { Neg Affect + } \\
(\text { Neg } \\
\text { Affect })^{\wedge} 2\end{array}$ & Intercepts & 4247.920 & 4283.105 & -2116.960 & 7 & 2 & 27.550 & $<.001$ \\
\hline Affiliation + Gender & Affiliation & Gender & Intercepts & 4200.735 & 4230.792 & -2094.367 & 6 & 1 & 2.160 & 0.142 \\
\hline Affiliation + Years of Education & Affiliation & Years Ed. & Intercepts & 4202.601 & 4232.657 & -2095.300 & 6 & 1 & 0.294 & 0.588 \\
\hline Time + Gender & Time & Gender & Intercepts & 4199.733 & 4224.780 & -2094.867 & 5 & 1 & 3.054 & 0.081 \\
\hline Time + Years of Education & Time & Years Ed. & Intercepts & 4202.085 & 4227.132 & -2096.043 & 5 & 1 & 0.702 & 0.402 \\
\hline
\end{tabular}

\section{Final Model: Affiliation}

\begin{tabular}{|l|l|l|l|l|l|}
\hline Fixed Effects & Estimate & SE & $\mathbf{9 5 \%}$ Cl & t \\
\hline Intercept & 4.792 & 0.093 & $4.610-4.975$ & 51.504 \\
\hline Clinton - Trump & 0.322 & 0.165 & $-0.001-0.645$ & 1.955 \\
\hline Clinton - Other & -0.823 & 0.180 & $-1.177--0.469$ & -4.563 \\
\hline Trump - Other & -1.175 & 0.206 & $-1.580--0.770$ & -5.691 & 0.051 \\
\hline
\end{tabular}

\begin{tabular}{|l|l|l|}
\hline \multicolumn{2}{|l|}{ Random Effects } & Variance \\
\hline Subject & 1.564 & SD \\
\hline Model Fit & Marginal & 1.251 \\
\hline & 0.047 & Conditional \\
\hline $\mathbf{R}^{2}$ & 0.525 \\
\hline
\end{tabular}

Final Model: Time

\begin{tabular}{|l|l|l|l|l|}
\hline Fixed Effects & Estimate & SE & $\mathbf{9 5 \%}$ Cl & t \\
\hline & 5.200 & 0.109 & $4.986-5.415$ & $\mathbf{p}$ \\
\hline Intercept & -0.276 & 0.049 & $-0.372--0.181$ & -.008 \\
\hline Time & & $<.668$ & $<.001$ \\
\hline
\end{tabular}

\begin{tabular}{|l|l|l|}
\hline Random Effects & Sariance & SD \\
\hline
\end{tabular}




\begin{tabular}{|l|l|l|}
\hline Subject & 1.701 & 1.304 \\
\hline Model Fit & \multicolumn{2}{|l|}{} \\
\hline & Marginal & Conditional \\
\hline $\mathbf{R}^{\mathbf{2}}$ & 0.015 & 0.538 \\
\hline
\end{tabular}

Final Model: Affiliate + Neg Affect + (Neg Affect) ${ }^{2}$ (linear and quadratic terms)

Fixed Effects

\begin{tabular}{|c|c|c|c|c|c|}
\hline 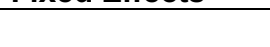 & Estimate & SE & $95 \% \mathrm{Cl}$ & $t$ & $p$ \\
\hline Intercept & 4.286 & 0.135 & $4.022-4.549$ & 31.846 & $<.001$ \\
\hline $\begin{array}{l}\text { Affiliation } \\
\text { (Clinton - Trump) }\end{array}$ & 0.378 & 0.274 & $-0.159-0.915$ & 1.380 & 0.168 \\
\hline $\begin{array}{l}\text { Affiliation } \\
\text { (Clinton - Other) }\end{array}$ & -0.552 & 0.196 & $-0.937--0.167$ & -2.811 & 0.005 \\
\hline $\begin{array}{l}\text { Affiliation } \\
\text { (Trump - Other) }\end{array}$ & -0.930 & 0.252 & $-1.424--0.435$ & -3.687 & $<.001$ \\
\hline Neg Affect & 0.144 & 0.053 & $0.040-0.249$ & 2.703 & 0.007 \\
\hline$(\text { Neg Affect) })^{2}$ & 0.104 & 0.021 & $0.062-0.146$ & 4.861 & $<.001$ \\
\hline
\end{tabular}

\begin{tabular}{|l|l|l|}
\hline Random Effects & Variance & SD \\
\hline & 1.425 & 1.194 \\
\hline Subject & Marginal & Conditional \\
\hline Model Fit & 0.085 & 0.522 \\
\hline
\end{tabular}




\section{SB6. AMQ: In-Words}

\begin{tabular}{|c|c|c|c|c|c|c|c|c|c|c|}
\hline \multirow[t]{2}{*}{ Model Specification } & \multirow{2}{*}{$\begin{array}{l}\text { Baseline } \\
\text { Model }\end{array}$} & \multirow{2}{*}{$\begin{array}{l}\text { Fixed } \\
\text { Effects } \\
\text { Added }\end{array}$} & \multirow{2}{*}{$\begin{array}{l}\text { Random } \\
\text { Effect (of } \\
\text { Subject) }\end{array}$} & \multicolumn{4}{|l|}{ Model Fit } & \multicolumn{3}{|c|}{ LRT } \\
\hline & & & & AIC & BIC & LL & df & df & $\begin{array}{l}\text { Likelihood } \\
\text { Ratio }\end{array}$ & $\begin{array}{l}\text { LRT p- } \\
\text { value }\end{array}$ \\
\hline Null (RE only) & -- & -- & Intercepts & 4259.639 & 4274.718 & -2126.820 & 3 & & & \\
\hline Affiliation $^{* *}$ & Null & Affiliation & Intercepts & 4246.666 & 4271.798 & -2118.333 & 5 & 2 & 16.973 & $<.001$ \\
\hline Surprise & Null & Surprise & Intercepts & 4258.816 & 4278.921 & -2125.408 & 4 & 1 & 2.824 & 0.093 \\
\hline Time & Null & Time & Intercepts & 4256.632 & 4276.738 & -2124.316 & 4 & 1 & 5.007 & 0.025 \\
\hline $\begin{array}{l}\text { Affiliation + Neg Affect (linear } \\
\text { term alone) }\end{array}$ & Affiliation & Neg Affect & Intercepts & 4248.543 & 4278.701 & -2118.271 & 6 & 1 & 0.123 & 0.725 \\
\hline $\begin{array}{l}\text { Affiliation + Neg Affect + (Neg } \\
\text { Affect) }{ }^{2} \text { (linear and quadratic } \\
\text { terms) }\end{array}$ & Affiliation & $\begin{array}{l}\text { Neg Affect }+ \\
(\text { Neg } \\
\text { Affect) })^{\wedge} 2\end{array}$ & Intercepts & 4248.071 & 4283.256 & -2117.035 & 7 & 2 & 4.007 & 0.045 \\
\hline Affiliation + Gender & Affiliation & Gender & Intercepts & 4179.053 & 4209.109 & -2083.526 & 6 & 1 & 0.093 & 0.761 \\
\hline Affiliation + Years of Education & Affiliation & Years Ed. & Intercepts & 4178.059 & 4208.116 & -2083.030 & 6 & 1 & 1.086 & 0.297 \\
\hline
\end{tabular}

\section{Final Model: Affiliation}

\section{Fixed Effects}

\begin{tabular}{|l|l|l|l|l|l|}
\hline & Estimate & SE & $\mathbf{9 5 \%}$ Cl & t & $\mathbf{p}$ \\
\hline Intercept & 4.105 & 0.090 & $3.929-4.281$ & 45.758 \\
\hline Clinton - Trump & 0.049 & 0.159 & $-0.263-0.360$ & 0.307 \\
\hline Clinton - Other & -0.671 & 0.174 & $-1.012--0.330$ & -.001 \\
\hline Trump - Other & -0.720 & 0.198 & $-1.109--0.331$ & -361 \\
\hline
\end{tabular}

\begin{tabular}{|l|l|l|}
\hline \multicolumn{2}{|l|}{ Random Effects } & \multicolumn{2}{l|}{} \\
\hline & Variance & SD \\
\hline Subject & 1.393 & 1.180 \\
\hline Model Fit & Marginal & Conditional \\
\hline & 0.025 & 0.482 \\
\hline $\mathbf{R}^{2}$ &
\end{tabular}




\section{SB7. AMQ: Story}

\begin{tabular}{|c|c|c|c|c|c|c|c|c|c|c|}
\hline \multirow[t]{2}{*}{ Model Specification } & \multirow{2}{*}{$\begin{array}{l}\text { Baseline } \\
\text { Model }\end{array}$} & \multirow{2}{*}{$\begin{array}{l}\text { Fixed } \\
\text { Effects } \\
\text { Added }\end{array}$} & \multirow{2}{*}{$\begin{array}{l}\text { Random } \\
\text { Effect (of } \\
\text { Subject) }\end{array}$} & \multicolumn{4}{|l|}{ Model Fit } & \multicolumn{3}{|c|}{ LRT } \\
\hline & & & & AIC & BIC & LL & df & df & $\begin{array}{l}\text { Likelihood } \\
\text { Ratio }\end{array}$ & $\begin{array}{l}\text { LRT } p- \\
\text { value }\end{array}$ \\
\hline Null (RE only) & -- & -- & Intercepts & 3937.323 & 3952.403 & -1965.662 & 3 & & & \\
\hline Affiliation ${ }^{* *}$ & Null & Affiliation & Intercepts & 3906.979 & 3932.111 & -1948.489 & 5 & 2 & 34.345 & $<.001$ \\
\hline Surprise & Null & Surprise & Intercepts & 3939.177 & 3959.282 & -1965.588 & 4 & 1 & 0.147 & 0.702 \\
\hline Time $^{* *}$ & Null & Time & Intercepts & 3911.105 & 3931.210 & -1951.552 & 4 & 1 & 28.219 & $<.001$ \\
\hline Affiliation $x$ Time & $\begin{array}{l}\text { Affiliation + } \\
\text { Time ME }\end{array}$ & $\begin{array}{l}\text { Affiliation } x \\
\text { Time }\end{array}$ & Intercepts & 3884.797 & 3925.009 & -1934.399 & 8 & 2 & 0.527 & 0.768 \\
\hline $\begin{array}{l}\text { Affiliation }+ \text { Neg Affect (linear } \\
\text { term alone) }\end{array}$ & Affiliation & Neg Affect & Intercepts & 3906.597 & 3936.756 & -1947.299 & 6 & 1 & 2.382 & 0.123 \\
\hline $\begin{array}{l}\text { Affiliation + Neg Affect + (Neg } \\
\text { Affect) }^{2} \text { (linear and quadratic } \\
\text { terms) }\end{array}$ & Affiliation & $\begin{array}{l}\text { Neg Affect + } \\
(\text { Neg } \\
\text { Affect })^{\wedge} 2\end{array}$ & Intercepts & 3880.169 & 3915.354 & -1933.085 & 7 & 2 & 30.809 & $<.001$ \\
\hline Affiliation + Gender & Affiliation & Gender & Intercepts & 3837.097 & 3867.153 & -1912.548 & 6 & 1 & 0.256 & 0.613 \\
\hline Affiliation + Years of Education & Affiliation & Years Ed. & Intercepts & 3836.896 & 3866.953 & -1912.448 & 6 & 1 & 0.456 & 0.499 \\
\hline Time + Gender & Time & Gender & Intercepts & 3843.216 & 3868.263 & -1916.608 & 5 & 1 & 0.477 & 0.490 \\
\hline Time + Years of Education & Time & Years Ed. & Intercepts & 3843.089 & 3868.136 & -1916.544 & 5 & 1 & 0.604 & 0.437 \\
\hline
\end{tabular}

Final Model: Affiliation

\begin{tabular}{|l|l|l|l|l|l|}
\hline Fixed Effects & Estimate & SE & $\mathbf{9 5 \%}$ Cl & t & P \\
\hline & 5.115 & 0.076 & $4.966-5.264$ & 67.225 \\
\hline Intercept & 0.385 & 0.135 & $0.121-0.649$ & 2.859 \\
\hline Clinton - Trump & -0.612 & 0.147 & $-0.902--0.323$ & -4.154 \\
\hline Clinton - Other & -0.998 & 0.168 & $-1.328--0.668$ & -001 \\
\hline Trump - Other & & -5.930 & $<.004$ \\
\hline
\end{tabular}

\begin{tabular}{|l|l|l|}
\hline \multicolumn{2}{|l|}{ Random Effects } & Variance \\
\hline & 0.976 & SD \\
\hline Subject & Marginal & 0.988 \\
\hline Model Fit & 0.049 & Conditional \\
\hline \multicolumn{2}{|l|}{} & 0.477 \\
\hline $\mathbf{R}^{2}$ &
\end{tabular}

Final Model: Time

Fixed Effects

\begin{tabular}{|l|l|l|l|l|l|}
\hline Fixed Effects & Estimate & SE & $\mathbf{9 5 \%}$ Cl & t \\
\hline Intercept & 5.478 & 0.092 & $5.297-5.659$ & 59.380 \\
\hline Time & -0.226 & 0.042 & $-0.308--0.143$ & -5.363 & $<.001$ \\
\hline
\end{tabular}




\begin{tabular}{|l|l|l|}
\hline Random Effects & \multicolumn{2}{l|}{} \\
\hline & Variance & SD \\
\hline Subject & 1.100 & 1.049 \\
\hline Model Fit & Marginal & Conditional \\
\hline & 0.015 & 0.497 \\
\hline $\mathbf{R}^{\mathbf{2}}$ & &
\end{tabular}

Final Model: Affiliate + Neg Affect + (Neg Affect) ${ }^{2}$ (linear and quadratic terms)

Fixed Effects

\begin{tabular}{|l|l|l|l|l|l|}
\hline & Estimate & SE & $\mathbf{9 5 \%}$ Cl & t \\
\hline Intercept & 4.699 & 0.110 & $4.484-4.914$ & 42.777 \\
\hline $\begin{array}{l}\text { Affiliation } \\
\text { (Clinton - Trump) }\end{array}$ & 0.306 & 0.224 & $-0.133-0.744$ & 1.367 \\
\hline $\begin{array}{l}\text { Affiliation } \\
\text { (Clinton - Other) }\end{array}$ & -0.423 & 0.160 & $-0.737--0.109$ & -2.641 \\
\hline $\begin{array}{l}\text { Affiliation } \\
\text { (Trump - Other) }\end{array}$ & -0.729 & 0.206 & $-1.132--0.325$ & -3.542 \\
\hline Neg Affect & 0.097 & 0.043 & $0.012-0.182$ & 2.226 \\
\hline (Neg Affect) $^{2}$ & 0.094 & 0.017 & $0.060-0.128$ & $<.009$ \\
\hline
\end{tabular}

\begin{tabular}{|l|l|l|}
\hline Random Effects & \multicolumn{2}{l|}{} \\
\hline & Variance & SD \\
\hline Subject & 0.876 & 0.936 \\
\hline Model Fit & Marginal & Conditional \\
\hline \multicolumn{2}{|l|}{} & 0.475 \\
\hline $\mathbf{R}^{\mathbf{2}}$ & 0.090 &
\end{tabular}




\section{SB8. AMQ: Importance}

\begin{tabular}{|c|c|c|c|c|c|c|c|c|c|c|}
\hline \multirow[t]{2}{*}{ Model Specification } & \multirow{2}{*}{$\begin{array}{l}\text { Baseline } \\
\text { Model }\end{array}$} & \multirow{2}{*}{$\begin{array}{l}\text { Fixed } \\
\text { Effects } \\
\text { Added }\end{array}$} & \multirow{2}{*}{$\begin{array}{l}\text { Random } \\
\text { Effect (of } \\
\text { Subject) }\end{array}$} & \multicolumn{4}{|l|}{ Model Fit } & \multicolumn{3}{|c|}{ LRT } \\
\hline & & & & AIC & BIC & LL & df & df & $\begin{array}{l}\text { Likelihood } \\
\text { Ratio }\end{array}$ & $\begin{array}{l}\text { LRT p- } \\
\text { value }\end{array}$ \\
\hline Null (RE only) & -- & -- & Intercepts & 4021.492 & 4036.571 & -2007.746 & 3 & & & \\
\hline Affiliation $^{* *}$ & Null & Affiliation & Intercepts & 3993.590 & 4018.722 & -1991.795 & 5 & 2 & 31.902 & $<.001$ \\
\hline Surprise & Null & Surprise & Intercepts & 4021.707 & 4041.813 & -2006.854 & 4 & 1 & 1.785 & 0.182 \\
\hline Time & Null & Time & Intercepts & 4012.484 & 4032.589 & -2002.242 & 4 & 1 & 11.009 & 0.001 \\
\hline Affiliation $x$ Time & $\begin{array}{l}\text { Affiliation + } \\
\text { Time ME }\end{array}$ & $\begin{array}{l}\text { Affiliation } \mathrm{x} \\
\text { Time }\end{array}$ & Intercepts & 3986.364 & 4026.575 & -1985.182 & 8 & 2 & 2.157 & 0.340 \\
\hline $\begin{array}{l}\text { Affiliation }+ \text { Neg Affect (linear } \\
\text { term alone)** }\end{array}$ & Affiliation & Neg Affect & Intercepts & 3984.540 & 4014.699 & -1986.270 & 6 & 1 & 11.050 & 0.001 \\
\hline $\begin{array}{l}\text { Affiliation + Neg Affect + (Neg } \\
\text { Affect) }^{2} \text { (linear and quadratic } \\
\text { terms) }\end{array}$ & Affiliation & $\begin{array}{l}\text { Neg Affect + } \\
(\text { Neg } \\
\text { Affect })^{\wedge} 2\end{array}$ & Intercepts & 3980.039 & 4015.224 & -1983.020 & 7 & 2 & 17.551 & $<.001$ \\
\hline Affiliation + Gender ${ }^{\star *}$ & Affiliation & Gender & Intercepts & 3912.601 & 3942.657 & -1950.300 & 6 & 1 & 16.753 & $<.001$ \\
\hline Affiliation + Years of Education & Affiliation & Years Ed. & Intercepts & 3929.146 & 3959.202 & -1958.573 & 6 & 1 & 0.208 & 0.648 \\
\hline Time + Gender** & Time & Gender & Intercepts & 3927.753 & 3952.800 & -1958.877 & 5 & 1 & 21.844 & $<.001$ \\
\hline Time + Years of Education & Time & Years Ed. & Intercepts & 3948.146 & 3973.193 & -1969.073 & 5 & 1 & 1.451 & 0.228 \\
\hline
\end{tabular}

Final Model: Affiliation

\begin{tabular}{|l|l|l|l|l|l|}
\hline Fixed Effects & Estimate & SE & $\mathbf{9 5 \%}$ Cl & t & P \\
\hline & 3.287 & 0.093 & $3.106-3.469$ & 35.530 \\
\hline Intercept & -0.198 & 0.163 & $-0.519-0.122$ & -1.213 \\
\hline Clinton - Trump & -1.025 & 0.179 & $-1.377--0.673$ & -5.716 \\
\hline Clinton - Other & -0.827 & 0.204 & $-1.228--0.426$ & -0.226 & -4.050 \\
\hline Trump - Other & & $<01$ & $<.001$ \\
\hline
\end{tabular}

\begin{tabular}{|l|l|l|}
\hline \multicolumn{2}{|l|}{ Random Effects } & Variance \\
\hline & 1.793 & SD \\
\hline Subject & Marginal & 1.339 \\
\hline Model Fit & 0.052 & Conditional \\
\hline & & 0.658 \\
\hline $\mathbf{R}^{2}$ &
\end{tabular}

Final Model: Time

Fixed Effects

\begin{tabular}{|l|l|l|l|l|l|}
\hline Fixed Effects & Estimate & SE & $\mathbf{9 5 \%}$ Cl & t \\
\hline Intercept & 3.257 & 0.097 & $3.067-3.448$ & 33.517 \\
\hline Time & -0.133 & 0.040 & $-0.211--0.054$ & -3.326 \\
\hline
\end{tabular}




\begin{tabular}{|c|c|c|}
\hline \multicolumn{3}{|c|}{ Random Effects } \\
\hline & Variance & SD \\
\hline Subject & 1.948 & 1.396 \\
\hline \multicolumn{3}{|c|}{ Model Fit } \\
\hline & Marginal & Conditional \\
\hline $\mathbf{R}^{2}$ & 0.004 & 0.663 \\
\hline
\end{tabular}

\section{Final Model: Affiliate + Neg Affect (linear term alone)}

\begin{tabular}{|c|c|c|c|c|c|}
\hline \multicolumn{6}{|l|}{ Fixed Effects } \\
\hline & Estimate & SE & $95 \% \mathrm{Cl}$ & $t$ & $p$ \\
\hline Intercept & 2.229 & 0.330 & $1.582-2.876$ & 6.754 & $<.001$ \\
\hline $\begin{array}{l}\text { Affiliation } \\
\text { (Clinton - Trump) }\end{array}$ & 0.515 & 0.268 & $-0.010-1.041$ & 1.923 & 0.055 \\
\hline $\begin{array}{l}\text { Affiliation } \\
\text { (Clinton - Other) }\end{array}$ & -0.729 & 0.198 & $-1.119--0.340$ & -3.676 & $<.001$ \\
\hline $\begin{array}{l}\text { Affiliation } \\
\text { (Trump - Other) }\end{array}$ & -1.245 & 0.238 & $-1.711--0.779$ & -5.237 & $<.001$ \\
\hline Neg Affect & 0.181 & 0.054 & $0.075-0.287$ & 3.336 & 0.001 \\
\hline
\end{tabular}

\begin{tabular}{|l|l|l|}
\hline Random Effects & \multicolumn{2}{l|}{} \\
\hline & Variance & SD \\
\hline Subject & 1.744 & 1.321 \\
\hline Model Fit & Marginal & Conditional \\
\hline \multicolumn{2}{|l|}{} & 0.659 \\
\hline $\mathbf{R}^{\mathbf{2}}$ & 0.071 &
\end{tabular}

Final Model: Affiliate + Neg Affect + (Neg Affect) ${ }^{2}$ (linear and quadratic terms)

\begin{tabular}{|l|l|l|l|l|l|}
\hline Fixed Effects & Estimate & SE & $\mathbf{9 5 \%} \mathbf{C l}$ & $\mathbf{t}$ \\
\hline Intercept & 2.868 & 0.135 & $2.603-3.133$ & 21.235 \\
\hline $\begin{array}{l}\text { Affiliation } \\
\text { (Clinton - Trump) }\end{array}$ & 0.253 & 0.275 & $-0.286-0.792$ & 0.922 \\
\hline $\begin{array}{l}\text { Affiliation } \\
\text { (Clinton - Other) }\end{array}$ & -0.699 & 0.197 & $-1.086--0.312$ & -3.541 \\
\hline $\begin{array}{l}\text { Affiliation } \\
\text { (Trump - Other) }\end{array}$ & -0.952 & 0.254 & $-1.449--0.455$ & -3.755 \\
\hline Neg Affect & 0.188 & 0.054 & $0.083-0.294$ & 3.512 \\
\hline (Neg Affect) & & 0.058 & 0.021 & $0.016-0.100$ & 2.722 \\
\hline
\end{tabular}

\begin{tabular}{|c|c|c|}
\hline \multicolumn{3}{|c|}{ Random Effects } \\
\hline & Variance & SD \\
\hline Subject & 1.707 & 1.307 \\
\hline
\end{tabular}




\begin{tabular}{|l|l|l|}
\hline Model Fit \\
\hline & Marginal & Conditional \\
\hline $\mathbf{R}^{\mathbf{2}}$ & 0.080 & 0.657 \\
\hline
\end{tabular}

Final Model: Affiliation + Gender

\begin{tabular}{|c|c|c|c|c|c|}
\hline \multicolumn{6}{|l|}{ Fixed Effects } \\
\hline & Estimate & SE & $95 \% \mathrm{Cl}$ & $t$ & $p$ \\
\hline Intercept & 2.987 & 0.116 & $2.759-3.215$ & 25.712 & $<.001$ \\
\hline $\begin{array}{l}\text { Affiliation } \\
\text { (Clinton - Trump) }\end{array}$ & -0.069 & 0.163 & $-0.388-0.250$ & -0.423 & 0.672 \\
\hline $\begin{array}{l}\text { Affiliation } \\
\text { (Clinton - Other) }\end{array}$ & -0.931 & 0.179 & $-1.281--0.580$ & -5.209 & $<.001$ \\
\hline $\begin{array}{l}\text { Affiliation } \\
\text { (Trump - Other) }\end{array}$ & -0.862 & 0.201 & $-1.256--0.467$ & -4.285 & $<.001$ \\
\hline Gender & 0.570 & 0.138 & $0.299-0.841$ & 4.127 & $<.001$ \\
\hline
\end{tabular}

\begin{tabular}{|c|c|c|}
\hline \multicolumn{3}{|c|}{ Random Effects } \\
\hline & Variance & SD \\
\hline Subject & 1.685 & 1.298 \\
\hline \multicolumn{3}{|c|}{ Model Fit } \\
\hline & Marginal & Conditional \\
\hline $\mathbf{R}^{2}$ & 0.082 & 0.653 \\
\hline
\end{tabular}

Final Model: Time + Gender

Fixed Effects

\begin{tabular}{|l|l|l|l|l|}
\hline Fixed Effects & Estimate & SE & $\mathbf{9 5 \%}$ Cl & t \\
\hline Intercept & 2.968 & 0.115 & $2.743-3.194$ & $\mathbf{p}$ \\
\hline Time & -0.133 & 0.040 & $-0.212--0.054$ & -3.293 \\
\hline Gender & 0.661 & 0.140 & $0.386-0.935$ & 0.001 \\
\hline
\end{tabular}

\begin{tabular}{|l|l|l|}
\hline Random Effects & \multicolumn{2}{|l|}{} \\
\hline & Variance & SD \\
\hline Subject & 1.820 & 1.349 \\
\hline Model Fit & Marginal & Conditional \\
\hline \multicolumn{2}{|l|}{} & 0.658 \\
\hline $\mathbf{R}^{\mathbf{2}}$ & 0.041 &
\end{tabular}




\section{SB9. AMQ: Rehearsal (Thought)}

\begin{tabular}{|c|c|c|c|c|c|c|c|c|c|c|}
\hline \multirow[t]{2}{*}{ Model Specification } & \multirow{2}{*}{$\begin{array}{l}\text { Baseline } \\
\text { Model }\end{array}$} & \multirow{2}{*}{$\begin{array}{l}\text { Fixed } \\
\text { Effects } \\
\text { Added }\end{array}$} & \multirow{2}{*}{$\begin{array}{l}\text { Random } \\
\text { Effect (of } \\
\text { Subject) }\end{array}$} & \multicolumn{4}{|l|}{ Model Fit } & \multicolumn{3}{|c|}{ LRT } \\
\hline & & & & AIC & BIC & LL & df & df & $\begin{array}{l}\text { Likelihood } \\
\text { Ratio }\end{array}$ & $\begin{array}{l}\text { LRT } p \\
\text { value }\end{array}$ \\
\hline Null (RE only) & -- & -- & Intercepts & 4131.650 & 4146.729 & -2062.825 & 3 & & & \\
\hline Affiliation $^{* *}$ & Null & Affiliation & Intercepts & 4117.024 & 4142.156 & -2053.512 & 5 & 2 & 18.626 & $<.001$ \\
\hline Surprise & Null & Surprise & Intercepts & 4131.063 & 4151.168 & -2061.531 & 4 & 1 & 2.587 & 0.108 \\
\hline Time & Null & Time & Intercepts & 4079.186 & 4099.292 & -2035.593 & 4 & 1 & 54.464 & $<.001$ \\
\hline Affiliation $\times$ Time & $\begin{array}{l}\text { Affiliation + } \\
\text { Time ME }\end{array}$ & $\begin{array}{l}\text { Affiliation } x \\
\text { Time }\end{array}$ & Intercepts & 4067.461 & 4107.672 & -2025.730 & 8 & 2 & 1.173 & 0.556 \\
\hline $\begin{array}{l}\text { Affiliation + Neg Affect (linear } \\
\text { term alone) }\end{array}$ & Affiliation & Neg Affect & Intercepts & 4112.724 & 4142.883 & -2050.362 & 6 & 1 & 6.300 & 0.012 \\
\hline $\begin{array}{l}\text { Affiliation + Neg Affect }+ \text { (Neg } \\
\text { Affect) }^{2} \text { (linear and quadratic } \\
\text { terms) })^{\star *}\end{array}$ & Affiliation & $\begin{array}{l}\text { Neg Affect }+ \\
(\text { Neg } \\
\text { Affect)^2 }\end{array}$ & Intercepts & 4099.231 & 4134.416 & -2042.615 & 7 & 2 & 21.793 & $<.001$ \\
\hline Affiliation + Gender & Affiliation & Gender & Intercepts & 4050.575 & 4080.631 & -2019.287 & 6 & 1 & 2.388 & 0.122 \\
\hline Affiliation + Years of Education & Affiliation & Years Ed. & Intercepts & 4052.312 & 4082.368 & -2020.156 & 6 & 1 & 0.651 & 0.420 \\
\hline Time + Gender & Time & Gender & Intercepts & 4013.870 & 4038.917 & -2001.935 & 5 & 1 & 3.561 & 0.059 \\
\hline Time + Years of Education & Time & Years Ed. & Intercepts & 4015.595 & 4040.642 & -2002.797 & 5 & 1 & 1.837 & 0.175 \\
\hline
\end{tabular}

\section{Final Model: Affiliation}

\begin{tabular}{|l|l|l|l|l|l|}
\hline Fixed Effects & Estimate & SE & $\mathbf{9 5 \%}$ Cl & t & P \\
\hline & 5.028 & 0.081 & $4.868-5.187$ & 61.839 \\
\hline Intercept & 0.039 & 0.144 & $-0.244-0.322$ & 0.271 \\
\hline Clinton - Trump & -0.642 & 0.158 & $-0.951--0.322$ & -4.073 \\
\hline Clinton - Other & -0.681 & 0.180 & $-1.033--0.328$ & -3.785 & 0.787 \\
\hline Trump - Other & & $<.001$ & $<.001$ \\
\hline
\end{tabular}

\begin{tabular}{|l|l|l|}
\hline \multicolumn{2}{|l|}{ Random Effects } & Variance \\
\hline & 1.054 & SD \\
\hline Subject & Marginal & 1.027 \\
\hline Model Fit & 0.026 & Conditional \\
\hline \multicolumn{2}{|l|}{} & 0.429 \\
\hline $\mathbf{R}^{2}$ &
\end{tabular}

\section{Final Model: Time}

Fixed Effects

\begin{tabular}{|l|l|l|l|l|l|}
\hline Fixed Effects & Estimate & SE & $\mathbf{9 5 \%}$ Cl & t \\
\hline Intercept & 5.505 & 0.100 & $5.310-5.701$ & 50.263 \\
\hline Time & -0.346 & 0.046 & $-0.437--0.256$ & -7.502 & $<.001$ \\
\hline
\end{tabular}




\begin{tabular}{|l|l|l|}
\hline Random Effects & Variance & SD \\
\hline & 1.144 & 1.070 \\
\hline Subject & \multicolumn{1}{|l|}{} \\
\hline Model Fit & Marginal & Conditional \\
\hline & 0.030 & 0.468 \\
\hline
\end{tabular}

Final Model: Affiliate + Neg Affect + (Neg Affect) ${ }^{2}$ (linear and quadratic terms)

Fixed Effects

\begin{tabular}{|l|l|l|l|l|l|}
\hline & Estimate & SE & $\mathbf{9 5 \%}$ CI & $\mathbf{p}$ \\
\hline Intercept & 4.621 & 0.119 & $4.389-4.853$ & 38.973 \\
\hline $\begin{array}{l}\text { Affiliation } \\
\text { (Clinton - Trump) }\end{array}$ & 0.176 & 0.241 & $-0.297-0.649$ & 0.728 \\
\hline $\begin{array}{l}\text { Affiliation } \\
\text { (Clinton - Other) }\end{array}$ & -0.402 & 0.173 & $-0.741--0.063$ & -2.328 \\
\hline $\begin{array}{l}\text { Affiliation } \\
\text { (Trump - Other) }\end{array}$ & -0.578 & 0.222 & $-1.031--0.143$ & -2.604 \\
\hline Neg Affect & 0.131 & 0.047 & $0.039-0.223$ & 2.801 \\
\hline (Neg Affect) $^{2}$ & 0.077 & 0.019 & $0.040-0.114$ & 0.010 \\
\hline
\end{tabular}

\begin{tabular}{|l|l|l|}
\hline Random Effects & \multicolumn{2}{l|}{} \\
\hline & Variance & SD \\
\hline Subject & 0.971 & 0.986 \\
\hline Model Fit & Marginal & Conditional \\
\hline \multicolumn{2}{|l|}{} & 0.427 \\
\hline $\mathbf{R}^{2}$ & 0.056 &
\end{tabular}




\section{SB10. AMQ: Rehearsal (Talk)}

\begin{tabular}{|c|c|c|c|c|c|c|c|c|c|c|}
\hline \multirow[t]{2}{*}{ Model Specification } & \multirow{2}{*}{$\begin{array}{l}\text { Baseline } \\
\text { Model }\end{array}$} & \multirow{2}{*}{$\begin{array}{l}\text { Fixed } \\
\text { Effects } \\
\text { Added }\end{array}$} & \multirow{2}{*}{$\begin{array}{l}\text { Random } \\
\text { Effect (of } \\
\text { Subject) }\end{array}$} & \multicolumn{4}{|l|}{ Model Fit } & \multicolumn{3}{|c|}{ LRT } \\
\hline & & & & AIC & BIC & LL & df & df & $\begin{array}{l}\text { Likelihood } \\
\text { Ratio }\end{array}$ & $\begin{array}{l}\text { LRT p- } \\
\text { value }\end{array}$ \\
\hline Null (RE only) & -- & -- & Intercepts & 4094.153 & 4109.232 & -2044.076 & 3 & & & \\
\hline Affiliation $^{* *}$ & Null & Affiliation & Intercepts & 4084.835 & 4109.967 & -2037.417 & 5 & 2 & 13.318 & 0.001 \\
\hline Surprise & Null & Surprise & Intercepts & 4094.163 & 4114.269 & -2043.082 & 4 & 1 & 1.990 & 0.158 \\
\hline Time & Null & Time & Intercepts & 4056.631 & 4076.736 & -2024.315 & 4 & 1 & 39.522 & $<.001$ \\
\hline Affiliation $x$ Time & $\begin{array}{l}\text { Affiliation + } \\
\text { Time ME }\end{array}$ & $\begin{array}{l}\text { Affiliation } \mathrm{x} \\
\text { Time }\end{array}$ & Intercepts & 4049.528 & 4089.739 & -2016.764 & 8 & 2 & 1.930 & 0.381 \\
\hline $\begin{array}{l}\text { Affiliation + Neg Affect (linear } \\
\text { term alone) }\end{array}$ & Affiliation & Neg Affect & Intercepts & 4078.010 & 4108.169 & -2033.005 & 6 & 1 & 8.825 & 0.003 \\
\hline $\begin{array}{l}\text { Affiliation + Neg Affect + (Neg } \\
\text { Affect) }{ }^{2} \text { (linear and quadratic } \\
\text { terms) })^{* *}\end{array}$ & Affiliation & $\begin{array}{l}\text { Neg Affect + } \\
(\text { Neg } \\
\text { Affect) })^{\wedge}\end{array}$ & Intercepts & 4042.328 & 4077.513 & -2014.164 & 7 & 2 & 46.507 & $<.001$ \\
\hline Affiliation + Gender ${ }^{\star *}$ & Affiliation & Gender & Intercepts & 4002.619 & 4032.676 & -1995.310 & 6 & 1 & 17.412 & $<.001$ \\
\hline Affiliation + Years of Education & Affiliation & Years Ed. & Intercepts & 4019.109 & 4049.166 & -2003.555 & 6 & 1 & 0.922 & 0.337 \\
\hline Time + Gender** & Time & Gender & Intercepts & 3972.224 & 3997.271 & -1981.112 & 5 & 1 & 20.536 & $<.001$ \\
\hline Time + Years of Education & Time & Years Ed. & Intercepts & 3990.222 & 4015.269 & -1990.111 & 5 & 1 & 2.538 & 0.111 \\
\hline
\end{tabular}

\section{Final Model: Affiliation}

\begin{tabular}{|l|l|l|l|l|l|}
\hline Fixed Effects & Estimate & SE & $\mathbf{9 5 \%}$ Cl & t & p \\
\hline Intercept & 4.953 & 0.083 & $4.790-5.117$ & 59.370 \\
\hline Clinton - Trump & -0.115 & 0.148 & $-0.404-0.175$ & -0.777 \\
\hline Clinton - Other & -0.592 & 0.162 & $-0.909--0.274$ & -.001 & -3.659 \\
\hline Trump - Other & 0.477 & 0.184 & $0.115-0.839$ & 2.585 \\
\hline
\end{tabular}

\begin{tabular}{|l|l|l|}
\hline \multicolumn{2}{|l|}{ Random Effects } & Variance \\
\hline & 1.203 & SD \\
\hline Subject & \multicolumn{1}{l|}{1.097} \\
\hline Model Fit & Marginal & Conditional \\
\hline & 0.020 & 0.478 \\
\hline
\end{tabular}

\section{Final Model: Time}

\begin{tabular}{|l|l|l|l|l|l|}
\hline Fixed Effects & Estimate & SE & 95\% Cl & t & P \\
\hline Intercept & 5.292 & 0.098 & $5.099-5.485$ & 53.805 \\
\hline Time & -0.285 & 0.045 & $-0.372--0.197$ & -6.392 & $<.001$ \\
\hline
\end{tabular}




\begin{tabular}{|l|l|l|}
\hline Random Effects & \multicolumn{2}{l|}{} \\
\hline & Variance & SD \\
\hline Subject & 1.306 & 1.143 \\
\hline Model Fit & Marginal & Conditional \\
\hline & 0.020 & 0.515 \\
\hline
\end{tabular}

Final Model: Affiliate + Neg Affect (linear term alone)

Fixed Effects

\begin{tabular}{|l|l|l|l|l|l|}
\hline Fixed Effects & Estimate & SE & $\mathbf{9 5 \%}$ Cl & $\mathbf{~}$ \\
\hline Intercept & 4.100 & 0.298 & $3.516-4.684$ & 13.757 \\
\hline $\begin{array}{l}\text { Affiliation } \\
\text { (Clinton - Trump) }\end{array}$ & 0.461 & 0.242 & $-0.015-0.936$ & 1.900 \\
\hline $\begin{array}{l}\text { Affiliation } \\
\text { (Clinton - Other) }\end{array}$ & -0.351 & 0.179 & $-0.703-0.001$ & 0.058 \\
\hline $\begin{array}{l}\text { Affiliation } \\
\text { (Trump - Other) }\end{array}$ & -0.812 & 0.215 & $-1.233--0.391$ & -1.958 \\
\hline Neg Affect & 0.146 & 0.049 & $0.050-0.242$ & -3.781 \\
\hline
\end{tabular}

\begin{tabular}{|l|l|l|}
\hline Random Effects & Variance & SD \\
\hline & 1.169 & 1.081 \\
\hline Subject & Marginal & Conditional \\
\hline Model Fit & 0.033 & 0.478 \\
\hline \multicolumn{2}{|l|}{}
\end{tabular}

Final Model: Affiliate + Neg Affect + (Neg Affect) ${ }^{2}$ (linear and quadratic terms)

Fixed Effects

\begin{tabular}{|l|l|l|l|l|l|}
\hline & Estimate & SE & $\mathbf{9 5 \%} \mathbf{C l}$ & $\mathbf{~}$ & $\mathbf{p}$ \\
\hline Intercept & 4.367 & 0.118 & $4.136-4.599$ & 36.949 \\
\hline $\begin{array}{l}\text { Affiliation } \\
\text { (Clinton - Trump) }\end{array}$ & -0.026 & 0.241 & $-0.498-0.446$ & -0.108 \\
\hline $\begin{array}{l}\text { Affiliation } \\
\text { (Clinton - Other) }\end{array}$ & -0.274 & 0.172 & $-0.612-0.064$ & -1.591 \\
\hline $\begin{array}{l}\text { Affiliation } \\
\text { (Trump - Other) }\end{array}$ & -0.248 & 0.221 & $-0.682-0.186$ & -1.122 \\
\hline Neg Affect & 0.172 & 0.047 & 0.112 & \\
\hline (Neg Affect) $^{2}$ & 0.119 & 0.019 & $0.080-0.263$ & 3.670 \\
\hline
\end{tabular}

\begin{tabular}{|l|l|l|}
\hline Random Effects & \multicolumn{2}{l|}{} \\
\hline & Variance & SD \\
\hline Subject & 1.017 & 1.008 \\
\hline
\end{tabular}




\begin{tabular}{|l|l|l|}
\hline Model Fit \\
\hline & Marginal & Conditional \\
\hline $\mathbf{R}^{\mathbf{2}}$ & 0.084 & 0.473 \\
\hline
\end{tabular}

Final Model: Affiliation + Gender

\begin{tabular}{|l|l|l|l|l|l|}
\hline \multicolumn{2}{|l|}{ Fixed Effects } & Estimate & SE & $\mathbf{9 5 \%} \mathbf{C l}$ & $\mathbf{t}$ \\
\hline $\begin{array}{l}\text { Intercept } \\
\text { Affiliation } \\
\text { (Clinton - Trump) }\end{array}$ & 4.700 & 0.106 & $4.492-4.907$ & $\mathbf{p}$ \\
\hline $\begin{array}{l}\text { Affiliation } \\
\text { (Clinton - Other) }\end{array}$ & -0.029 & 0.149 & $-0.321-0.262$ & -0.198 \\
\hline $\begin{array}{l}\text { Affiliation } \\
\text { (Trump - Other) }\end{array}$ & -0.496 & 0.162 & $-0.814--0.177$ & 0.843 \\
\hline Gender & -0.466 & 0.183 & $-0.826--0.107$ & -3.052 & -2.547 \\
\hline
\end{tabular}

\begin{tabular}{|l|l|l|}
\hline Random Effects & Variance & SD \\
\hline & 1.154 & 1.074 \\
\hline Subject & Marginal & Conditional \\
\hline Model Fit & 0.046 & 0.483 \\
\hline \multicolumn{2}{|l|}{}
\end{tabular}

Final Model: Time + Gender

\begin{tabular}{|l|l|l|}
\hline Fixed Effects & Estimate & SE \\
\hline & 5.055 & 0.113 \\
\hline Intercept & -0.281 & 0.045 \\
\hline Time & 0.573 & 0.125 \\
\hline Gender & Variance \\
\hline \multicolumn{2}{|l|}{} \\
\hline Random Effects & 1.240 & SD \\
\hline \multicolumn{2}{|l|}{} \\
\hline Subject & Marginal & 1.114 \\
\hline Model Fit & 0.051 & Conditional \\
\hline & & 0.518 \\
\hline $\mathbf{R}^{2}$ &
\end{tabular}


$\underline{\text { Testing for Effects of Gender \& Years of Education }}$

Given our observation that gender and years of education differed between participant groups determined on the basis of Political Affiliation and Surprise (see Demographic Differences as a Function of Political Affiliation and Surprise), with surprised Clinton supporters being more likely to be female and more highly educated than other participant groups, we re-ran our primary analyses of interest, including gender and years of education, to determine whether these predictors could account for the differences observed as a function of our predictor variables of interest (Political Affiliation, Surprise, and Time). The analyses below are organized by their headers in the original text.

\section{Emotion Differences as a Function of Political Affiliation and Surprise}

We reran our analyses examining positive and negative affect after the event reported at T1 as a function of Political Affiliation x Surprise, adding gender and years of education as covariates. When examining positive affect, Political Affiliation remained significant $\left[F(2,283)=157.822, p<.001, \eta_{p}^{2}=.395\right]$ while controlling for these covariates. When examining negative affect, both the main effect of Political Affiliation $\left[F(2,483)=33.686, p<.001 \eta_{p}^{2}=.122\right]$, and the interaction of Political Affiliation $x$ Surprise $\left[F(2,483)=4.591, p=.011, \eta_{p}^{2}=.019\right]$ again remained significant while controlling for these covariates.

We also reran our analyzes of emotion change scores (difference scores of positive and negative affect reported before versus after election outcome) as a function of Political Affiliation x Surprise, adding gender and years of education as covariates. 
When examining changes in positive affect, Political Affiliation remained significant $\left[F(2,483)=59.565, p<.001, \eta_{p}^{2}=.198\right]$, as did the significant interaction of Political Affiliation $x$ Surprise $\left[F(2,483)=5.771, p=.003, \eta_{p}^{2}=.023\right]$, while controlling for these covariates. When examining changes in negative affect, the main effect of Political Affiliation $\left[F(2,483)=39.121, p<.001, \eta_{p}^{2}=.139\right]$ and interaction of Political Affiliation $\mathrm{x}$ Surprise $\left[F(2,483)=7.605, p=.001, \eta_{p}^{2}=.031\right]$ remained significant, while Surprise dropped from significant to a trend $\left[F(1,483)=2.743, p=.098, \eta_{p}^{2}=.006\right]$, when controlling for these covariates.

Differences in Autobiographical Memory as a Function of Political Affiliation, Surprise, and Time

As noted in the main text, we examined ERQ and $A M Q$ using mixed linear models with Political Affiliation, Surprise, and Time modeled as fixed effects. Where two or more fixed effects significantly predicted model outcome, follow-up analyses including the interaction term(s) between the fixed effects were conducted. For all MLMs with these fixed effects significant relative to baseline model, we added gender and years of education as fixed effects and tested for significant model improvement with the addition of these predictors, using an adjusted alpha criterion $(.05 / 18=.003)$ to correct for family-wise error rate, as was done with the prior MLM analyses examining ERQ and AMQ outcomes. Model output with the additions of gender and years of education are presented along with the output of the original models in Supplementary Tables A and B. Models that were significantly improved by the addition of gender or years of education, surviving the adjusted alpha criterion above, are described below. 
Emotion intensity (ERQ). Adding Gender as a fixed effect, in addition to Political Affiliation, significantly improved the model fit $(\operatorname{LR}=15.138, p<.001)$. The revised model indicated that in addition to the observation of decreased emotion intensity in third-party/non-voters versus Clinton supporters (estimate $=-0.834,95 \% \mathrm{Cl}=-1.113-$ $0.556, p<.001$ ) and Trump supporters (estimate $=-0.884,95 \% \mathrm{Cl}=-1.199--0.569, p$ $<.001$ ), female participants reported higher emotion intensity than male participants (estimate $=0.433,95 \% \mathrm{Cl}=0.216-0.650, p<.001)$.

Perceived personal event importance (ERQ). Adding Gender as a fixed effect, in addition to Political Affiliation, significantly improved the model fit $(\mathrm{LR}=12.814, p$ $<.001)$. The revised model indicated that in addition to the observation of decreased perceived personal event importance in third-party/non-voters versus Clinton supporters (estimate $=-0.784,95 \% \mathrm{Cl}=-1.071--0.498, p<.001$ ) and Trump supporters (estimate $=-0.981,95 \% \mathrm{Cl}=-1.305--0.657, p<.001)$, female participants reported higher perceived personal event importance than male participants (estimate $=0.409,95 \% \mathrm{Cl}$ $=0.186-0.632, p<.001)$.

Perceived broader event importance (ERQ). Adding Gender as a fixed effect, in addition to Time, significantly improved the model fit $(\mathrm{LR}=11.833, p=.001)$. The revised model indicated that in addition to the observation of decreased perceived broader event importance over time (estimate $=-0.171,95 \% \mathrm{Cl}=-0.257--0.086, p$ 
$<.001$ ), female participants reported higher perceived broader event importance than male participants (estimate $=0.349,95 \% \mathrm{Cl}=0.151-0.547, p=.001$ )

Rehearsal (Frequency of speaking; ERQ). Adding Gender as a fixed effect, in addition to Time, significantly improved the model fit $(\mathrm{LR}=10.176, p=.001)$. The revised model indicated that in addition to the observation of decreased frequency of speaking about the event over time (estimate $=-0.141,95 \% \mathrm{Cl}=-0.241--0.041, p$ $=.006$ ), female participants reported more frequent speaking about the event than males (estimate $=0.378,95 \% \mathrm{Cl}=0.147-0.609, p=.001)$. Note that with the addition of gender to the model, Time was no longer considered a significant effect at the corrected alpha criterion $(.05 / 18=.003)$.

Importance of the memory event (AMQ). Adding Gender as a fixed effect, in addition to Political Affiliation, significantly improved the model fit $(\mathrm{LR}=16.753, p$ $<.001)$. The revised model indicated that in addition to the observation of decreased reported memory importance in third-party/non-voters versus Clinton supporters (estimate $=-0.931,95 \% \mathrm{Cl}=-1.281--0.580, p<.001$ ) and Trump supporters (estimate $=-0.862,95 \% \mathrm{Cl}=-1.256--0.467, p<.001)$, female participants reported higher memory importance than male participants (estimate $=0.570,95 \% \mathrm{Cl}=0.299-0.841$, $p<.001)$.

Additionally, adding Gender as a fixed effect in addition to Time significantly improved the model fit $(\mathrm{LR}=21.844, p<.001)$. The revised model indicated that in addition to the observation of decreased reported memory importance over time 
(estimate $=-0.133,95 \% \mathrm{Cl}=-0.212--0.054, p=.001$ ), female participants reported higher memory importance than male participants (estimate $=0.661,95 \% \mathrm{Cl}=0.386-$ $0.935, p<.001)$.

Rehearsal (Talk; $A M Q)$. Adding Gender as a fixed effect, in addition to Political Affiliation, significantly improved the model fit $(\operatorname{LR}=17.412 ; p<.001)$. The revised model indicated that in addition to the observation of decreased reported talking about the event in third-party/non-voters versus Clinton supporters (estimate $=-0.496,95 \% \mathrm{Cl}$ $=-0.814--0.177, p=.002$ ), female participants reported increased talking about the event relative to male participants (estimate $=0.528,95 \% \mathrm{Cl}=0.282-0.775, p<.001$ )

Additionally, adding Gender as a fixed effect in addition to Time significantly improved the model fit $(\operatorname{LR}=20.536, p<.001)$. the revised model indicated that in addition to reported talking about the event decreasing over time (estimate $=-0.281$, $95 \% \mathrm{Cl}=-0.369--0.194, p<.001)$, female participants reported increased talking about the event relative to male participants (estimate $=0.573,95 \% \mathrm{Cl}=0.327-0.819$, $p<.001)$.

Taken together, these findings indicate that, for the most part, our observed effects of Political Affiliation, Surprise, and Time remained significant when accounting for effects of gender and years of education. Gender accounted for significant variance over and above our original predictors in a limited number of emotion and memory outcome measures, with female participants reporting greater emotion intensity, perceived event importance, and memory rehearsal than male participants. While some 
studies have suggested sex and gender differences in autobiographical memory generally (Davis, 1999; Young, Bellgowan, Bodurka, \& Drevets, 2013), the election of Donald Trump as president may have elicited a stronger emotional response in many women relative to men, given the defeat of candidate Hillary Clinton (who would have been the first American president) and misogynistic comments by Trump and his allies during and after the campaign (Dignam \& Rohlinger, 2019; Harp, 2018), as well as related differences in reported memory properties. These and related details may have led to gender differences in experienced emotional response to the election outcome over and above differences related to reported political affiliation. However, given our data, we cannot definitively confirm that these differences in emotion and memory are due to the nature of the event and not biological differences related to sex or gender. We did not observe any evidence that our emotion and memory outcomes were significantly modulated by years of education over and above related differences in years of education observed between participant groups. 